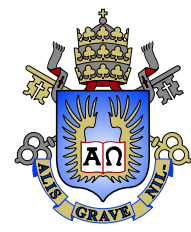

Vinicius Ferreira de Souza

\title{
Um novo algoritmo branch-and-cut para o problema de influência de menor custo generalizado em redes
}

Dissertação de Mestrado

Dissertação apresentada como requisito parcial para obtenção do grau de Mestre pelo Programa de Pós-graduação em Informática do Departamento de Informática da PUC-Rio.

Orientador : Prof. Thibaut Victor Gaston Vidal Co-orientador: Prof. Artur Alves Pessoa 


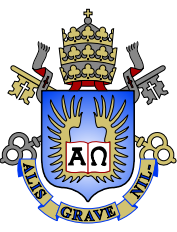

Vinicius Ferreira de Souza

\title{
Um novo algoritmo branch-and-cut para o problema de influência de menor custo generalizado em redes
}

\begin{abstract}
Dissertação apresentada como requisito parcial para obtenção do grau de Mestre pelo Programa de Pós-graduação em Informática do Departamento de Informática da PUC-Rio. Aprovada pela Comissão Examinadora abaixo:
\end{abstract}

Prof. Thibaut Victor Gaston Vidal

Orientador

Departamento de Informática - PUC-Rio

Prof. Artur Alves Pessoa

Co-orientador

Departamento de Engenharia de Produção - UFF

Prof. Marcus Vinícius Soledade Poggi de Aragão

Departamento de Informática - PUC-Rio

Prof. Rafael Martinelli Pinto

Departamento de Engenharia Industrial - PUC-Rio

Rio de Janeiro, 24 de setembro de 2020 
Todos os direitos reservados. É proibida a reprodução total ou parcial do trabalho sem autorização da universidade, do autor e do orientador.

\section{Vinicius Ferreira de Souza}

Bacharel em Ciência da Computação (2013) pela Universidade Federal Rural de Pernambuco (UFRPE) - Unidade Acêmica de Garanhuns (UAG).

Ficha Catalográfica

de Souza, Vinicius Ferreira

Um novo algoritmo branch-and-cut para o problema de influência de menor custo generalizado em redes / Vinicius Ferreira de Souza; orientador: Thibaut Victor Gaston Vidal; co-orientador: Artur Alves Pessoa. - Rio de Janeiro: PUC-Rio, Departamento de Informática, 2020.

v., $71 \mathrm{f}$ : il. color. ; $30 \mathrm{~cm}$

Dissertação (Mestrado) - Pontifícia Universidade Católica do Rio de Janeiro, Departamento de Informática.

Inclui bibliografia

1. Influence propagation;. 2. Mixed-integer programming;. 3. Branch-and-cut;. I. Vidal, Thibaut Victor Gaston. II. Pessoa, Artur Alves. III. Pontifícia Universidade Católica do Rio de Janeiro. Departamento de Informática. IV. Título. 


\section{Agradecimentos}

Não sei por onde começar para agradecer a tantas pessoas que contribuíram e me deram suporte para a conclusão deste trabalho, mas com certeza absoluta isso só foi possível por estar em ombros de gigantes.

Gostaria primeiramente de agradecer meus pais, que mesmo distantes fisicamente, estão sempre aqui comigo, me dando forças e apoiando em tudo, mesmo que parafraseando meu pai não entendem nada do que eu faço, (mas tudo bem, eu também não). Amo muito vocês.

Gostaria de agradecer a uma pessoa especial, Maria Eugênia, por todo amor, carinho, companheirismo e muita paciência durante essa caminhada e que tornou tudo isso mais fácil. Amo você! Quero estender isso também para outras duas pessoas, que não medem esforços para dar apoio e que me acolheram tão afetuosamente. Meus sogros, Zuleide Meliano e José Antônio (Medeiros), muito obrigado.

Agradeço imensamente aos meus professores e orientadores Thibaut Vidal e Artur Pessoa em toda essa caminhada. Minha sincera gratidão por tudo que fizeram e continuam fazendo por mim, por todo o suporte, paciência e aprendizados compartilhados. E espero que esta parceria se mantenha em trabalhos futuros. Obrigado mais uma vez. Agradeço também aos membros da banca Marcus Poggi e Rafael Martinelli pelas sugestões e comentários que muito contribuíram para este trabalho.

Minha eterna gratidão a professora Simone Diniz, a quem tenho uma extrema admiração e que sempre me estendeu a mão, de todas as formas possíveis, em especial ao 'Simone Opina Sobre (SOS)'; e a um dado conselho que me fez segurar as pontas até aqui, "colocando um tijolo de cada vez". Também não poderia deixar de agradecer ao professor Hélio Lopes por todo suporte dado e oportunidades de trabalho oferecidas. Tenho um extremo carinho por ambos e espero poder retribuir tudo isso. Muito obrigado!

Muito grato aos professores do Departamento de Informática da PUC - Rio pelo conhecimento compartilhado, e que com certeza tiveram bastante influência na minha formação. Além disso, nada disso seria possível sem as pessoas que fazem tudo acontecer, muito obrigado Regina, (Alex por sempre trazer BIS $\left.{ }^{\circledR}\right)$, Cosme, Mariana (em especial pelos lanchinhos e churrasco do final de ano), a Dona Ângela (ainda mais pelos biscoitos no lanche da tarde) e a todos os funcionários e profissionais por toda ajuda e suporte.

Mais uma vez quero agradecer a Rian Gabriel pelo constante apoio e pela grande força que me deu em diversos momentos. Meus sinceros agradecimentos também a Renatha Cápua por todas as contribuições e também pelos excelentes comentários e sugestões a respeito do presente texto. 
Para todos os amigos que fiz na PUC - Rio e todos os integrantes do DasLab que tornaram o dia-a-dia mais fácil e criaram um ambiente extremamente amigável e colaborativo. Em especial, meus sinceros agradecimentos, ao Alysson, André Davys, Dalai (não só pelas dicas sobre infovis), Lauro, Luísa, Marisa, Pedro Torres, Rodrigo, Rômulo e Sérgio, obrigado por tudo, vocês tem um espaço enorme no meu coração, estou aqui para o que der e vier e levarei todos para o resto da vida. Enfim, para todos amigos que a PUC - Rio me trouxe, aquele abraço!

Quero agradecer também para mais três pessoas que me ajudaram a passar esse caminho com mais leveza. Muito obrigado Juliany, Maria das Graças e Maria Gabriela pelas divertidas conversas e que me ajudaram a manter a sanidade.

Por último, e não menos importante, a trilha sonora de toda essa história, em especial, ao Gorillaz; Hot e Oreia; Djonga; Rincon Sapiência; Red Hot Chili Peppers ; Black Alien e muitas outras que me fizeram companhia em todos os momentos.

O presente trabalho foi realizado com apoio da Coordenação de Aperfeiçoamento de Pessoal de Nível Superior - Brasil (CAPES) - Código de Financiamento 001. 


\section{Resumo}

de Souza, Vinicius Ferreira; Vidal, Thibaut Victor Gaston; Pessoa, Artur Alves. Um novo algoritmo branch-and-cut para o problema de influência de menor custo generalizado em redes. Rio de Janeiro, 2020. 71p. Dissertação de Mestrado - Departamento de Informática, Pontifícia Universidade Católica do Rio de Janeiro.

A propagação de influências tem sido objeto de extensos estudos devido a seu importante impacto em redes sociais, epidemiologia e muitas outras áreas. A compreensão do mecanismo de propagação é crítica, por exemplo, para controlar a disseminação de notícias falsas ou controlar uma epidemia. Neste trabalho, seguimos uma perspectiva de otimização e identificamos o menor grupo de usuários que precisam ser convertidos para atingir um certo nível de influência em toda a rede. Portanto, estudamos formalmente o problema de influência de menor custo generalizado, propondo algoritmos de programação matemática para resolver este problema. Introduzimos novos algoritmos de planos de corte e separação, e os incorporamos em um algoritmo de branch-and-cut. Nossos resultados experimentais em instâncias da literatura demonstram a capacidade do método de resolver pequenas e médias instâncias, bem como diminuir o gap da melhor solução conhecida e inclusive encontrando também soluções ótimas para alguns problemas em aberto.

\section{Palavras-chave}

Propagação de influência; Programação Inteira Mista; Branch-andCut; 


\section{Abstract}

de Souza, Vinicius Ferreira; Vidal, Thibaut Victor Gaston (Advisor); Pessoa, Artur Alves (Co-Advisor). A new branch-and-cut algorithm for the generalized least cost influence problem in networks. Rio de Janeiro, 2020. 71p. Dissertação de Mestrado - Departamento de Informática, Pontifícia Universidade Católica do Rio de Janeiro.

Influence propagation has been the subject of extensive study due to its important role in social networks, epidemiology, and many other areas. Understanding the propagation mechanism is critical, e.g., to control the spread of fake news or to control an epidemic. In this work, we follow an optimization perspective, and attempt to identify the smallest group of users that needs to be converted to achieve an certain influence level over the entire network. We therefore formally study the generalized least cost influence problem, proposing mathematical programming algorithms to solve the challenging problem. We introduce new cutting plane and separation algorithms and embed them into a branch-and-cut algorithm. Our experimental results on classical benchmark instances demonstrates the method ability to solve small-to medium-scale benchmark instances, also finding optimal solutions for some open problems.

\section{Keywords}

Influence propagation; Mixed-integer programming; Branch-andcut; 


\section{Sumário}

1 Introdução $\quad 12$

$\begin{array}{lll}1.1 & \text { Estrutura da Tese } & 14\end{array}$

2 Literatura $\quad 15$

2.1 O mecanismo de propagação de influência $\quad 15$

2.2 Maximização de influência como um problema de otimização 17

$\begin{array}{lll}2.2 .1 & \text { Target Set Selection Problem } & 17\end{array}$

2.2.2 Weight Target Set Selection Problem 19

2.2.3 Least Cost Influence Problem 20

2.2.4 Generalized Least Cost Influence Problem 22

2.2.4.1 Generalized propagation constraints 27

3 Metodologia $\quad 28$

3.1 Formulação Matemática 28

3.1.1 Algoritmo de separação das restrições para eliminação de ciclos 29

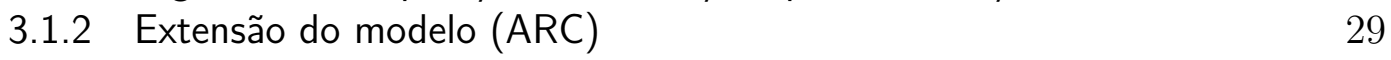

3.2 Cover Propagation Elimination Cut 32

3.2.1 Algoritmo de separação 36

$4 \quad$ Experimentos computacionais $\quad 39$

4.1 Instâncias e detalhes de implementação 39

4.2 Calibração do número de rodadas de corte 41

4.3 Resultados Experimentais 43

5 Conclusões $\quad 56$

5.1 Discussões e contribuições $\quad 56$

5.2 Trabalhos Futuros 56

A Resultados computacionais detalhados $\quad 62$ 


\section{Lista de figuras}

Figura 2.1 Exemplo de instância do GLCIP com 10 vértices. 24

Figura 2.2 Soluções para diferentes valores de $\alpha$ da instância da

$\begin{array}{ll}\text { Figura } 2.1 & 25\end{array}$

Figura 3.1 Ilustração do cover propagation elimination cut 34

Figura 3.2 Ilustração do cover propagation elimination cut em uma instância aleatória

Figura 4.1 Exemplo do método de Watts-Strogatz

Figura 4.2 Impacto do número de rodadas de corte para a instância "SW-n50-k8-b0.3-d1-10-g0.7-i2"

Figura 4.3 Comparação do gap entre os modelos $C_{e}^{+}, F C C$ e $L C C$ para $K \in\{4,8,12,16\} \operatorname{com} \Gamma=0.9$.

Figura 4.4 Comparação do gap entre os modelos $C_{e}^{+}, F C C$ e $L C C$ para $K \in\{4,8,12,16\}$ e $n \in\{50,75,100\} \operatorname{com} \Gamma=0.9$.

Figura 4.5 Comparação do tempo total de execução entre os mode$\operatorname{los} C_{e}^{+}, F C C$ e $L C C$ para $K \in\{4,8,12,16\} \operatorname{com} \Gamma=0.9$.

Figura 4.6 Comparação do tempo total de execução entre os mode$\operatorname{los} C_{e}^{+}, F C C$ e $L C C$ para $K \in\{4,8,12,16\}$ e $n \in\{50,75,100\}$ com $\Gamma=0.9$.

Figura 4.7 Comparação do gap entre os modelos $C_{e}^{+}, F C C$ e $L C C$ para $K \in\{4,8,12,16\} \operatorname{com} \Gamma=1.0$.

Figura 4.8 Comparação do gap entre os modelos $C_{e}^{+}, F C C$ e $L C C$ para $K \in\{4,8,12,16\}$ com $\Gamma=1.0$.

Figura 4.9 Comparação do tempo total de execução entre os mode$\operatorname{los} A, C_{e}^{+}, F C C$ e $L C C$ para $K \in\{4,8,12,16\} \operatorname{com} \Gamma=1.0$

Figura 4.10 Comparação do tempo total de execução entre os modelos $A, C_{e}^{+}, F C C$ e $L C C$ para $K \in\{4,8,12,16\}$ e $n \in$ $\{50,75,100\} \operatorname{com} \Gamma=1.0$

Figura 4.11 Comparação do gap entre os modelos $C_{e}^{+}, F C C$ e $L C C$ para $K \in\{4,8,12,16\} \operatorname{com} \Gamma=1.1$.

Figura 4.12 Comparação do gap entre os modelos $C_{e}^{+}, F C C$ e $L C C$ para $K \in\{4,8,12,16\}$ com $\Gamma=1.1$.

Figura 4.13 Comparação do tempo total de execução entre os mode$\operatorname{los} C_{e}^{+}, F C C$ e $L C C$ para $K \in\{4,8,12,16\} \operatorname{com} \Gamma=1.1$

Figura 4.14 Comparação do tempo total de execução entre os mode$\operatorname{los} C_{e}^{+}, F C C$ e $L C C$ para $K \in\{4,8,12,16\}$ e $n \in\{50,75,100\}$ $\operatorname{com} \Gamma=1.1$ 


\section{Lista de tabelas}

Tabela 4.1 Resultados da variação do número de rodadas de corte para a instância "SW-n50-k8-b0.3-d1-10-g0.7-i2"

Tabela 4.2 Resultados comparativos entre os modelos $C_{e}^{+}, F C C$ e $L C C$ para $\Gamma=0.9$

Tabela 4.3 Resultados comparativos entre os modelos $A, C_{e}^{+}, F C C$ e $L C C$ para $\Gamma=1.0$

Tabela 4.4 Resultados comparativos entre os modelos $C_{e}^{+}, F C C$ e $L C C$ para $\Gamma=1.1$

Tabela A.1 Resultados detalhados dos modelos para $\Gamma=0.9$, em todas as instâncias com $k=4$.

Tabela A.2 Resultados detalhados dos modelos para $\Gamma=0.9$, em todas as instâncias com $k=8$.

Tabela A.3 Resultados detalhados dos modelos para $\Gamma=0.9$, em todas as instâncias com $k \in\{12,16\}$.

Tabela A.4 Resultados detalhados dos modelos para $\Gamma=1.0$, em todas as instâncias com $k=4$.

Tabela A.5 Resultados detalhados dos modelos para $\Gamma=1.0$, em todas as instâncias com $k=8$.

Tabela A.6 Resultados detalhados dos modelos para $\Gamma=1.0$, em todas as instâncias com $k \in\{12,16\}$.

Tabela A.7 Resultados detalhados dos modelos para $\Gamma=1.1$, em todas as instâncias com $k=4$.

Tabela A.8 Resultados detalhados dos modelos para $\Gamma=1.1$, em todas as instâncias com $k=8$.

Tabela A.9 Resultados detalhados dos modelos para $\Gamma=1.1$, em todas as instâncias com $k \in\{12,16\}$. 


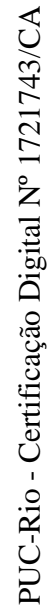

"Toda vez que dou um passo o mundo sai do lugar."

Siba 


\section{Introdução}

As redes sociais desempenham um papel importante na disseminação de informações, opiniões, ideias, inovação, boatos, etc. (Günneç et al., 2017). A década passada testemunhou o nascimento do estudo da propagação de informações nas redes sociais (Banerjee et al., 2018)

Geralmente motivado por aplicações em marketing viral, um problema central que recebeu considerável atenção nesse domínio é o problema de maximização de influência, cujo objetivo é identificar um pequeno subconjunto de indivíduos em uma rede social que possam servir como adotantes iniciais de uma nova tecnologia ou produto e sejam capazes de desencadear um grande efeito "boca a boca" na rede (Singer, 2012). Porém o número de soluções para tal problema é exponencial, o que sugere estudar o problema sob a ótica de um problema de otimização combinatória.

Banerjee et al. (2018) ilustra esse processo para um estabelecimento comercial, cujo objetivo é atrair novos clientes para a compra de um determinado produto. Eles declararam que a melhor maneira de fazer isso é distribuir amostras grátis (oferecer descontos ou algum outro incentivo financeiro) para um conjunto de indivíduos altamente influentes. Se eles gostarem do produto, compartilharão as informações com seus vizinhos, e assim devido à sua alta influência, muitos vizinhos tentarão o produto e por sua vez também irão compartilhar suas opiniões com seus conhecidos. Esse processo em cascata será continuado e, finalmente, uma grande fração dos usuários tentará o produto. Naturalmente, o número de amostras grátis (incentivos financeiros) é limitado devido a razões econômicas.

Portanto, a eficácia do processo tem uma extrema dependência com a escolha inicial dos indivíduos para oferecer incentivos financeiros, idealmente distribuídos entre os indivíduos com maior influência da rede. Demaine et al. (2014) também observam que um problema-chave nessa área é entender como o comportamento em cascata pode começar. Por exemplo, se uma empresa deseja introduzir um novo software e acredita que os amigos dos usuários provavelmente se tornarão usuários, como eles devem alocar cópias gratuitas do software para maximizar o tamanho de sua base de usuários?

Grande parte da pesquisa sobre propagação de influência concentra-se 
em marketing viral como citam Brown and Reingen (1987), Domingos and Richardson (2001), Goldenberg et al. (2001) e Chen et al. (2010). Mas existem trabalhos também que visam selecionar perfis influentes do Twitter (Weng et al., 2010; Bakshy et al., 2011); selecionar um conjunto de blogs informativos que estão mais atualizados, para tentar capturar a maioria das histórias que se propagam no meio dos blogs (Leskovec et al., 2007); classificar o feed de um microblogging para maximizar a atividade geral na rede, através do compartilhamento de memes (Ienco et al., 2010).

Apesar da aplicação direta voltada para marketing viral, compreender esse mecanismo de propagação é crucial, por exemplo, para controlar uma epidemia ou para detectar e controlar a disseminação de rumores e notícias falsas (Kimura et al., 2009; Dreyer Jr and Roberts, 2009; Zhang et al., 2016, 2019).

Além desses trabalhos no contexto de redes sociais, há outros trabalhos voltados a áreas como: encontrar as melhores localizações para sensores em uma rede de distribuição de água em uma região metropolitana (Ostfeld et al., 2008); escolher o conjunto inicial de usuários de uma rede móvel para receber e propagar informações de forma a minimizar o tráfego de dados móveis (Han et al., 2010; Cheng et al., 2015); auxiliar no processo de anotação de imagens para uma base dados (Houle et al., 2011, 2013).

O comportamento em cascata é crucial para diversas aplicações na internet e entender esse fenômeno pode levar a percepções importantes (Kleinberg, 2007). Observar esse mecanismo de difusão além de ajudar a entender como funciona a propagação de novas ideias, pode também ajudar a prever o sucesso ou fracasso de certos processos, inovações, etc. em seus estágios iniciais. Com isso, podemos utilizar esse conhecimento de forma a moldar o processo de modo a aumentar ou reduzir as chances de sucesso (Kleinberg, 2007).

Dessa forma, visando compreender melhor esse mecanismo de propagação, se faz necessário mais estudos sobre o tema.

Neste trabalho, seguimos uma perspectiva de otimização combinatória e estudamos formalmente o problema de influência de menor custo generalizado (GLCIP, do inglês Generalized Least Cost Influence Problem ) (Fischetti et al., 2018), no qual buscamos identificar o grupo mínimo de indivíduos para serem convertidos inicialmente, através de incentivos, de forma a atingir um certo nível de influência em toda a rede.

Para isso, usamos grafos para modelar essa rede, com indivíduos ou organizações representados como vértices e os relacionamentos ou interações como arestas. Ao longo dessa dissertação, utilizaremos o termo vizinho para denominar os indivíduos que estão conectados ao nó de interesse, ou seja, que 
possuem alguma aresta com esse nó.

Neste trabalho desenvolvemos novas abordagens utilizando programação matemática para tratar o GLCIP, e para isso, usamos como base uma formulação matemática introduzida por Fischetti et al. (2018) e a partir desta, primeiramente mostramos como estender esse modelo de forma a lidar com certos casos não tratados inicialmente. Além disso, introduzimos um novo algoritmo de plano de corte e separação, incorporando-os em um algoritmo de branch-and-cut.

Nós avaliamos o método em um conjunto de instâncias sintéticas fornecidos por Fischetti et al. (2018) e os resultados demonstram que o algoritmo consegue alcançar o valor ótimo em cerca de 30 instâncias que estavam em aberto, enquanto que nas outras ou alcança o valor ótimo já reportado ou consegue aumentar o limite inferior, e consequentemente o gap entre o limite inferior e limite superior, em comparação com os resultados reportados no estado da arte, demonstrando assim que o método é competitivo. Vale destacar também que nas instâncias mais densas que foram avaliadas, o método proposto consegue reduzir bastante o gap entre o limite inferior e superior do valor da melhor solução, inclusive naquelas que não se tinha nenhum resultado reportado na literatura até então.

\section{1}

\section{Estrutura da Tese}

O restante desse texto é organizado como segue: usamos o Capítulo 2 para nos aprofundar em algumas nomenclaturas e definições em comum que cercam o GLCIP, e alguns trabalhos da literatura sobre variantes desse problema. A seguir, no Capítulo 3, descrevemos o método de plano de corte e separação desenvolvido, bem como o algoritmo de branch-and-cut proposto. O Capítulo 4 apresenta detalhes sobre os experimentos e análises dos resultados encontrados. Finalmente, no Capítulo 5 discutimos as limitações, descobertas do trabalho e possíveis direções para pesquisas futuras. 


\section{Literatura}

Nesse capítulo, nós discutimos alguns dos modelos básicos de propagação de influência, visando definir o mecanismo pelo qual a difusão de informação ocorre. Além disso, descrevemos alguns tipos de problemas de otimização que envolvem esse tema, e como essas variantes são generalizadas até servir de base para definir formalmente o GLCIP.

\section{1}

\section{O mecanismo de propagação de influência}

A difusão ou propagação em uma rede acontece quando um indivíduo se torna ativo ao executar uma determinada ação, como comprar um determinado produto, compartilhar uma música, anunciar um evento, espalhar alguma fofoca, etc. Esses indivíduos que são ativos inicialmente, os early adopters, são chamados de seeds. A partir daí, este indivíduo pode compartilhar com um de seus vizinhos para realizar a mesma ação, então, este se torna ativo também. Esse processo pode se repetir, à medida que os recém-ativos compartilham a mesma ação com seus respectivos vizinhos, e assim, a ativação pode propagar por toda a rede (Vallet et al., 2015).

Obviamente, essa ideia é bastante simplificada quanto ao real mecanismo, servindo apenas como ilustração do processo. E por isso, diferentes modelos de propagação foram desenvolvidos para tentar capturar especificidades e assim, ter uma maior eficiência ao replicar diferentes fenômenos observados nas redes do mundo real (Vallet et al., 2015).

No campo da matemática, a pesquisa inicial a respeito de difusão de informações deu início por volta da década de 1970, a partir de trabalhos como o de Granovetter (1978), Schelling (2006), entre outros, que formularam modelos matemáticos básicos pelos quais ideias e comportamentos se difundem por uma população.

Esses modelos de difusão podem ser classificados em progressivos e nãoprogressivos. Essa propriedade modela a direção que a influência é propagada. Dessa forma, nos modelos progressivos, uma vez que um nó se torna ativo, então permanecerá ativo nos passos seguintes do processo de propagação. Essa característica tipicamente é desejada para modelar, por exemplo, a adoção 
de uma nova tecnologia ou compra de um produto, já que não são facilmente reversíveis. Enquanto que nos modelos não-progressivos, os nós podem alternar entre os estados ativos ou inativos ao longo do processo. Isso geralmente é desejado para, por exemplo, na difusão de ideias ou opiniões, que podem mudar a partir de novas informações coletadas (Chen et al., 2013).

Entre os vários modelos de propagação existentes, neste trabalho vamos limitar em ilustrar apenas os dois modelos progressivos mais básicos e amplamente utilizados, mas que diversas extensões podem ser consideradas. Ambos discutidos no clássico trabalho de Kempe et al. (2003):

1. Independent Cascade Model: modelo proposto por Goldenberg et al. (2001), que dado um grafo $G=(V, A)$, no qual cada arco possui a probabilidade de influência $p(u, v)$. Nesse modelo, inicialmente, apenas o nós seeds estão ativos. Assim, dado um nó ativo $u$ no tempo $t-1$ (incluindo os nós seeds ativos no $t=0$ ), então no tempo $t$, o nó $u$ tem uma única chance de ativar um de seus vizinhos $v \in \delta^{+}(u)$ com probabilidade $p(u, v)$, e essa ativação é independente de outras ativações. Se $u$ não ativa o nó $v$ no tempo $t$, então não irá tentar ativar nos passos futuros (Chen et al., 2013). Este é adequado para modelar a difusão de informações ou vírus, por exemplo, já que a exposição para apenas uma única fonte pode ser suficiente para ativar um indivíduo, chamado também de contágio simples (Centola and Macy, 2007).

2. Linear Threshold Model: modelo proposto por Granovetter (1978), que dado um grafo $G=(V, A)$, no qual cada nó u possui um limiar necessário para ativá-lo, dado por $h_{u}$; e cada arco representa a influência que um nó $u$ exerce sobre um nó $v$, dado por $d_{u, v}$. Nesse modelo, um nó $u$ se torna ativo no tempo $t$, se a soma das influências recebidas de seus vizinhos já ativos no tempo $t-1$ alcançam um determinado limiar. Esse limiar $h_{u}$ determina a probabilidade que o nó $u$ é influenciado pelos seus vizinhos ativos $v \in \delta^{-}(u)$, assim, quanto maior o valor de $h_{u}$, maior o número de vizinhos ativos necessários para influenciar o nó u (Chen et al., 2013). Por outro lado, esse modelo é mais próximo do chamado contágio complexo, como, por exemplo, para a adoção de novas tecnologias ou para realizar migrações de risco, já que múltiplas fontes de ativação são necessárias, pois o contato com apenas um vizinho ativo pode não ser suficiente para ativar o nó (Centola and Macy, 2007).

Seguindo o contexto de marketing viral, daqui em diante seguiremos o Linear Threshold Model e diremos que um nó é ativo (ou influenciado) se este 
adotou o produto (ou ideia, tecnologia, foi contaminado com um vírus, etc.) e caso contrário esse nó é dito inativo.

\section{2}

\section{Maximização de influência como um problema de otimização}

A intenção de maximizar a disseminação de informações virais em uma rede sugere naturalmente muitos problemas de otimização interessantes.

Domingos and Richardson (2001) e Richardson and Domingos (2002) deram início a essa gama de problemas relacionados com a propagação de influências, ao iniciar o que seria conhecido como problema de Maximização de Influências, no contexto de marketing viral. Nesse problema, um pequeno conjunto de usuários influentes, chamado de conjunto de alvos, deve ser alvejado inicialmente para desencadear uma adoção em cadeia. Sendo os clientes como os nós em uma rede social, modelaram a influência entre cada nó dentro de um framework probabilístico através de Markov Random Fields.

Baseado nesses trabalhos, Kempe et al. (2003) foram os primeiros a formular a maximização de influências como um problema de otimização, utilizando o Linear Threshold Model, modelo de difusão descrito anteriormente, proposto por Granovetter (1978), que explicitamente representa o passo-apasso do mecanismo de propagação.

Assim, dado um grafo direcionado (uma rede social, por exemplo) $G=(V, A)$, no qual os nós representam os usuários, as arestas representam a influência entre os indivíduos; e um número $k$, que pode ser entendido como um orçamento. Então o objetivo é encontrar $k$ indivíduos, chamados de seeds, tal que se ativados inicialmente, maximizam a propagação de acordo com algum modelo de difusão (Kempe et al., 2003).

Além disso, Kempe et al. (2003) também provaram que é NP-difícil computar o subconjunto ótimo de seeds para serem ativadas inicialmente e, assim, desenvolveram algoritmos aproximativos para o problema.

A partir daí, diversas variantes desse problema foram desenvolvidas, devido à sua importância prática e algumas delas são descritas a seguir.

\subsection{1}

\section{Target Set Selection Problem}

Introduzida por Chen (2009), outra variante do problema de Maximização de Influências foi desenvolvida, mas voltada para a minimização de custos, na qual o objetivo é encontrar o número mínimo de nós para atingir toda a rede, ao invés de maximizar a propagação para um número $k$ de indivíduos serem ativados inicialmente. 
Nessa variante, chamada de Target Set Selection Problem (TSSP), dado um grafo conexo $G=(V, E)$, que por exemplo, modela uma rede social, assim como o problema antecessor. Inicialmente todos os nós estão inativos e seja $\delta(i)$ o grau do nó $i$, então cada nó $i$ possui um limiar $1 \leq h_{i} \leq \delta(i)$. Assim, um subconjunto de nós é selecionado para serem ativados inicialmente (o chamado target set). Após isso, iterativamente um nó $i$ se torna ativo se pelo menos $h_{i}$ de seus vizinhos estão ativos no passo anterior. O objetivo é encontrar o menor target set para garantir que todos os nós (ou uma fração fixa) estejam ativos ao final do processo (Chen, 2009). Neste trabalho, os autores também discutem que o problema é NP-difícil.

Ackerman et al. (2010) deram um passo a frente, tendo como primeira contribuição propor um formulação matemática baseada em programação linear inteira para o TSPP.

Essa formulação utiliza variáveis para mapear os nós e arestas do grafo. Seja um grafo direcionado $G=(V, A)$, seja $E^{\prime}$ o conjunto de não-arestas $\{(u, v) \mid(u, v) \notin E\}$. Cada vértice $i \in V$ possui um limiar mínimo de ativação $h_{i}$ e a variável $x_{i}$ representa quando o vértice $i$ é selecionado para o target set. $\mathrm{O}$ objetivo é ter um subconjunto de $E \cup E^{\prime}$ que produz um dígrafo acíclico cujo grafo subjacente não direcionado está completo. Assim, para cada (não-) aresta $(u, v) \in E \cup E^{\prime}$, as variáveis $z_{i, j}$ mapeiam quando $(u, v)$ pertencem a esse subconjunto de $E \cup E^{\prime}$ e representam o caminho que propagação acontece, assim, se $z_{i j}=1$, então o vértice $i$ influencia o nó $j$.

\section{(ACK)}

$$
\begin{aligned}
& \operatorname{MIN} \sum_{i \in V} x_{i} \\
& \text { s.t. } \sum_{(i, j) \in E} z_{i, j} \geq h_{i} \cdot\left(1-x_{i}\right), \quad \forall i \in V \\
& z_{i, j}+z_{j, i}=1, \quad \forall i, j \in V ; i \neq j \\
& z_{i, j}+z_{j, k}+z_{k, i} \leq 2, \quad \forall i, j, k \in V ; i \neq j \neq k \\
& x_{i} \in\{0,1\} \text {, } \\
& \forall i \in V \\
& z_{i, j} \in\{0,1\} \text {, } \\
& \forall(i, j) \in E
\end{aligned}
$$

A Função Objetivo (2-1) minimiza o número de nós selecionados para o target set. O conjunto de restrições (2-2) modela a propagação de influências, assim, um vértice $i$ é ativo ou quando a soma de seus vizinhos já ativos ultrapassa seu limiar $h_{i}$ ou quando este vértice $i$ é selecionado diretamente para o target set. As restrições (2-3) garantem que a propagação ocorre em apenas 
uma direção entre quaisquer dois nós do grafo. As restrições (2-4) garantem que o grafo induzido pelas arestas e não arestas que são escolhidos é acíclico e isso decorre do fato que uma corda em um ciclo direcionado cria um ciclo mais curto, seja qual for sua orientação (Ackerman et al., 2010). Por fim, em (2-5) e (2-6) são as restrições de integralidade.

\subsection{2}

\section{Weight Target Set Selection Problem}

Baseados nessa ideia do TSSP, Zhang (2016) deu um passo além e introduziu o Weight Target Set Selection Problem (WTSSP). Assim, para cada nó $i \in V$ há um peso positivo $b_{i}$, para modelar o fato que diferentes nós (indivíduos) requerem diferentes níveis de esforço para se tornarem adotantes iniciais. Vale ressaltar, que o valor $h_{i}$ diz respeito apenas a fração mínima de vizinhos que precisam ser ativos antes para influenciar o nó $i$, enquanto que o $b_{i}$ está associado com o esforço necessário para ativar o nó $i$ diretamente, sem nenhuma influência de seus vizinhos.

Zhang (2016) apresentaram uma formulação extendida, embutida em um algoritmo de branch-and-cut para o WTSSP.

Primeiramente, criam um novo grafo $G_{t}$ à partir do grafo de entrada $G=(V, E)$ adicionando um nó dummy entre cada aresta em $G$. Assim, para cada aresta $(i, j) \in E$, inserem um nó dummy $d$ e seja $D$ o conjunto de nós dummy. Dessa forma, os nós dummy dividiram cada aresta no grafo original em duas, substituindo cada aresta original $(i, j) \in E$ por duas arestas $(i, d)$ e $(d, j)$ no grafo $G_{t}=\left(V \cup D, E_{t}\right)$. Os nós dummy $d \in D$ não podem ser selecionados para o target set, e todos possuem um limiar $h_{d}=1$, e, consequentemente, se o seu vizinho for ativado, então este irá propagar a influência para outro vizinho (Zhang, 2016).

Assim, uma variável binária $x_{i}$ é criada para cada nó $i \in V$ para indicar quando o nó $i$ é selecionado para o target set. Duas variáveis binárias são criadas $e_{i, d}$ e $e_{d, i}$ para cada aresta $(i, d) \in E_{t}, i \in V, d \in D$ para representar a direção da propagação de influência, e, assim, se um nó $i$ influência o nó $d$, então $e_{i, d}=1$ e 0 caso contrário. Seja $i \in V \cup D$, o conjunto de vizinhos é dado por $N_{i}$ (Zhang, 2016).

A variável $e_{i, d} \in E_{t}$ é definida em termos do grafo auxiliar $G_{t}$, mas visando que a solução seja acíclica, uma terceira variável é utilizada, definida no grafo original. Seja o conjunto de variáveis $z_{i, j}$ e $z_{j, i}$ para toda aresta $(i, j) \in E$, assim, se $z_{i, j}=1$, então o nó $i$ influência o nó $j, z_{i, j}=0$ caso contrário (Zhang, 2016). Denominada de $B I P \mathscr{2}$, a formulação é descrita à seguir: 
(BIP2)

$$
\begin{aligned}
& \text { MIN } \sum_{i \in V} b_{i} x_{i} \\
& \text { s.t. } \quad \sum_{i \in N_{d}} e_{i, d} \geq 1 \text {, } \\
& \forall d \in D \\
& x_{i} \leq e_{i, d} \text {, } \\
& \forall i \in V ; \forall d \in N_{i} \\
& e_{i, d}+e_{d, i}=1 \text {, } \\
& \forall(i, d) \in E_{t} \\
& \sum_{d \in N_{i}} e_{d, i}+h_{i} x_{i} \geq h_{i}, \\
& i \in V \\
& \sum_{(i, j) \in C} z_{i j} \leq|C|-1, \\
& \forall \text { ciclo } C \subseteq E \\
& z_{i, j}+z_{j, i}=1 \text {, } \\
& \forall(i, j) \in E \\
& z_{i, j} \leq e_{i, d}, z_{j, i} \leq e_{j, d}, \\
& \forall(i, j) \in E ; \forall(i, d),(j, d) \in E_{t} \\
& x_{i} \in\{0,1\} \text {, } \\
& \forall i \in V \\
& z_{i, j}, z_{j, i} \in\{0,1\}, \\
& \forall(i, j) \in E \\
& e_{i, d}, e_{d, i} \in\{0,1\} \text {, }
\end{aligned}
$$

A Função Objetivo (2-7) minimiza o custo total. As restrições (2-8) garantem que os nós dummy possuem pelo menos um arco de entrada. As restrições (2-9) dizem que se um nó é selecionado, então este propaga a influência para todos os seus vizinhos. As restrições (2-10) garantem que a influência só seja propagada em uma única direção. Em (2-11) dizem que um nó $i \in V$ deve ser selecionado para o target set ou possui exatamente $h_{i}$ arcos de entrada. O conjunto de restrições (2-12) garante que o grafo solução $G(\mathbf{z})$ seja um grafo acíclico direcionado $(D A G)$. Por sua vez, as restrições (2-13) certificam que a influência se propaga em apenas uma direção no grafo original. As restrições (2-14) são utilizadas para vincular e sincronizar a influência propagada entre $G_{t}$ e o grafo original $G$. Por fim, as restrições (2-15), (2-16) e (2-17) são as restrições de integralidade.

Nesse modelo, existe um número exponencial das restrições (2-12) e, por isso, os autores propõem um algoritmo de separação dessas inequações baseados em um algoritmo de caminho mais curto (shortest path algorithm) para utilizar em um algoritmo de branch-and-cut e adicionar tais cortes em tempo de execução (Zhang, 2016).

\section{2 .3}

\section{Least Cost Influence Problem}

Outro problema relacionado é o denominado de Least Cost Influence Problem (LCIP) proposto por Gunnec (2012) e investigado posteriormente 
em Gunnec and Raghavan (2017) e Günneç et al. (2017). Nessa variante do WTSSP é permitido pagar incentivos (ou pagamentos) parciais para incentivar um nó a se tornar ativo ao invés de pagar a quantia máxima $b_{i}$ para o nó $i$ que é selecionado para o target set, isso reduz o limiar $h_{i}$ e permite a combinação de incentivos parciais com a influência de seus vizinhos.

Motivados por considerações práticas, a introdução desses incentivos personalizados permite modelar o fato de que os indivíduos podem ser parcialmente influenciados através de incentivos financeiros, como cupons de desconto para reduzir o preço de um produto ao invés de receber o produto gratuitamente, única forma possível considerando o WTSSP, a versão anterior desse problema (Günneç et al., 2017).

Vale ressaltar que apesar da definição do LCIP introduzir incentivos parciais ao WTSSP, há outros dois trabalhos que consideram o uso de incentivos parciais no contexto de marketing viral: Demaine et al. (2014) e Cordasco et al. (2015). Nesses trabalhos, os autores descrevem sobre o aspecto teórico de introduzir incentivos parciais para esse tipo de problema e propõem algoritmos aproximativos para resolvê-los.

Dessa forma, assim como nas versões anteriores, no LCIP cada nó $i$ possui um limiar $h_{i}$ e o valor $d_{i, j}$ indica a influência que o nó $i$ exerce sobre o nó $j$, se $i$ foi ativado em um passo anterior que o nó $j$. Logo, um nó $i$ se torna ativo quando a soma das influências de seus vizinhos que já foram ativados antes e um incentivo (pagamento) $p_{i}$ for maior ou igual ao seu limiar $h_{i}$ (Gunnec, 2012). O objetivo do LCIP é minimizar a soma dos incentivos oferecidos ativando uma fração de pelo menos $\alpha$ nós.

Günneç et al. (2017) provaram que o LCIP é NP-difícil e desenvolveram formulações matemáticas baseadas em programação linear inteira para o problema. Desenvolveram uma primeira formulação mais simples, indexada no tempo, que será detalhada mais adiante.

Nesse trabalho, também observaram que o número de vizinhos influentes $h_{i}$ necessários para ativar o nó $i$ pode ser pré-computado, e, a partir disso, desenvolvem uma outra formulação com três variáveis por arco indicando a influência total, parcial ou nenhuma influência exercida. Para cada nó, no máximo $h_{i}-1$ vizinhos podem exercer influência total sobre o nó $i$, em contrapartida no máximo um vizinho pode exercer influência parcial. Baseado nisso, uma formulação de programação linear inteira é desenvolvida, que utiliza também restrições para eliminação de ciclos e garantir também que o grafo solução seja um DAG (Günneç et al., 2017).

A seguir é descrita a formulação indexada no tempo proposta por Günneç et al. (2017) para o LCIP, que tem ideias reaproveitadas em formulações 
seguintes. Esse modelo de programação inteira mista introduz a noção de períodos de tempo $t=1,2, \ldots, T$ (como existem $|V|$ nós, então no pior caso, $T=|V|)$ em que um nó se torna ativo. As variáveis binárias $y_{i, t}$ indicam que o nó $i$ está ativo no tempo $t$ (e permanece ativo até o fim), e $y_{i, T}=1$ determina que o nó $i$ está ativo no final do processo de propagação. Enquanto que as variáveis $p_{i}$ indicam o incentivo oferecido para o nó $i$. Assim como descrito anteriormente, $N_{i}$ é o conjunto de vizinhos do nó $i$.

O objetivo do problema é minimizar a soma de incentivos garantindo que uma fração de $\alpha$ nós estejam ativos ao final. Então o modelo pode ser formulado como segue:

\section{(MIP1)}

$$
\begin{array}{llr}
\text { MIN } & \sum_{i \in V} p_{i} & \\
\text { s.t. } & y_{i, 0}=0, & \forall i \in V \\
& p_{i}+\sum_{j \in N_{i}} d_{i j} y_{j, t-1} \geq h_{i} y_{i, t}, & \\
& \sum_{i \in V} y_{i, T} \geq \alpha|V|, & \\
& p_{i} \geq 0, & \\
& y_{i, t} \in\{0,1\}, & \forall i \in V ; t=1,2, \ldots, T \\
& & \forall i \in V ; t=1,2, \ldots, T
\end{array}
$$

A Função Objetivo (2-18) minimiza a soma de incentivos oferecidos. As restrições (2-19) atribuem todos os nós inativos no início do processo. Já as restrições (2-20) modelam o processo de propagação de influência de fato, no qual um nó inativo $i$ se torna ativo se o incentivo $p_{i}$ e a soma das influências vindas de seus vizinhos já ativos é maior ou igual $h_{i}$. A restrição (2-21) garante que no final do processo, $\alpha$ nós estejam ativos. Por fim, as restrições (2-22) e (2-23) garantem que as variáveis $p$ e $y$ sejam binárias.

\subsection{4}

\section{Generalized Least Cost Influence Problem}

Introduzido por Fischetti et al. (2018), o Generalized Least Cost Influence Problem (GLCIP), é modelado através de um grafo direcionado $G=(V, A)$, cujo os vértices representam indivíduos dessa rede, e as arestas mapeiam a relação entre eles. A seguir são listadas as demais definições do problema:

- O valor $d_{i, j}>0 \forall(i, j) \in A$ mede o quanto um nó $i \in V$ exerce ao nó $j \in V$; 
- O limiar $h_{i}>0$ define o limite que precisa ser alcançado através das influências e incentivos oferecidos para ativar o nó $i \in V$;

- Cada nó possui um conjunto de incentivos positivos possíveis $P_{i}$ e o custo $w_{i, p}>0$ para oferecer o incentivo $p \in P_{i}$ ao nó $i \in V$. Vale ressaltar que para cada vértice, esse incentivo pode ser 0 , com custo 0 ;

- O parâmetro $0 \leq \alpha \leq 1$ define a proporção de nós que precisam estar ativos;

- $N_{i}=\{j \in V \mid(j, i) \in A\}$ denota o conjunto de vizinhos, ou seja, os nós que diretamente influenciam o nó $i \in V$;

- A função de ativação é dada por $f_{i}(U, p)$, assim, um nó $i \in V$ se torna ativo (influenciado) se, e somente se, $f_{i}(U, p) \geq h_{i}$, ou seja, se um potencial incentivo oferecido $p$ e a influência recebida de um sub-conjunto de vizinhos ativos $U \subseteq N_{i}$ alcançar seu limiar $h_{i}$.

O objetivo do GLCIP é determinar quais incentivos devem ser oferecidos aos nós de forma a minimizar os custos totais $\sum_{i \in V} w_{i, p_{i}}$.

Fischetti et al. (2018) desenvolveram uma generalização do LCIP e que engloba também todas essas outras versões descritas anteriormente. O TSSP é um caso especial do GLCIP com $P_{i}=\left\{0, h_{i}\right\}$ e $w_{i, h_{i}}=1, \forall i \in V$. Por sua vez, o WTSSP é um caso do GLCIP em que todos os vizinhos possuem a mesma influência, ou seja, $d_{i, j}=d_{i}, \forall j \in N_{i}$ e dois arcos, com influência $d_{i}=1$, opostamente direcionados são introduzidos para cada aresta não direcionada. E assim como TSSP, os incentivos para ativar um nó é o próprio valor de $h_{i}=\left\lceil\frac{b_{i}}{d_{i}}\right\rceil$. O LCIP é também um caso especial do GLCIP em que todo incentivo $p \in\left\{0, h_{i}\right\}$ com o custo $w_{i p}=p$ de oferecer o incentivo $p$ ao nó $i$ e a função de ativação é dada por $f_{i}(U, p)=p+\sum_{j \in U} d_{j i}, \forall U \in N_{i} ; p \in P_{i}$.

A seguir, na Figura 2.1 está um exemplo de uma instância para o GLCIP, com 10 vértices. Nessa imagem, cada vértice é representado por $i(\mathbf{h}(\mathbf{i}))$ e as arestas contém o valor $d_{i j}$.

Para uma mesma instância, diferentes soluções podem ser geradas, a depender do valor de $\alpha$, que define a fração mínima de nós que precisam estar ativos (influenciados). Assim, a Figura 2.2 contém 3 exemplos de diferentes soluções para os valores de $\alpha \in\{0.1,0.5,1.0\}$ para a instância da Figura 2.1. Nessa imagem, os vértices na cor verde são os nós que estão ativos, enquanto que os nós em vermelho são os nós que não estão ativos. Bem como, as arestas em verde representam por onde a influência está sendo exercida, enquanto que as arestas em azul representam o incentivo $p$ recebido por determinado nó $i$. Vale observar que a solução da Figura 2.2a contém mais do que $\alpha|V|$ 


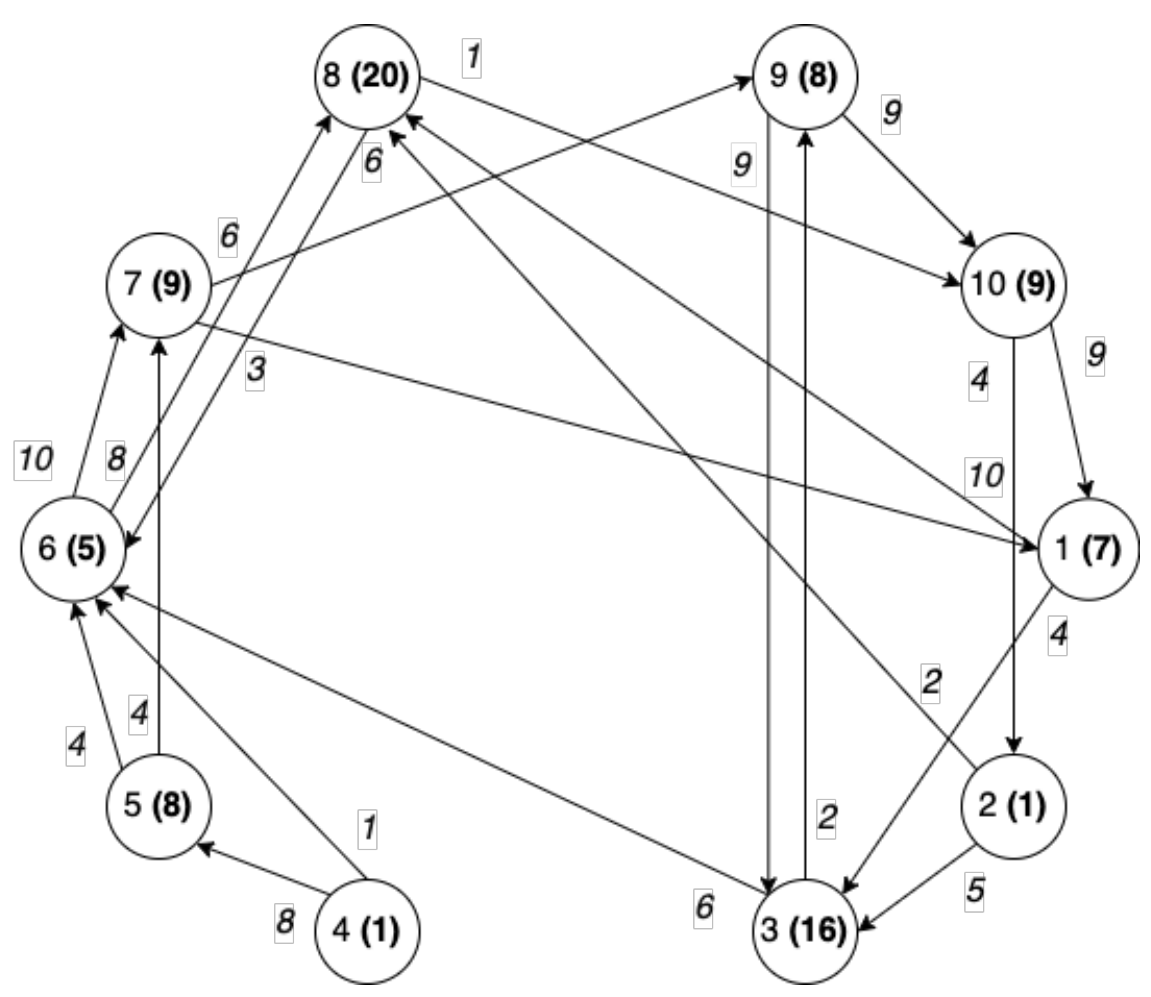

Figura 2.1: Exemplo de instância do GLCIP com 10 vértices.

nós ativos, mas não influencia no custo final da solução, já que o custo só é calculado em relação aos incentivos oferecidos.

Na Seção 4.1 será melhor detalhado o conjunto de instâncias utilizadas neste trabalho.

Fischetti et al. (2018) propuseram dois diferentes modelos exatos utilizados como base: uma formulação baseada em Set Covering, chamada de COV; e uma outra formulação baseada em arcos, chamada de $A R C$. Os autores desenvolveram também duas variações do modelo $C O V$, além de dois algoritmos heurísticos.

Na Seção 3.1 está descrito o modelo $A R C$, que é utilizado como modelo base nesta dissertação e a diante, segue a definição do modelo $C O V$.

Primeiramente, seja $U \subseteq N_{i}$ um subconjunto de vizinhos ativos de um nó $i \in V$, com $p^{\prime}=\min \left\{\tilde{p} \in P_{i} \mid f_{i}(U, \tilde{p}) \geq h_{i}\right\}$ sendo o menor incentivo (possivelmente igual a zero) requerido para tal ativação. Então, esse subconjunto $U$ é definido como conjunto mínimo de influências se, e somente se, não existe um subconjunto $U^{\prime} \subset U$ tal que $f_{i}\left(U^{\prime}, p^{\prime}\right) \geq h_{i}$. Com isso, para cada nó $i \in V$, $\Lambda_{i} \subseteq N_{i}$ é definido como o conjunto com todos os subconjuntos mínimos de influência (Fischetti et al., 2018).

Dessa forma, o modelo $C O V$ é descrito a seguir, que utiliza três conjuntos de variáveis:

1. As variáveis dos nós: $x_{i} \in\{0,1\}, \forall i \in V$, utilizadas para indicar quando 


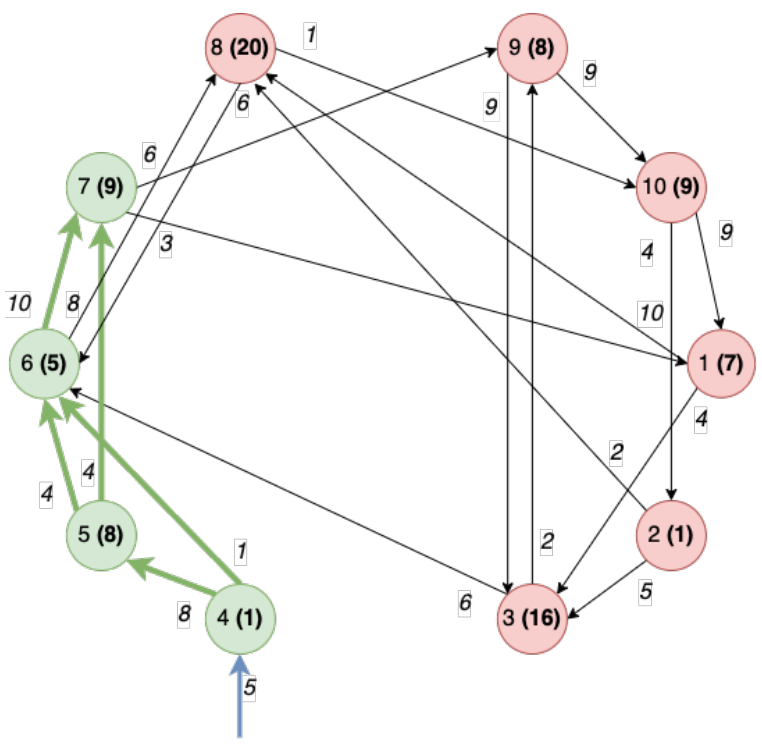

(a) $\alpha=0.1$

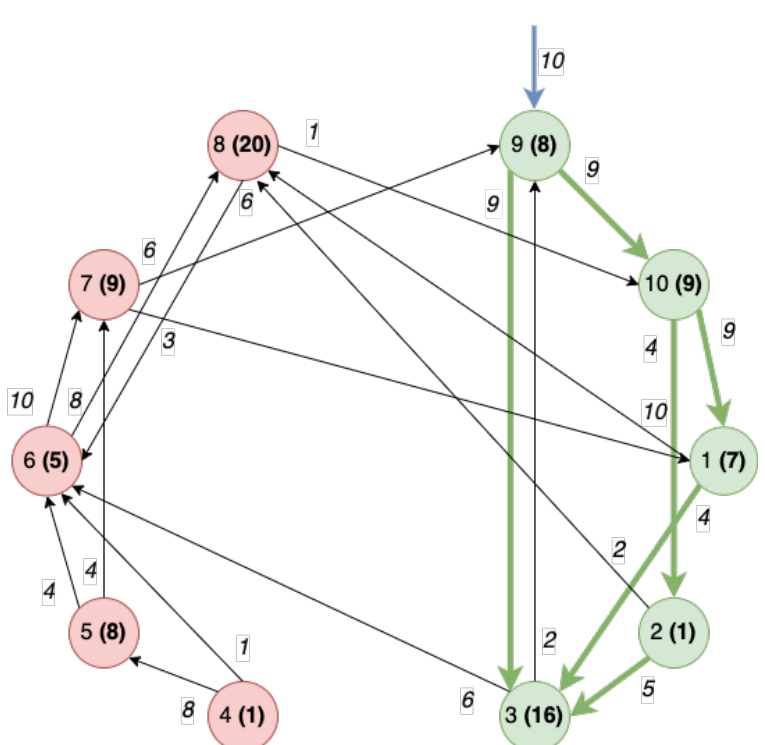

(b) $\alpha=0.5$

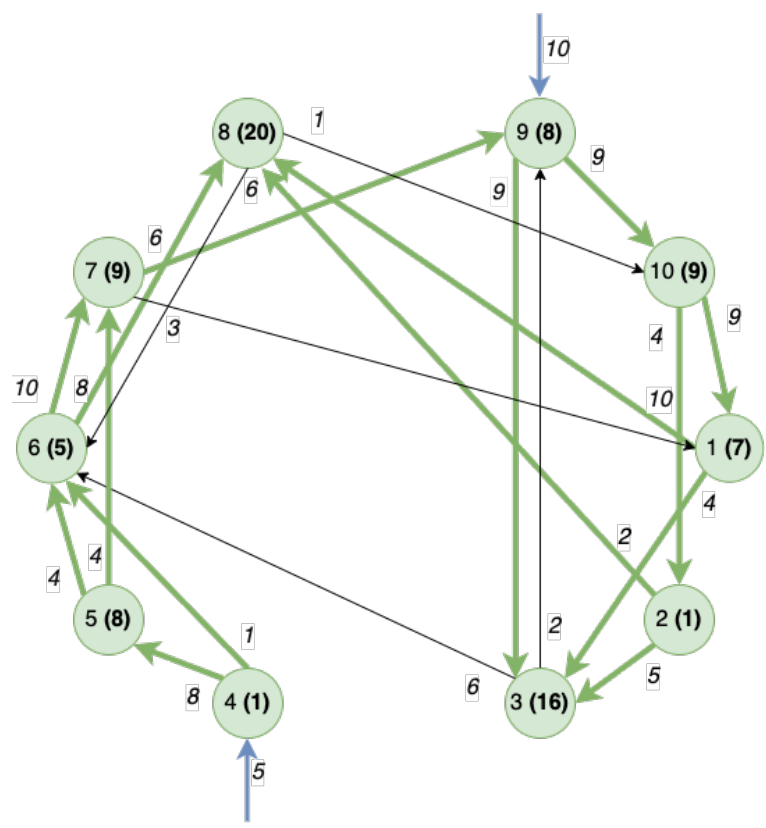

(c) $\alpha=1.0$

Figura 2.2: Soluções para diferentes valores de $\alpha$ da instância da Figura 2.1 
o nó $i$ está ativado ou não;

2. As variáveis referentes aos arcos: $z_{i, j} \in\{0,1\}, \forall(i, j) \in A$, usadas para indicar os arcos em que a influência é exercida;

3. As variáveis dos subconjuntos de influência: $\lambda_{i}^{U} \in\{0,1\}, \forall i \in V ; \forall U \in$ $\Lambda_{i}$, para indicar quando um conjunto mínimo de influências $U$ é utilizado (com o incentivo apropriado) na ativação do nó $i$.

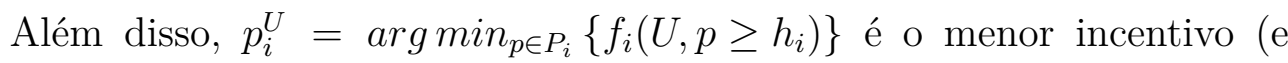
único) para ativar o nó $i$ quando influenciado pelo subconjunto $U$, e o custo deste incentivo $p_{i}^{U}$ é constante e dado por $w_{i}^{U}=w_{i, p_{i}^{U}}$. Vale destacar que $w_{i}^{U}=0$ se apenas o subconjunto $U$ é suficiente para ativar o nó $i$ sem nenhum incentivo.

\section{(COV)}

$$
\begin{aligned}
& \operatorname{MIN} \sum_{i \in V} \sum_{U \in \Lambda_{i}} w_{i}^{U} \lambda_{i}^{U} \\
& \text { s.t. } \sum_{U \in \Lambda_{i}} \lambda_{i}^{U} \geq x_{i} \text {, } \\
& \forall i \in V \\
& \sum_{U \in \Lambda_{j}: i \in U} \lambda_{j}^{U}=z_{i, j}, \\
& \forall(i, j) \in A \\
& \sum_{(i, j) \in C} z_{i, j} \leq \sum_{i \in V(C) \backslash\{k\}} x_{i}, \quad \forall \text { ciclo } C \in A ; \forall k \in V(C) ; \\
& z_{i, j} \leq x_{i} \\
& \forall(j, i) \in A \text { s.t. }(i, j) \notin A \\
& \sum_{i \in V} x_{i} \geq\lceil\alpha|V|\rceil \\
& x_{i} \in\{0,1\} \text {, } \\
& \forall i \in V \\
& z_{i, j} \in\{0,1\} \text {, } \\
& \forall(j, i) \in A \\
& \lambda_{i}^{U} \geq 0 \text {, }
\end{aligned}
$$

A Função Objetivo (2-24) minimiza a soma total de todos os incentivos oferecidos. As restrições (2-25) garantem que apenas um subconjunto de influências deve ser selecionado para cada nó ativado $i \in V$. As restrições (2-26) asseguram que todos os arcos nos quais a influência é exercida sejam escolhidos também. As restrições (2-27) garantem que o sub-grafo formado pelos arcos em que a influência é exercida seja acíclico, nas quais $V(C)=\{i \in V \mid(i, j) \in C\}$. Por sua vez, as restrições (2-28) garantem que a influência só pode ser exercida no $\operatorname{arco}(i, j) \in A$ se o nó $i \in V$ está ativo. As restrições de cobertura (2-29) são responsáveis por garantir que a fração mínima de $\alpha$ nós estejam ativos. 
Por fim, as restrições (2-30), (2-31) e (2-32) são as restrições de integralidade e definições das variáveis do modelo.

Vale ressaltar que existe um número exponencial das variáveis $\lambda_{i}^{U}$ referentes aos subconjuntos de influência, sendo assim, é preciso de um método de geração de colunas que resolve um algoritmo de pricing para adicionar tais variáveis ao modelo a medida que vai sendo necessário. Como utilizamos esse modelo $C O V$ apenas para comparação, então para mais informações sobre esse algoritmo de pricing vide Fischetti et al. (2018). Além disso, também existe um número exponencial das restrições (2-27) e, dessa forma, se faz necessário um algoritmo de separação para adicionar tais restrições ao modelo apenas quando necessário. Esse algoritmo de separação é descrito na Seção 3.1.1.

\subsubsection{1}

\section{Generalized propagation constraints}

Fischetti et al. (2018) desenvolveram também uma família de cortes para o modelo $C O V$ visando fortalecer ainda mais o modelo, denominada de restrições de propagação generalizadas (Generalized propagation constraints). Este corte é baseado na observação de que para cada conjunto de nós $X \subseteq V$ contendo um nó ativo $k$, pelo menos uma das seguintes condições é verdadeira:

- Pelo menos um nó $j \in X$ é ativado através de um conjunto mínimo de influência $U \in \Lambda_{j}$ (com incentivo $p_{j}$ ) que não contém nós de $X$, ou seja, $U \cap X=\emptyset$;

- Pelo menos um nó $j \in X$ recebe incentivo $p_{j} \mid f_{j}\left(\emptyset, p_{j}\right) \geq h_{j}$, assim, esse nó $j$ é ativado sem receber nenhuma influência de seus vizinhos $N_{j}$.

Se nenhuma dessas condições forem válidas, então o subgrafo induzido pelo conjunto de variáveis de arco escolhidos induz um ciclo dentro de $X$. Com isso, as seguintes inequações são válidas:

$$
\sum_{j \in X} \sum_{U \in \Lambda_{j}: U \cap X=\emptyset} \lambda_{j}^{U} \geq x_{k} \quad \forall k \in X, \forall X \subseteq V
$$

Fischetti et al. (2018) propõem dois algoritmos para separar as restrições (2-33), sendo um heurístico e outro exato. E, com isso, implementam duas variações do modelo $C O V$ : a variante $C^{+}$que utiliza um algoritmo de separação heurística; e a variante $C_{e}^{+}$que usa separação heurística e exata. 


\section{Metodologia}

Esse capítulo descreve o modelo de programação matemática, proposto para resolver o GLCIP. Para isso, utilizamos uma modelagem baseada em arcos, proposta por Fischetti et al. (2018), e introduzimos novos planos de corte e separação, e os incorporamos em um algoritmo de branch-and-cut.

\section{1}

\section{Formulação Matemática}

Essa formulação com variáveis de arco (referida como $A R C$ ) generaliza formulações de arco semelhantes da literatura para variantes do GLCIP (Fischetti et al., 2018) com função de ativação $f_{i}(U, p)=\sum_{j \in U} d_{j, i}+p$. A principal característica dessa formulação é garantir ao final um grafo de propagação acíclica direcionada $(D A G)$. Nesse modelo, as variáveis $x_{i} \in$ $\{0,1\}, \forall i \in V$ indicam quando o nó $i$ está ativo (influenciado) ou não; as variáveis de arco $z_{i j} \in\{0,1\}, \forall(i, j) \in A$ indicam em que arcos a influência é exercida, ou seja, $z_{i j}=1$ se o nó $j$ influencia o nó $i, 0$ caso contrário; e as variáveis $y_{i p} \in\{0,1\}, \forall i \in V, \forall p \in P_{i}$ se referem ao incentivo $p$ dado ao nó $i$.

\section{(ARC)}

$$
\begin{aligned}
& \operatorname{MIN} \sum_{i \in V} \sum_{p \in P_{i}} w_{i, p} y_{i, p} \\
& \text { s.t. } \sum_{p \in P_{i}} p y_{i, p}+\sum_{(j, i) \in A} d_{j, i} z_{i, j} \geq h_{i} x_{i} \\
& \sum_{p \in P_{i}} y_{i, p}=x_{i}, \quad \forall i \in V \\
& \sum_{(j, i) \in C} z_{i, j} \leq \sum_{i \in V(C) \backslash\{k\}} x_{i}, \quad \forall \text { ciclo } C \in A ; \forall k \in V(C) ; \\
& z_{i, j} \leq x_{i}, \quad \forall(j, i) \in A \text { s.t. }(i, j) \notin A \\
& \sum_{i \in V} x_{i} \geq\lceil\alpha|V|\rceil \\
& x_{i} \in\{0,1\}, \\
& \forall i \in V \\
& y_{i, p} \in\{0,1\}, \\
& \forall i \in V, \forall p \in P_{i} \\
& z_{i, j} \in\{0,1\}, \\
& \forall(j, i) \in A
\end{aligned}
$$


A função objetivo (3-1) minimiza a soma de todos os custos relacionados aos incentivos oferecidos. As restrições (3-2) modelam a propagação de influência entre os nós, assim, se as influências recebidas de seus vizinhos somadas com um potencial incentivo atingem seu limiar de ativação $\left(h_{i}\right)$, então o nó $i$ passa a ser ativo. As restrições (3-3) garantem que um nó ativo receba apenas um incentivo. As restrições (3-4) são utilizadas para eliminação de ciclos, e garantir que a solução seja acíclica. As restrições (3-5) garantem que um nó $i$ só pode exercer influência no nó $j$ se o nó $i$ estiver ativo. A restrição (3-6) é responsável pela fração mínima de nós que precisam ser ativos. Por fim, (3-7, 3-8 e 3-9) são as restrições de integralidade.

Vale destacar que no trabalho de Fischetti et al. (2018) a função de ativação é dada por $f_{i}(U, p)=\left(\sum_{j \in U} d_{j, i}\right)^{\Gamma}+p$, e com isso, a restrição (3-2) só funciona para $\Gamma=1$. Mais adiante, será apresentada uma generalização desta restrição para outros valores de $\Gamma$.

Além disso, exite um número exponencial das restrições (3-4), sendo assim, se faz necessário um algoritmo de separação para adicionar tais restrições quando estas estiverem violadas.

\subsection{1}

\section{Algoritmo de separação das restrições para eliminação de ciclos}

O algoritmo para separar as restrições (3-4) foi o mesmo utilizado no trabalho de Fischetti et al. (2018). Este método é uma adaptação do algoritmo de caminho mais curto proposto em Grötschel et al. (1985) para separação dos clássicos cortes de eliminação de ciclos.

Neste método, sejam $\overline{x_{i}}, \overline{z_{i j}}$ referentes aos valores relaxados das variáveis (3-7) e (3-9) respectivamente. Então, para cada aresta do grafo são calculados os pesos $w_{i j}:=\bar{x}_{i}-\overline{z_{i j}} \geq 0, \forall(i, j) \in A$. Assim, para cada nó $k \in V$ é computado o caminho mais curto para todos os seus vizinhos $N_{k}$, para isso é utilizado o algoritmo de Floyd-Warshall (Floyd, 1962; Warshall, 1962) que computa o caminho mais curto entre todos os pares de vértices. Se o peso total desse ciclo $C$ formado pelo caminho de $k$ até o nó $j \in N_{k}$ e pelo arco $(j, k)$ for menor do que $\overline{x_{k}}$, então encontramos uma restrição de eliminação de ciclos (3-4) violada e adicionamos-a ao modelo.

\subsection{2}

\section{Extensão do modelo (ARC)}

Para determinar quando um nó passa a ser ativo, nós utilizamos a função de ativação: $f_{i}(U, p)=\left(\sum_{j \in N_{i}} d_{j i}\right)^{\Gamma}+p$, seguindo a mesma convenção utilizada em Fischetti et al. (2018). 
Para valores de $\Gamma=1$, então $f_{i}$ é uma função aditivamente separável e linear (Fischetti et al., 2018). Isso significa que não há um efeito cruzado de um argumento sobre o efeito marginal que o outro exerce sobre o valor da função, simplificando bastante a análise (Buja et al., 1989).

Valores de $\Gamma>1$, modelam, por exemplo, a pressão dos pares em que a influência exercida tem um efeito maior que o normal. Por sua vez, valores de $\Gamma<1$ caracterizam uma função sub modular e modelam a situação de influências marginais decrescentes (Fischetti et al., 2018).

Apesar da definição da função de ativação, o modelo $A R C$ foi proposto apenas para o caso de $\Gamma=1$. Assim sendo, nessa subseção propomos uma alteração no modelo para considerar diferentes valores de $\Gamma$ na função de ativação utilizada.

Primeiramente precisamos incluir o $\Gamma$ na restrição (3-2), para ser equivalente com a função de ativação $f_{i}(U, p)=\left(\sum_{j \in U} d_{j, i}\right)^{\Gamma}+p \geq h_{i}$ :

$$
\sum_{p \in P_{i}} p y_{i p}+\left(\sum_{(j, i) \in A} d_{j i} z_{j i}\right)^{\Gamma} \geq h_{i} x_{i}, \quad \forall i \in V
$$

Porém tal restrição passa a ser uma função não linear e por isso precisamos de alguma forma transformar tal restrição em uma função linear.

Apenas um incentivo pode ser oferecido para cada nó $i \in V$. Sendo assim, o somatório $\sum_{p \in P_{i}} p y_{i p}$ vai ter apenas um incentivo $p^{\prime}$ tal que $y_{i, p^{\prime}}=1 \mathrm{e}$ $y_{i, p}=0, \forall p \in P_{i} \backslash\left\{p^{\prime}\right\}$. Com isso, uma forma para linearizar a inequação (3-10) é realizar manipulações algébricas de forma a eliminar a potência elevada a $\Gamma$ do termo $\left(\sum_{(j, i) \in A} d_{j, i} z_{j, i}\right)^{\Gamma}$, podendo mover essa potência elevada a $\Gamma$ para os outros termos da inequação. Dessa forma, podemos chegar na inequação a seguir:

$$
\sum_{p \in P_{i}}\left(h_{i}^{1 / \Gamma}-\left(h_{i}-p\right)^{1 / \Gamma}\right) y_{i p}+\sum_{(j, i) \in A} d_{j i} z_{j i} \geq h_{i}^{1 / \Gamma} x_{i} \quad \forall i \in V
$$

Há casos em que o incentivo $p \in P_{i}$ oferecido ao nó $i \in V$ é maior que o limiar de ativação desse nó, ou seja, $p>h_{i}$. Como $h_{i}-p$ pode ser um valor negativo, então é desejável que $h_{i}-p$ seja substituído por 0 , nesses casos. E para isso podemos modificar a inequação anterior para a seguinte:

$$
\sum_{p \in P_{i}}\left(h_{i}^{1 / \Gamma}-\max \left(0, h_{i}-p\right)^{1 / \Gamma}\right) y_{i p}+\sum_{(j, i) \in A} d_{j i} z_{j i} \geq h_{i}^{1 / \Gamma} x_{i} \quad \forall i \in V
$$


Como os outros coeficientes são inteiros, para fortalecer a desigualdade podemos arredondar para cima todos os termos elevados a $1 / \Gamma$. Por fim, chegamos na inequação a seguir:

$$
\sum_{p \in P_{i}}\left(\left\lceil h_{i}^{1 / \Gamma}\right\rceil-\left\lceil\max \left(0, h_{i}-p\right)^{1 / \Gamma}\right\rceil\right) y_{i p}+\sum_{(j, i) \in A} d_{j i} z_{j i} \geq\left\lceil h_{i}^{1 / \Gamma}\right\rceil x_{i} \quad \forall i \in V
$$

Porém, precisamos ainda provar que ambas restrições são equivalentes e para isso vamos dividir em casos, fixando os valores de $x_{i}$ e $y_{i, p}$.

Prova.

1. Primeiramente, para $x_{i}=0$ :

$$
\sum_{p \in P_{i}}\left(\left\lceil h_{i}^{1 / \Gamma}\right\rceil-\left\lceil\max \left(0, h_{i}-p\right)^{1 / \Gamma}\right\rceil\right) y_{i p}+\sum_{(j, i) \in A} d_{j i} z_{j i} \geq 0, \quad \forall i \in V
$$

E com isso, independentemente dos valores das variáveis $y$, ambas as restrições (3-10) e (3-14) são satisfeitas.

2. Apenas um único incentivo é oferecido para um nó, logo apenas um valor da variável $y_{i, p}, \forall i \in V, p \in P_{i}$ é igual a 1 . Assim, para $x_{i}=1$ e seja $p^{\prime}$ o incentivo oferecido para o nó $i$, ou seja, $y_{i, p^{\prime}}=1$ e $y_{i, p}=0, \forall p \in P_{i} \backslash\left\{p^{\prime}\right\}$ :

$$
\begin{array}{r}
\left.\equiv h_{i}^{\frac{1}{i} \Gamma}\right\rceil-\left\lceil\max \left(0, h_{i}-p^{\prime}\right)^{1 / \Gamma}\right\rceil+\sum_{(j, i) \in A} d_{j i} z_{j i} \geq\left\lceil b_{i}^{1 / \Gamma}\right\rceil, \quad \forall i \in V \\
\equiv \sum_{(j, i) \in A} d_{j i} z_{j i} \geq\left\lceil\max \left(0, h_{i}-p^{\prime}\right)^{1 / \Gamma}\right\rceil, \quad \forall i \in V
\end{array}
$$

Com a inequação (3-16), vamos subdividi-la em dois casos.

(a) Para $h_{i}-p^{\prime}>0$, ou seja, quando apenas o incentivo $p^{\prime}$ não é suficiente para ativar o nó $i$, assumindo valores inteiros de $d_{j i}$, temos:

$$
\begin{array}{ll}
\equiv \sum_{(j, i) \in A} d_{j i} z_{j i} \geq\left\lceil\left(h_{i}-p^{\prime}\right)^{1 / \Gamma}\right\rceil, & \forall i \in V \\
\equiv \sum_{(j, i) \in A} d_{j i} z_{j i} \geq\left(h_{i}-p^{\prime}\right)^{1 / \Gamma}, & \forall i \in V
\end{array}
$$


Elevando a $\Gamma$ ambos os lados da inequação:

$$
\begin{aligned}
& \equiv\left(\sum_{(j, i) \in A} d_{j i} z_{j i}\right)^{\Gamma} \geq\left(\left(h_{i}-p^{\prime}\right)^{1 / \Gamma}\right)^{\Gamma}, \forall i \in V \\
& \equiv\left(\sum_{(j, i) \in A} d_{j i} z_{j i}\right)^{\Gamma} \geq h_{i}-p^{\prime}, \quad \forall i \in V \\
& \equiv p^{\prime}+\left(\sum_{(j, i) \in A} d_{j i} z_{j i}\right)^{\Gamma} \geq h_{i}, \quad \forall i \in V
\end{aligned}
$$

Como apenas um incentivo é pago para um nó, podemos substituir novamente $p^{\prime}$ por $\sum_{p \in P_{i}} p y_{i, p}$, obtendo a seguinte inequação equivalente a (3-10):

$$
\equiv \sum_{p \in P_{i}} p y_{i, p}+\left(\sum_{(j, i) \in A} d_{j i} z_{j i}\right)^{\Gamma} \geq h_{i}, \quad \forall i \in V
$$

(b) Em contrapartida, para $h_{i}-p^{\prime}<0$, o incentivo $p^{\prime}$ é maior que $h_{i}$, ou seja, suficiente para ativar o nó $i$. Neste caso, temos:

$$
\equiv \sum_{(j, i) \in A} d_{j i} z_{j i} \geq 0
$$

Esta inequação é satisfeita independentemente dos valores das variáveis $z$, assim como (3-10).

Podemos interpretar que essa transformação redefine os valores dos incentivos e custos associados, e, com isso, reduz qualquer caso com $\Gamma \neq 1.0$ para um caso equivalente ao caso linear com $\Gamma=1.0$, mas com os incentivos e custos alterados. E por simplicidade, nas formulações descritas daqui em diante, manteremos a restrição (3-2) original no modelo, sabendo que nos casos com $\Gamma \neq 1.0$ é necessário substitui-la pela restrição (3-13).

\section{2}

\section{Cover Propagation Elimination Cut}

Nesta seção propomos uma nova família de cortes para serem adicionados ao modelo, uma prova que esse tipo de corte é valido e o algoritmo usado para separação dessas restrições. Esse corte foi denominado de Cover Propagation Elimination Cut, porque usa ideias presentes nos cover cuts para o problema da Mochila (Knapsack Problem) (Crowder et al., 1983). 
Vale ressaltar que esse corte é inspirado e tem muita semelhança com o corte proposto em Fischetti et al. (2018), denominado de Generalized Propagation Constraints e descrito na Seção 2.2.4.1, que são expressos em relação a uma formulação estendida onde cada variável representa não apenas uma mas um conjunto de influências que um indivíduo pode sofrer de modo a ativá-lo. Trata-se de uma formulação baseada em um modelo de cobertura de conjuntos (set covering). A limitação desta formulação é que o número de variáveis pode crescer exponencialmente com o número de vizinhos de cada indivíduo.

Os cover propagation elimination cuts, apesar de supostamente mais fracos, têm a vantagem de serem expressos em relação a variáveis que não apresentam esta possibilidade de crescimento exponencial. Eles são expressos em relação a variáveis que só dão informação de apenas uma influência exercida, como o incentivo $p$ oferecido ao nó $i\left(y_{i, p}\right)$, qual vértice está ativo ou não $\left(x_{i}\right)$ ou para determinar quando um nó $i$ exerce influência sobre um nó $j\left(z_{i, j}\right)$. Dessa forma, utilizar da ideia presente nos cover cuts foi uma forma de traduzir os cortes propostos em Fischetti et al. (2018) para funcionar em uma formulação mais simples, baseada em arcos, ao invés de uma formulação baseada em conjuntos.

Ambos os cortes são baseados no fato de que, dado um conjunto de nós $X \subseteq V$ contendo um nó ativo $k$, pelo menos um nó $i \in X$ recebe um incentivo $p$ e influências vindas de nós que estão fora do conjunto $X$ suficientes para ativalo, ou seja, existe $U \subseteq V$ tal que $f_{i}(U \backslash X, p) \geq h_{i}$. Sejam $\tilde{N}_{i}$ e $\tilde{p}_{i}$ um conjunto de vizinhos de $i$ e uma influência que, juntos, não são capazes de ativar o nó $i \in X$, ou seja, $f_{i}\left(\tilde{N}_{i}, \tilde{p}_{i}\right)<h_{i}$. Este conjunto $\tilde{N}_{i}$ é inspirado no conjunto cover proposto para o problema da mochila, cujos elementos excedem a capacidade da mesma. Neste caso, o cover propagation elimination cut se baseia no fato de que existe pelo menos um nó $i \in X$ que recebe um incentivo $p>\tilde{p}_{i}$ ou pelo menos uma influência vinda de um nó que está fora dos conjuntos $X$ e $\tilde{N}_{i}$.

A Figura 3.1 contém uma representação visual para ilustrar o corte e nessa figura as arestas destacadas (mais escuras) representam quais arestas podem ser consideradas no corte, são as arestas que pertencem ao conjunto $N_{i} \backslash\left(X \cup \tilde{N}_{i}\right)$.

Seja um nó $k \in X \subseteq V$, e seja um conjunto $\tilde{N}_{i} \subseteq N_{i} \backslash X(i \in X)$ e $\tilde{p}_{i} \in P_{i}(i \in X)$ que não são suficientes para ativar o nó $i$, tal que $\forall i \in X$ :

$$
\left(\sum_{j \in \tilde{N}_{i}} d_{j i}\right)^{\Gamma}+\tilde{p}_{i}<h_{i}
$$




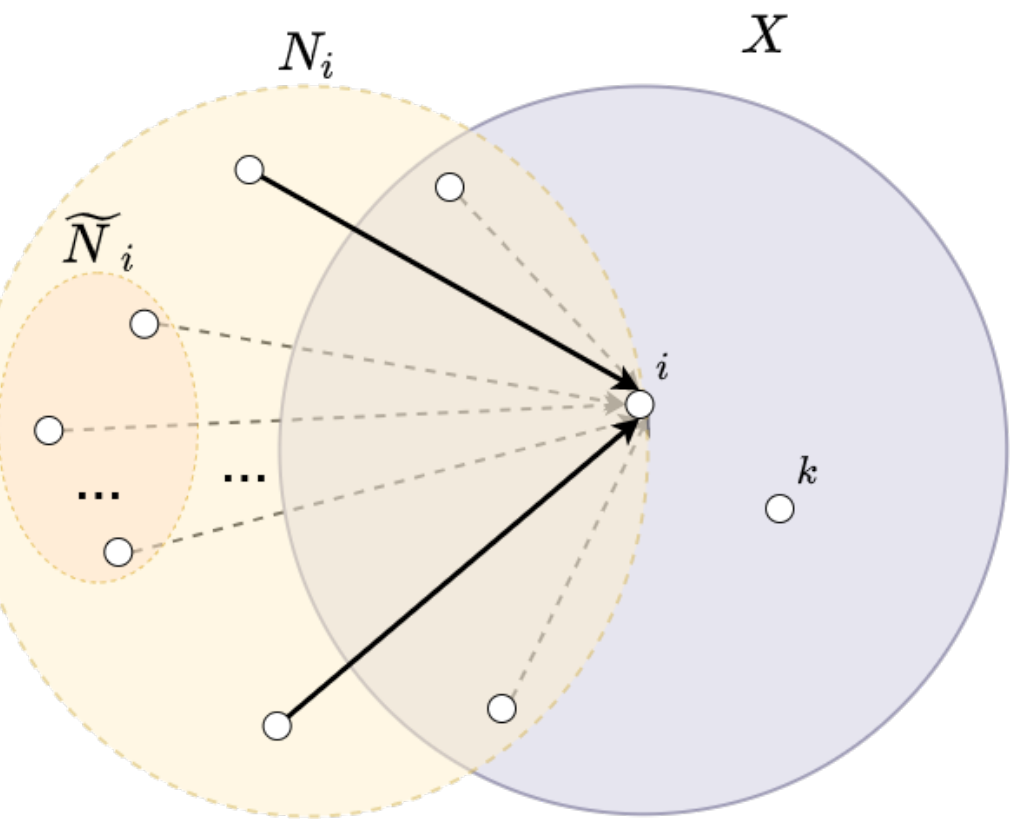

Figura 3.1: Ilustração do cover propagation elimination cut

Então,

$$
\sum_{i \in X} \sum_{\substack{p \in P_{i} \\ p>\tilde{p}_{i}}} y_{i p}+\sum_{i \in X} \sum_{j \in N_{i} \backslash\left(X \cup \tilde{N}_{i}\right)} z_{i j} \geq x_{k}
$$

é uma inequação válida $\forall k \in X$.

Prova. Seja $(\bar{x}, \bar{y}, \bar{z})$ uma solução viável. Dado $k, X, \tilde{N}, \tilde{P}$ satisfazendo as condições acima e se $\bar{x}_{k}=0$, então a restrição (3-25) é satisfeita. Caso contrário, seja $k^{\prime}$ o primeiro indivíduo ativado em $X$ (possivelmente $k^{\prime}=k$ ). Se $k^{\prime}$ recebe um incentivo maior que $\tilde{p}_{k^{\prime}}$, então existe um $p>\tilde{p}_{k^{\prime}}$ tal que $\bar{y}_{k^{\prime} p}=1$, que é suficiente para satisfazer a restrição (3-25).

No caso restante, nós demonstramos que (3-25) é satisfeita por contradição. Vamos assumir que tal restrição não está satisfeita e, portanto, que todas as influências recebidas por $k^{\prime}$ vem de $X$ ou $\tilde{N}_{k^{\prime}}$. Como $k^{\prime}$ é o primeiro nó ativado em $X$, influências que venham de $X$ não podem ser utilizadas. Seja $U=\left\{j \in N_{k^{\prime}} \backslash X \mid \bar{z}_{k^{\prime} j}=1\right\}$, e $p \in P_{k^{\prime}}$ é o único valor tal que $\bar{y}_{k^{\prime} p}=1$. Como (3-25) não é satisfeita, $U \subseteq \tilde{N}_{k^{\prime}}$ e $p \leq \tilde{p}_{k^{\prime}}$. Assim, por (3$24), f_{k^{\prime}}(U, p) \leq\left(\sum_{j \in \tilde{N}_{k^{\prime}}} d_{j k^{\prime}}\right)^{\Gamma}+\tilde{p}_{k^{\prime}}<h_{k^{\prime}}$ que contradiz a suposição que $k^{\prime}$ é ativado.

À seguir, apresentamos um exemplo numérico desse corte:

Exemplo 1: Seja uma instância $\operatorname{com} n=20, k=8$, $\beta=0.3, \alpha=1.0, \Gamma=1.0$ e conjunto de incentivos possíveis $P=\{0.0,9.0,17.0,26.0,34.0\}$. A Figura 3.2 retrata o corte em uma determinada iteração do branch-and-cut, na qual o conjunto 
$X=\{13,19\}, k=13, \tilde{p}_{i}=0, x_{13}=1$ e $x_{19}=1$. Nessa instância, o limiar de ativação dos nós $h_{13}=14, h_{19}=14$, bem como a lista de incentivos para os nós 13 e 19 é dado por: $P_{13}=\{0.0,9.0,17.0\}$ e $P_{19}=\{0.0,9.0,17.0\}$. Cada aresta $(i, j)$ da Figura 3.2 representa o valor $d_{i, j}$, influência que o nó $i$ exerce sobre o nó $j$.

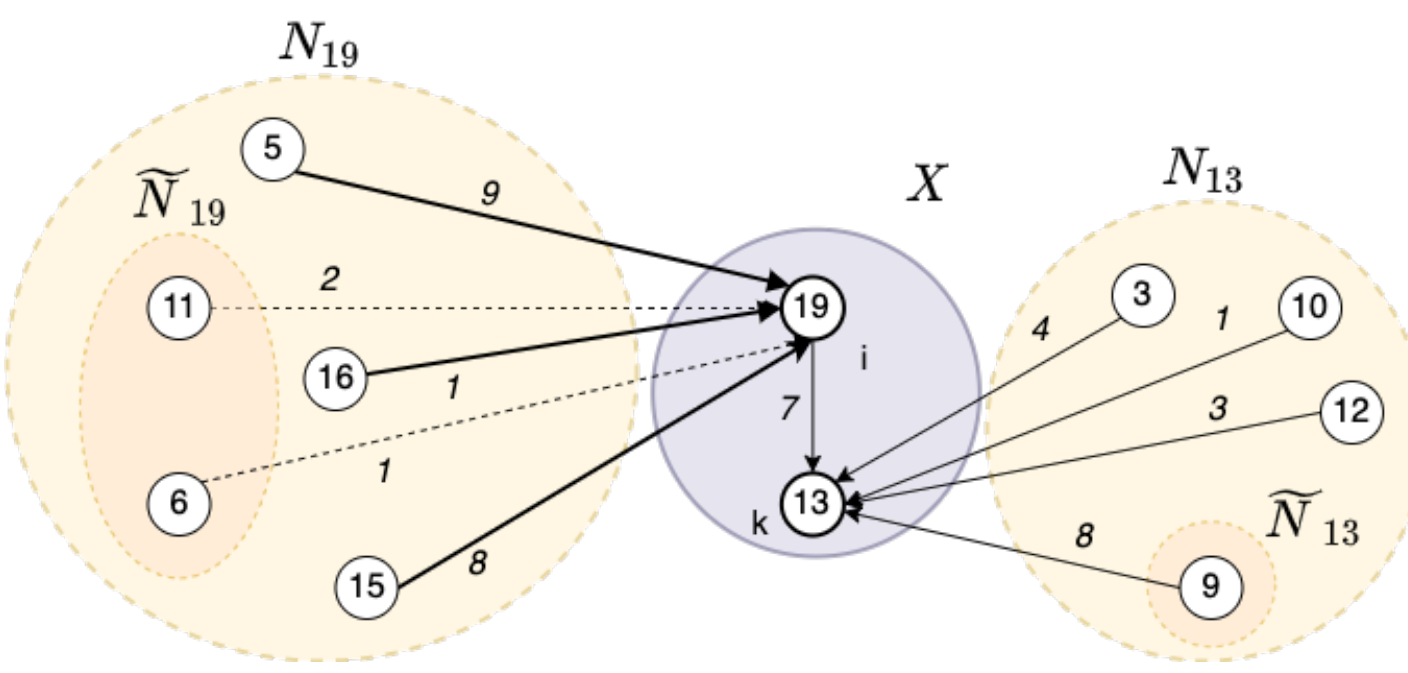

Figura 3.2: Ilustração do cover propagation elimination cut em uma instância aleatória

Com isso, o conjunto $\tilde{N}_{19}$ junto com o incentivo $\tilde{p}_{19}$ não são suficientes para ativar o nó $i=19$. Dessa forma, a inequação (3-25) é um corte válido e pode ser adicionado ao modelo:

$$
\begin{aligned}
y_{13,9}+y_{13,17}+y_{19,9}+y_{19,17}+z_{13,3}+z_{13,9}+ \\
z_{13,10}+z_{13,12}+z_{19,5}+z_{19,15}+z_{19,16} \geq x_{13}
\end{aligned}
$$

O nó $i=19$ está ativo e não recebe nenhuma influência vinda de algum elemento do conjunto $X$ e assim é um nó candidato a iniciar a propagação dentro do conjunto $X$ que vai levar a ativação do nó $k$. Como $x_{k}=1$, e a restrição (3-26) está violada já que o lado esquerdo da inequação é igual a zero, então adicionar tal restrição ao modelo vai forçar a pagar algum incentivo ou forçar que alguma influência seja exercida ao nó 13 ou ao nó 19.

Assim sendo, no corte, o nó $i$ é um possível candidato a iniciar a a propagação dentro do conjunto $X$, de forma a ativar o nó $k$.

O incentivo $\tilde{p}_{i}$ e o conjunto de indivíduos fora do conjunto $X$ que geram as influências $\tilde{N}_{i}$ são escolhidos a priori como parâmetros de entrada do corte. A escolha deles tem que ser feita de modo a satisfazer (3-24). Tipicamente vão existir incentivos e influências vindas de fora do conjunto $X$ suficientes para 
ativar o nó $k$. Se isso acontecer, temos que tirar alguns nós do conjunto $\tilde{N}_{i}$ e/ou reduzir $\tilde{p}_{i}$ até que a soma não seja suficiente para a ativação.

\subsection{1}

\section{Algoritmo de separação}

O problema de separação é resolvido de forma exata, através de um modelo de programação inteira mista $(M I P)$ e os cortes gerados são adicionados apenas na raiz do branch-and-cut. Assim, para cada nó ativo $k \in V$ o algoritmo resolve um $M I P$ e se a restrição (3-25) correspondente à solução encontrada estiver violada, esta é adicionada ao modelo. Isso acontece quando o lado esquerdo da inequação (3-25) é menor que o lado direito, dessa forma, o MIP de separação trata de um problema de minimização deste lado esquerdo, o que corresponde à maior violação possível.

Seja $(\bar{x}, \bar{y}, \bar{z})$ uma solução da relaxação linear do modelo (ARC). O algoritmo de separação resolve então um $M I P$, descrito mais adiante, para cada valor de $k \in V \mid \bar{x}_{k}>\epsilon$ buscando uma restrição (3-25) violada. Se o valor da função objetivo for menor do que o valor da variável $x_{k}$, então a inequação (3-25) está violada, e deve ser adicionada ao modelo (ARC). Sendo assim, para cada execução, o algoritmo pode adicionar zero ou mais cortes ao modelo, sendo um para cada $k$.

A formulação desse $M I P$, a qual nos referiremos como (SEP), utiliza cinco conjunto de variáveis: a variável $s_{i} \forall i \in V$ indica se o nó $i$ pertence ao subconjunto $X \subseteq V$ ou não. As variáveis $y_{i, p}^{0}$ e $z_{i, j}^{0}$ representam o incentivo $\tilde{p}_{i}$ e os nós $j \in \tilde{N}_{i}$ que não são capazes de ativar o nó $i$. Enquanto que as variáveis $y_{i, p}^{1}$ e $z_{i, j}^{1}$ representam os incentivos $p>\tilde{p}_{i}$ e os nós $j \in N_{i} \backslash\left(X \cup \tilde{N}_{i}\right)$, e consequentemente, são os valores que são considerados no corte. Dessa forma, o algoritmo determina quais nós devem ser incluídos no conjunto $\tilde{N}_{i}$ e incentivo $\tilde{p}_{i}$ de forma a maximizar a violação de (3-24). O modelo é descrito a seguir:

\section{Variáveis:}

- $s_{i}=1$ se $i \in X$ e 0 caso contrário

- $y_{i, p}^{0}=1$ se $p=\tilde{p}_{i}$ e 0 caso contrário

- $y_{i, p}^{1}=1$ se $i \in X$ e $p>\tilde{p}_{i}$ e 0 caso contrário

- $z_{i, j}^{0}=1$ se $j \in \tilde{N}_{i}$ e 0 caso contrário

- $z_{i, j}^{1}=1$ se $i \in X$ e $j \in N_{i} \backslash\left(X \cup \tilde{N}_{i}\right)$ e 0 caso contrário

Formulação: Seja uma relaxação linear formada por $(\bar{x}, \bar{y}, \bar{z})$, referente ao valores relaxados das variáveis (3-7), (3-8) e (3-9) respectivamente: 
(SEP)

$$
\begin{array}{llr}
\text { MIN } & \sum_{i \in V} \sum_{p \in P_{i}} \bar{y}_{i p} y_{i p}^{1}+\sum_{i \in V} \sum_{j \in N_{i}} \bar{z}_{i j} z_{i j}^{1} & \\
\text { s.t. } & \sum_{p \in P_{i}} y_{i p}^{0}+\sum_{j \in N_{i}} d_{i j} z_{i j}^{0} \leq h_{i}-1, & \forall i \in V \\
& y_{i p}^{1} \geq s_{i}-\sum_{q \in P_{i}} y_{i q}^{0}, & \forall i \in V, \forall p \in P_{i} \\
& & \\
& z_{i j}^{1} \geq s_{i}-s_{j}-z_{i j}^{0} & \\
& s_{i} \in\{0,1\}, & \forall i \in V, \forall j \in N_{i} \\
& z_{i j}^{1} \in\{0,1\}, \quad \forall i \in V \\
& z_{i j}^{0} \in\{0,1\}, & \forall i \in V, \forall j \in N_{i} \\
& y_{i p}^{1} \in\{0,1\}, & \forall i \in V, \forall p \in P_{i} \\
& y_{i p}^{0} \in\{0,1\}, & \forall i \in V, \forall p \in P_{i}
\end{array}
$$

A Função Objetivo (3-27) maximiza a violação da inequação (3-25), quando o lado direito da inequação está fixo. As restrições (3-28) garantem que o conjunto $\tilde{N}_{i}$ e um incentivo $\tilde{p}_{i}$ não sejam capazes de ativar um nó $i \in V$. Enquanto que as restrições (3-29) e (3-30) são utilizadas para vincular $y^{1}$ com $y^{0}$ e $z^{1}$ com $z^{0}$, respectivamente. Por fim, as restrições (3-31), (3-32), (3-33), (3-34) e (3-35) definem as variáveis binárias do modelo.

De maneira análoga ao que é descrito para as restrições (3-2), o caso em que $\Gamma \neq 1.0$ reduz para um caso equivalente com $\Gamma=1.0$, mas com os incentivos e custos associados alterados. Dessa forma, se faz necessário realizar uma substituição nas restrições (3-28) de maneira similar ao que ocorre nas restrições (3-13).

Vale notar que essa formulação permite $y_{i p}^{0}=y_{i q}^{0}=1$ para $p \neq q$, mas simplesmente atribuindo $y_{i, \min (p, q)}^{0}=0$ é viável com o mesmo custo. De maneira análoga, $z_{i j}^{0}=1$ quando $j \in X$. Finalmente é desejável que ambos o conjunto $\tilde{N}_{i}$ e o valor de $\tilde{p}_{i}$ sejam máximos em relação a (3-24). Se isso não ocorrer na solução do MIP acima, então deve-se aumentar ambos respeitando (3-24) até que não seja mais possível (lifting).

Cada execução deste algoritmo de separação é denominada de uma rodada de corte e como apresentado antes, uma rodada de corte pode adicionar zero ou mais cortes. Porém, vale destacar que o branch-and-cut é parametrizado em relação a esse número de rodadas de corte que vai executar e possui também um outro parâmetro que define o tempo máximo que vai continuar adicionando cortes ao modelo, dessa forma, o algoritmo para de adicionar cortes quando alcança esse limite de tempo ou quando alcança o número de rodadas de corte 
definido, a condição que for válida primeiro. Isso se faz necessário pelo fato do algoritmo ser pesado e pode fazer com o que o algoritmo passe muito tempo adicionando cortes e pode consumir muito do tempo total do branch-and-cut, e, consequentemente determinar o valor desses parâmetros é muito importante para o sucesso do método. 


\section{4}

\section{Experimentos computacionais}

Neste capítulo descrevemos os diferentes experimentos realizados para o algoritmo de branch-and-cut implementado, o conjunto de instâncias de benchmark utilizado, reportamos e discutimos os resultados. Os experimentos foram executados usando apenas 1 core de uma máquina Intel Xeon E5-2620v4, 2.1 GHz. Ambos os modelos foram implementados utilizando a linguagem de programação Julia ${ }^{1}$ através da biblioteca ${ }^{2}$ JuMP v0.18.5 (Dunning et al., 2017) e o solver IBM ILOG CPLEX 12.10, com seus parâmetros padrões.

A seguir são descritos o conjunto de instâncias de benchmark, bem como os resultados e análises dos experimentos avaliados.

\section{1}

\section{Instâncias e detalhes de implementação}

O conjunto de instâncias utilizado foi criado e cedido por Fischetti et al. (2018). Para isso, os autores geraram grafos usando o método proposto por Watts and Strogatz (1998). Este algoritmo clássico é utilizado para gerar grafos aleatórios com propriedades de pequeno mundo (small world networks), ou seja, um tipo de grafo no qual a maioria das ligações são estabelecidas entre os vértices mais próximos e a distância média entre quaisquer dois vértices não ultrapassa um número pequeno de vértices, dai o nome mundo pequeno (Watts and Strogatz, 1998).

O método de Watts-Strogatz começa com uma matriz circular de $N$ vértices. Cada nó na rede é inicialmente ligado entre seus $K$ vizinhos mais próximos. Após isso, o grafo passa por um processo de religação (rewiring) dessas arestas, e dessa forma, cada aresta tem uma probabilidade $\beta$ de ser religada à algum outro nó restante (Watts and Strogatz, 1998).

Vale ressaltar que quanto menor o valor de $\beta$, e mais próximo de 0 , menor será a aleatoriedade do grafo e mais regular será o grafo, e consequentemente, quanto maior o valor de $\beta$, e mais próximo de 1 , maior a aleatoriedade da rede (Watts and Strogatz, 1998). À seguir, a Figura 4.1 ilustra o processo de geração desse tipo de grafo.

\footnotetext{
${ }^{1}$ https://julialang.org

${ }^{2}$ https://jump.dev/JuMP.jl/v0.18/

${ }^{3}$ https://en.wikipedia.org/wiki/File:Watts-Strogatz-rewire.png
} 

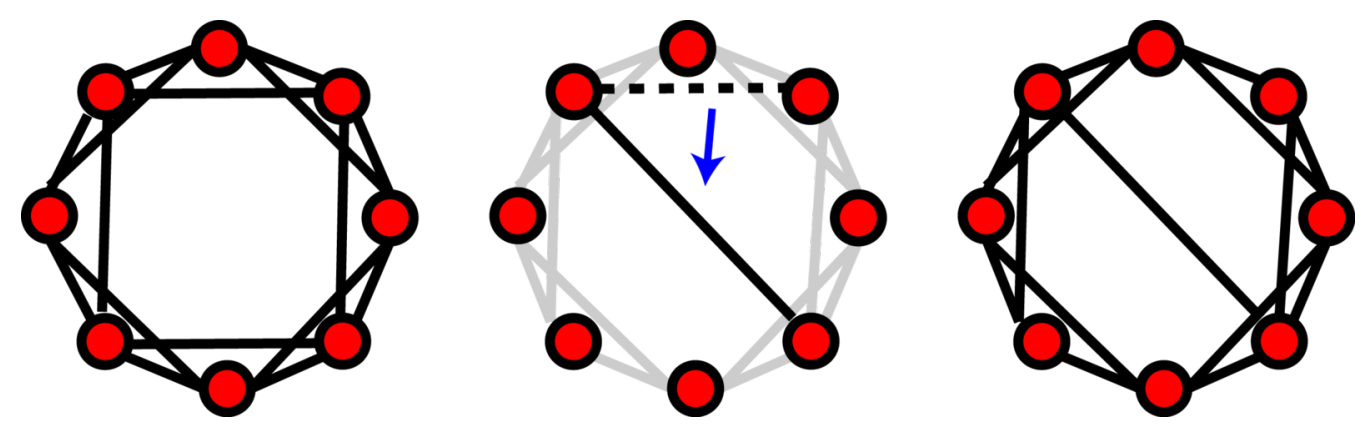

Figura 4.1: Exemplo do método de Watts-Strogatz

Fonte: Wikimedia Commons ${ }^{3}$

Dessa forma, Fischetti et al. (2018) geraram 5 diferentes instâncias usando o método de Watts-Strogatz para cada configuração de parâmetros descritas à seguir:

- Número de vértices do grafo: $n \in\{50,75,100\}$

- Grau médio de cada vértice: $K \in\{4,8,12,16\}$

- Probabilidade de rewiring: $\beta \in\{0.1,0.3\}$

Para cada configuração dos parâmetros a seguir foram geradas 5 instâncias aleatórias:

$-n=50, K \in\{4,8\}, \beta \in\{0.1,0.3\}$. Total $=1 \times 2 \times 2 \times 5=20$ instâncias

- $n=75, K \in\{4,8,12\}, \beta \in\{0.1,0.3\}$. Total $=1 \times 3 \times 2 \times 5=30$ instâncias

$-n=100, K \in\{4,8,12,16\}, \beta \in\{0.1,0.3\}$. Total $=1 \times 4 \times 2 \times 5=$

40 instâncias

Assim, no total são 90 instâncias, mas cada uma foi avaliada para diferentes valores de $\alpha \in\{0.1,0.5,1.0\}$, totalizando então em $90 \times 3=270$ testes realizados para cada valor de $\Gamma$.

Seguindo as mesmas convenções utilizadas por Fischetti et al. (2018): seja $\hat{h}=\max _{i \in V}\left(h_{i}\right)$ o maior limiar, o conjunto de incentivos é definido por $P_{i}=[0,0.25 \hat{h}, 0.5 \hat{h}, 0.75 \hat{h}, \hat{h}] \forall i \in V$ e o custo para oferecer o incentivo $p$ ao nó $i$ é dado por $w_{i, p}=p^{0.9}$; a função de ativação utilizada é dada por: $f_{i}(U, p)=\left(\sum_{j \in N_{i}} d_{j, i}\right)^{\Gamma}+p$, na qual o valor de $\Gamma$ varia seguindo o conjunto $\Gamma \in\{0.9,1.0,1.1\}$. Além disso, a fração mínima de nós ativos é avaliada seguindo $\alpha \in\{0.1,0.5,1.0\}$.

Por fim, utilizamos o valor reportado em Fischetti et al. (2018) da melhor solução exata conhecida +1 , como cutoff do modelo.

Vale ressaltar que apesar de não estar descrito no artigo de Fischetti et al. (2018), os autores informaram posteriormente que arredondaram os valores 
de $P_{i}, w_{i, p}$ e $f_{i}(U, p)$. Sendo assim, os incentivos em $P_{i}$ são inteiros obtidos arredondados para cima, os custos dos incentivos $w_{i, p}$ são inteiros obtidos truncando os valores fracionários e a função de ativação $f_{i}(U, p)$ é arredondada para o inteiro mais próximo.

Vale destacar também que para lidar com esse arredondamento na função de ativação faria com que as restrições (3-13) e (3-28) se tornassem inválidas e incluir tal função de arredondamento em ambas as restrições também tornariam-as em uma restrição não linear. Dessa forma, para lidar com esse problema resolvemos fazer uma alteração diretamente no valor de $h_{i}$ como $h_{i}=h_{i}-0.5$.

\section{2}

\section{Calibração do número de rodadas de corte}

Assim como descrito anteriormente, para cada rodada de corte o algoritmo pode adicionar zero ou mais cortes ao modelo e este é um parâmetro que precisa ser definido previamente.

Esse algoritmo de separação se mostrou promissor, mas ainda é bastante pesado, os resultados detalhados podem ser vistos na Sub-Seção 4.3. Dessa forma, não vale a pena gastar tempo calibrando esse parâmetro antes de fazer uma separação mais rápida. Porém, precisamos atribuir ainda o número de rodadas de corte que serão executadas e para isso definimos empiricamente 2000 rodadas de corte.

Como uma forma de fornecer uma intuição da escolha desse número e também avaliar o impacto do uso do corte implementado realizamos um teste inicial variando o número de rodadas de corte do modelo para uma das instâncias. O número de rodadas de corte avaliado segue o conjunto: $\{0,1,2,5,10,20,50,100,200,500,1000,2000,3000,5000,6000,8000,10000\} \quad$ e um tempo limite de 2 horas (7200 segundos) foi configurado para o branchand-cut.

Na Figura 4.2 apresentamos um gráfico dessa avaliação para uma instância com $n=50, k=8, \beta=0.3$ ("SW-n50-k8-b0.3-d1-10-g0.7-i2"), com $\alpha=0.1$ e $\Gamma=1.0$. No eixo $x$ estão o número de rodadas de corte testados para essa instância e no eixo $y$ no lado esquerdo e direito, respectivamente estão o tempo total de execução, em segundos, do branch-and-cut e o limite inferior obtido.

Vale notar que os cortes melhoram o desempenho final do algoritmo, mas o limite inferior da raiz se mantém quase constante, o que não é tao comum. Possivelmente, isso acontece porque quanto mais cortes são adicionados ao modelo, menor a árvore de branch-and-bound. 
Variação do número de rodadas de corte no modelo para a instância "SW-n50-k8-b0.3-d1-10-g0.7-i2"

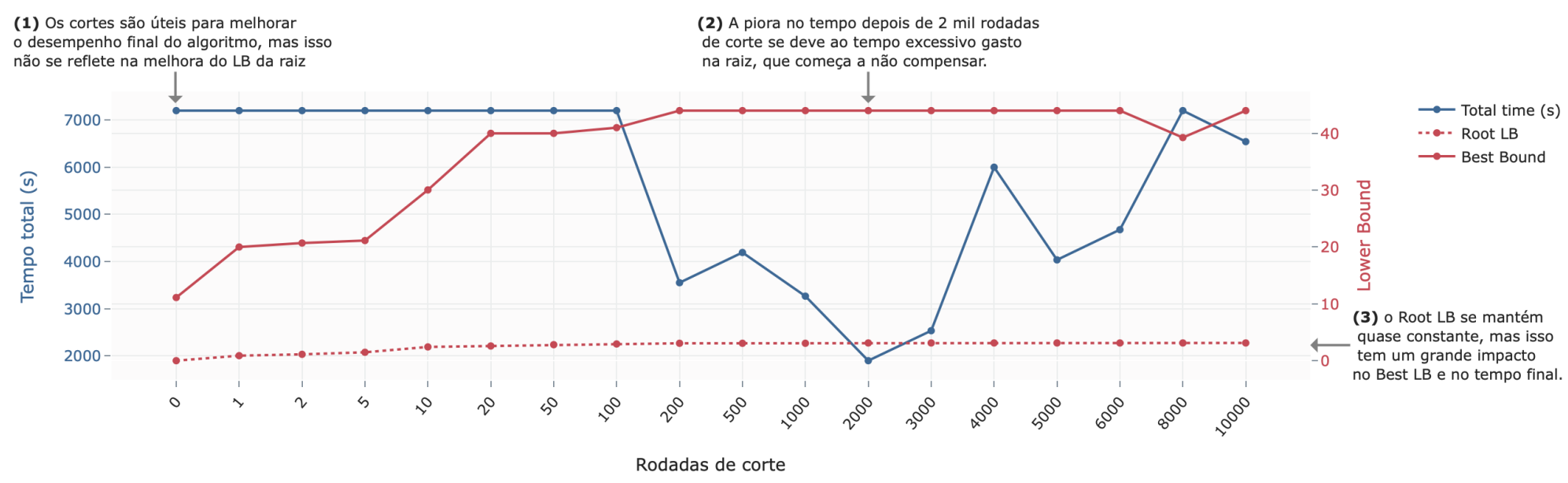

Figura 4.2: Impacto do número de rodadas de corte para a instância "SW-n50k8-b0.3-d1-10-g0.7-i2"

Podemos ver que com nenhuma rodada de corte, o algoritmo tem o pior limite inferior, e esse valor vai aumentando com mais rodadas, e se estabiliza por volta de 200 rodadas de corte e passa a alcançar o valor ótimo.

Além disso é possível perceber também uma diferença no tempo total do algoritmo, que com 200 rodadas de corte passa a executar em por volta da metade do tempo (1h), chegando no mínimo com 2000 rodadas. Porém, esse tempo volta a piorar para valores maiores que 2000, pois o tempo gasto na raiz passa a ser muito alto, que começa a não compensar mais.

\begin{tabular}{|c|c|c|c|c|c|c|c|c|}
\hline \multirow[b]{2}{*}{ Cut Rounds } & \multicolumn{2}{|c|}{ Nodes } & \multicolumn{2}{|c|}{ Lower Bound } & \multirow[b]{2}{*}{ Objective } & \multicolumn{3}{|c|}{ Time (s) } \\
\hline & Count & left & Root & Best Bound & & Root & $\mathrm{B} \& \mathrm{C}$ & Total \\
\hline 0 & 484330 & 430301 & 0,00 & 11,11 & 45.0 & 5,36 & 7194,64 & 7200,00 \\
\hline 1 & 582948 & 507827 & 0,88 & 20,00 & 45.0 & 3,66 & 7196,34 & 7200,00 \\
\hline 2 & 329746 & 259770 & 1,12 & 20,70 & 44.0 & 3,75 & 7196,26 & 7200,00 \\
\hline 5 & 373067 & 276067 & 1,47 & 21,14 & 45.0 & 7,15 & 7192,86 & 7200,00 \\
\hline 10 & 203632 & 129251 & 2,42 & 30,04 & 44.0 & 5,57 & 7194,43 & 7200,00 \\
\hline 20 & 339042 & 91702 & 2,58 & 40,00 & 44.0 & 6,75 & 7193,25 & 7200,00 \\
\hline 50 & 337699 & 47710 & 2,81 & 40,00 & 44.0 & 10,72 & 7189,28 & 7200,00 \\
\hline 100 & 207798 & 70165 & 2,94 & 41,00 & 45.0 & 18,59 & 7181,41 & 7200,00 \\
\hline 200 & 65592 & 1092 & 3,06 & 44,00 & 44.0 & 41,82 & 3510,03 & 3551,84 \\
\hline 500 & 110142 & 122 & 3,06 & 44,00 & 44.0 & 97,87 & 4094,92 & 4192,79 \\
\hline 1000 & 77580 & 143 & 3,06 & 44,00 & 44.0 & 192,89 & 3074,14 & 3267,03 \\
\hline 2000 & 48683 & 340 & 3,12 & 44,00 & 44.0 & 476,64 & 1422,54 & 1899,17 \\
\hline 3000 & 69813 & 295 & 3,12 & 44,00 & 44.0 & 1148,57 & 1385,80 & 2534,36 \\
\hline 4000 & 105677 & 426 & 3,12 & 44,00 & 44.0 & 1911,79 & 4088,14 & 5999,93 \\
\hline 5000 & 64790 & 1970 & 3,12 & 44,00 & 44.0 & 2566,03 & 1469,99 & 4036,02 \\
\hline 6000 & 59039 & 265 & 3,12 & 44,00 & 44.0 & 3289,89 & 1386,82 & 4676,72 \\
\hline 8000 & 66471 & 14091 & 3,12 & 39,26 & 44.0 & 4759,29 & 2440,71 & 7200,00 \\
\hline 10000 & 58184 & 314 & 3,12 & 44,00 & 44.0 & 5028,68 & 1514,22 & 6542,90 \\
\hline
\end{tabular}

Tabela 4.1: Resultados da variação do número de rodadas de corte para a instância "SW-n50-k8-b0.3-d1-10-g0.7-i2" 
Isso sugere que provavelmente podemos reduzir o número de rodadas de corte na raiz nos casos em que a separação é mais pesada.

A Tabela 4.1 contém os resultados detalhados para essa avaliação. Cada linha contém o número de rodadas de corte; a quantidade de nós abertos e a quantidade de nós que restaram seguir na árvore de branch-and-bound; o limite inferior da raiz; o limite inferior final; o limite superior final; e os tempos gastos na raiz, no branch-and-cut e tempo total do método.

Como dito anteriormente, nós definimos empiricamente que o algoritmo iria executar 2000 rodadas de corte. Porém, como uma forma de ter uma intuição do impacto do número de rodadas de corte no algoritmo para todas as instâncias, nós realizamos um segundo experimento utilizando apenas 200 rodadas de corte. Ambos os experimentos são descritos na seção à seguir.

\section{3 \\ Resultados Experimentais}

Para avaliar o branch-and-cut proposto foram realizados dois experimentos variando o tempo gasto na raiz para adicionar cortes ao modelo. Uma versão "light", denominada de Light Cover Cut ( $L C C)$, na qual o algoritmo para de adicionar cortes quando 200 rodadas de corte forem executadas ou se o método ultrapassar 5 minutos adicionando cortes na raiz do branch-andcut. Em contrapartida, no experimento " $f u l l$ ", denominado de Full Cover Cut (FCC), esses parâmetros foram definidos para 2000 rodadas de corte ou 1 hora gastos adicionando cortes na raiz, assim, o algoritmo para quando uma das duas condições for válida.

Fischetti et al. (2018) forneceram os resultados detalhados para fazer uma comparação por instância. Em seu trabalho, os autores computam os resultados para 6 diferentes modelos, nomeados como segue: $A, C, C^{+}, C_{e}^{+}, P^{+}$ e $P_{e}^{+}$, sendo os 4 primeiros modelos exatos e os 2 últimos algoritmos heurísticos.

A seguir uma breve descrição apenas dos modelo exatos propostos em Fischetti et al. (2018):

- O modelo $A$ é o que introduz a formulação descrita na Seção 3.1, e que utiliza o algoritmo de separação das restrições para eliminação de ciclos (3-4), descrito na Seção 3.1.1;

- Os modelos $C, C^{+}, C_{e}^{+}$seguem a formulação descrita na Seção 2.2.4, através das restrições (2-24) - (2-32). Porém, a diferença entre esses três modelos diz respeito ao uso de algoritmos de separação para as generalized propagation constraints (2-33), descritas na Seção 2.2.4.1. Sendo assim, a variante $C^{+}$é obtida incluindo uma separação heurística dessas restrições (2-33), enquanto que a variante $C_{e}^{+}$inclui um algoritmo 
de separação heurística e exata dessas restrições (2-33). Para mais detalhes desses algoritmos de separação ver Fischetti et al. (2018).

Sendo assim, decidimos por comparar os resultados dos modelos implementados nesta dissertação ( $F C C$ e $L C C$ ) com apenas os resultados dos modelos $A$ (quando disponível) e o modelo $C_{e}^{+}$propostos em Fischetti et al. (2018). O modelo $A$ foi escolhido porque utilizamos este como base para o desenvolvimento do branch-and-cut implementado nesta dissertação, com a adição do cover propagation elimination cut proposto; e o modelo $C_{e}^{+}$é o modelo exato com os melhores resultados no trabalho de Fischetti et al. (2018).

A seguir, nas Tabelas 4.2, 4.3 e 4.4 estão os resultados agregados para cada valor de $\Gamma \in\{0.9,1.0,1.1\}$ respectivamente. Como há 5 diferentes instâncias para uma mesma configuração dos parâmetros $n, K, \beta$ e $\alpha$, então nessas três tabelas estão o gap e o tempo médio dessas 5 instâncias para cada configuração, para cada um dos algoritmos. Os melhores valores são destacados em negrito.

Vale destacar que um bug foi detectado nos resultados fornecidos por Fischetti et al. (2018), e reportado esse bug para os autores, eles nos enviaram os novos resultados. Sendo assim, para as nossas comparações, nas tabelas adiante são utilizados os valores corrigidos.

\section{Experimentos para $\Gamma=0.9$ :}

Primeiramente vale ressaltar que dos modelos definidos em Fischetti et al. (2018), o modelo $(A)$ não trata instâncias com $\Gamma=0.9$, e dessa forma, nessa seção só comparamos os nossos resultados apenas com o modelo $C_{e}^{+}$.

A Figura 4.3 contém um boxplot comparativo dos valores do gap obtido por cada um dos modelos $C_{e}^{+}, F C C$ e $L C C$, para $\Gamma=0.9$, agrupados para cada valor de $K$.

Podemos ver que o grau médio de cada nó $(K)$ tem um grande impacto nos resultados, quanto menor o seu valor, geralmente, menor o gap, e vice-versa. Para as instâncias com $K \in\{12,16\}$, por exemplo, todos os algoritmos tem os maiores gaps, inclusive em muitas dessas instâncias o algoritmo não alcança o valor ótimo e atinge o tempo limite de execução definido de 7200 segundos (2 horas). Enquanto que, por sua vez, para $K=4$, todos os algoritmos obtiveram um gap igual a zero, todas as soluções alcançaram o valor ótimo, mas o modelo $C_{e}^{+}$executa em poucos segundos nessas instâncias, diferentemente dos modelos $F C C$ e $L C C$.

Quando esses resultados são agrupados não só pelo valor de $K$, mas também pelo número de vértices do grafo $(n)$ podemos ver que o valor de $n$ tem 
Distribuição dos gaps de otimalidade com $\Gamma=0.9$ para diferentes valores de $K \in\{4,8,12,16\}$

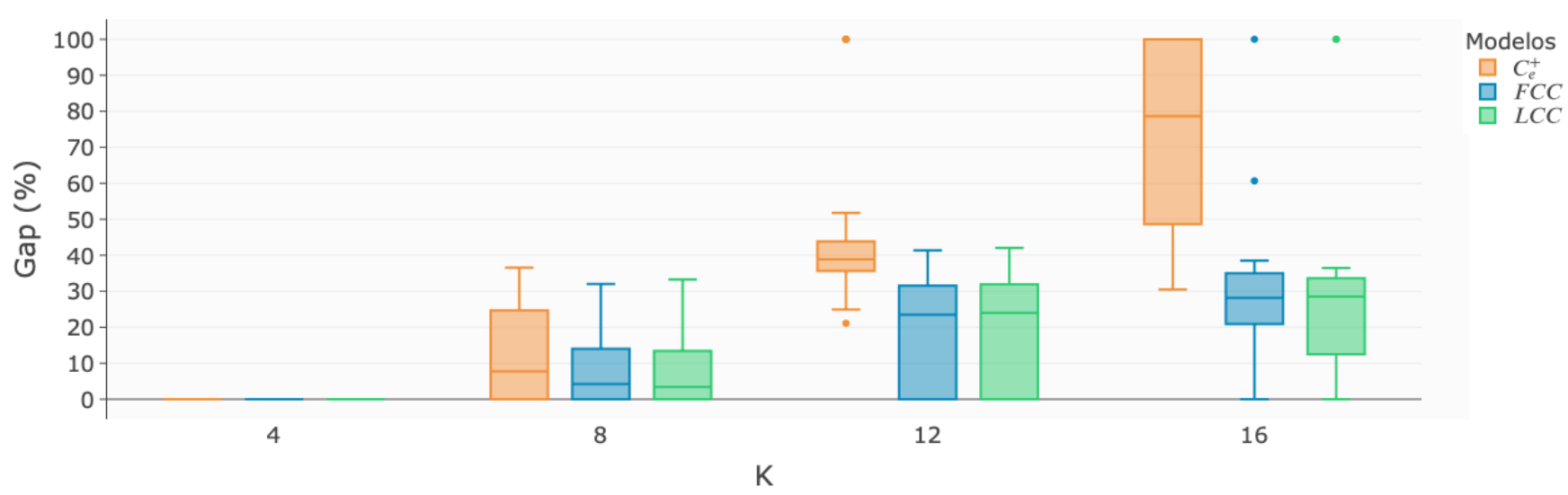

Figura 4.3: Comparação do gap entre os modelos $C_{e}^{+}, F C C$ e $L C C$ para $K \in\{4,8,12,16\} \operatorname{com} \Gamma=0.9$.

um impacto menor nos resultados, o que sugere uma possibilidade funcionar bem com grafos com muitos vértices, mas com grau médio $(K)$ pequeno, ou seja, grafos muito esparsos. A Figura 4.4 contém um boxplot comparativo do gap obtido por cada um dos modelos, agrupados pelos valores de $K$ e $n$.

Distribuição dos gaps de otimalidade com $\Gamma=0.9$ para diferentes valores de $K \in\{4,8,12,16\}$ e $n \in\{50,75,100\}$ $=50$ $n=75$ $\mathrm{n}=100$

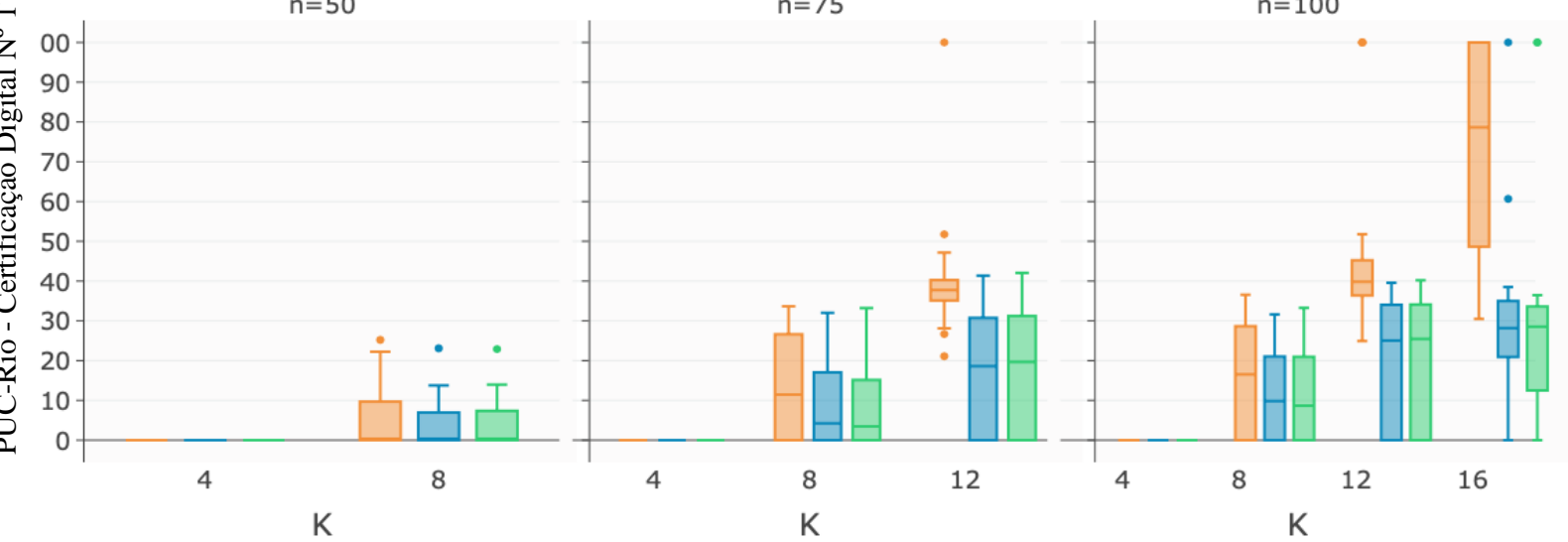

Figura 4.4: Comparação do gap entre os modelos $C_{e}^{+}, F C C$ e $L C C$ para $K \in\{4,8,12,16\}$ e $n \in\{50,75,100\} \operatorname{com} \Gamma=0.9$.

A Tabela 4.2 contém os resultados agregados para o caso com $\Gamma=0.9$, e esta tabela exibe o gap médio e o tempo médio das 5 instâncias para cada combinação do número de nós do grafo $(n)$, grau médio de cada nó $(K)$, probabilidade de rewiring $(\beta)$ e fração mínima de nós que precisam estar ativos ao final $(\alpha)$.

Ambos os métodos $F C C$ e $L C C$ alcançam gaps médios bem menores que o modelo $C_{e}^{+}$, em comparação. Para as instâncias com $n=100, k=16, \beta=0.1$ e $\alpha=1.0$ por exemplo, o modelo $C_{e}^{+}$obtém um gap médio igual a $100 \%$ contra 


\begin{tabular}{|c|c|c|c|c|c|c|c|c|c|}
\hline \multirow[b]{2}{*}{$\mathbf{n}$} & \multirow[b]{2}{*}{$\mathrm{k}$} & \multirow[b]{2}{*}{$\beta$} & \multirow[b]{2}{*}{$\alpha$} & \multicolumn{3}{|c|}{ Avg. gap (\%) } & \multicolumn{3}{|c|}{ Avg. total time (s) } \\
\hline & & & & $C_{e}^{+}$ & FCC & $\mathrm{LCC}$ & $C_{e}^{+}$ & FCC & $\mathrm{LCC}$ \\
\hline 50 & 4 & 0,1 & 0,1 & 0,00 & 0,00 & 0,00 & 2,14 & 171,20 & 81,38 \\
\hline 50 & 4 & 0,1 & 0,5 & 0,00 & 0,00 & 0,00 & 12,79 & 1414,27 & 216,07 \\
\hline 50 & 4 & 0,1 & 1,0 & 0,00 & 0,00 & 0,00 & 1,00 & 116,46 & 88,04 \\
\hline 50 & 4 & 0,3 & 0,1 & 0,00 & 0,00 & 0,00 & 3,59 & 82,52 & 30,53 \\
\hline 50 & 4 & 0,3 & 0,5 & 0,00 & 0,00 & 0,00 & 13,63 & 1545,72 & 144,94 \\
\hline 50 & 4 & 0,3 & 1,0 & 0,00 & 0,00 & 0,00 & 5,99 & 2253,60 & 241,47 \\
\hline 50 & 8 & 0,1 & 0,1 & 0,00 & 0,00 & 0,00 & 354,50 & 1239,57 & 124,74 \\
\hline 50 & 8 & 0,1 & 0,5 & 0,00 & 0,00 & 0,00 & 2163,95 & 2737,32 & 338,81 \\
\hline 50 & 8 & 0,1 & 1,0 & 1,27 & 7,84 & 8,03 & 2070,42 & 7200,00 & 7200,00 \\
\hline 50 & 8 & 0,3 & 0,1 & 0,00 & 0,00 & 0,00 & 342,35 & 840,18 & 63,78 \\
\hline 50 & 8 & 0,3 & 0,5 & 16,10 & 0,88 & 1,47 & 7200,00 & 3616,78 & 2645,17 \\
\hline 50 & 8 & 0,3 & 1,0 & 9,26 & 14,67 & 14,75 & 7200,00 & 7200,00 & 7200,00 \\
\hline 75 & 4 & 0,1 & 0,1 & 0,00 & 0,00 & 0,00 & 2,87 & 252,10 & 38,07 \\
\hline 75 & 4 & 0,1 & 0,5 & 0,00 & 0,00 & 0,00 & 9,69 & 489,00 & 199,92 \\
\hline 75 & 4 & 0,1 & 1,0 & 0,00 & 0,00 & 0,00 & 3,42 & 330,46 & 203,60 \\
\hline 75 & 4 & 0,3 & 0,1 & 0,00 & 0,00 & 0,00 & 10,66 & 182,00 & 39,08 \\
\hline 75 & 4 & 0,3 & 0,5 & 0,00 & 0,00 & 0,00 & 109,58 & 2154,10 & 226,63 \\
\hline 75 & 4 & 0,3 & 1,0 & 0,00 & 0,00 & 0,00 & 4,95 & 1377,53 & 212,49 \\
\hline 75 & 8 & 0,1 & 0,1 & 0,00 & 0,00 & 0,00 & 1534,58 & 1635,61 & 138,77 \\
\hline 75 & 8 & 0,1 & 0,5 & 7,49 & 1,91 & 0,82 & 5897,76 & 5057,16 & 3417,46 \\
\hline 75 & 8 & 0,1 & 1,0 & 17,06 & 12,71 & 12,82 & 7200,00 & 7200,00 & 7200,00 \\
\hline 75 & 8 & 0,3 & 0,1 & 0,00 & 0,00 & 0,00 & 1639,33 & 1764,50 & 156,50 \\
\hline 75 & 8 & 0,3 & 0,5 & 24,38 & 13,15 & 11,24 & 7200,00 & 7200,00 & 7200,00 \\
\hline 75 & 8 & 0,3 & 1,0 & 29,90 & 24,17 & 25,21 & 7200,00 & 7200,00 & 7200,00 \\
\hline 75 & 12 & 0,1 & 0,1 & 43,47 & 0,00 & 0,00 & 7200,00 & 3185,64 & 486,97 \\
\hline 75 & 12 & 0,1 & 0,5 & 38,51 & 15,07 & 14,04 & 7200,00 & 7200,00 & 7200,00 \\
\hline 75 & 12 & 0,1 & 1,0 & 36,36 & 31,12 & 32,03 & 7200,00 & 7200,00 & 7200,00 \\
\hline 75 & 12 & 0,3 & 0,1 & 32,53 & 0,00 & 0,00 & 7200,00 & 2244,88 & 287,67 \\
\hline 75 & 12 & 0,3 & 0,5 & 38,87 & 28,65 & 26,73 & 7200,00 & 7200,00 & 7200,00 \\
\hline 75 & 12 & 0,3 & 1,0 & 46,50 & 32,76 & 33,06 & 7200,00 & 7200,00 & 7200,00 \\
\hline 100 & 4 & 0,1 & 0,1 & 0,00 & 0,00 & 0,00 & 5,99 & 1269,37 & 177,49 \\
\hline 100 & 4 & 0,1 & 0,5 & 0,00 & 0,00 & 0,00 & 30,85 & 2953,96 & 314,89 \\
\hline 100 & 4 & 0,1 & 1,0 & 0,00 & 0,00 & 0,00 & 6,46 & 940,05 & 431,81 \\
\hline 100 & 4 & 0,3 & 0,1 & 0,00 & 0,00 & 0,00 & 3,39 & 590,86 & 69,54 \\
\hline 100 & 4 & 0,3 & 0,5 & 0,00 & 0,00 & 0,00 & 91,93 & 3120,01 & 318,28 \\
\hline 100 & 4 & 0,3 & 1,0 & 0,00 & 0,00 & 0,00 & 36,07 & 2547,95 & 1188,05 \\
\hline 100 & 8 & 0,1 & 0,1 & 2,22 & 0,00 & 0,00 & 3328,77 & 2120,23 & 184,96 \\
\hline 100 & 8 & 0,1 & 0,5 & 13,43 & 8,83 & 7,06 & 7200,00 & 7200,00 & 7200,00 \\
\hline 100 & 8 & 0,1 & 1,0 & 32,20 & 21,17 & 22,55 & 7200,00 & 7200,00 & 7200,00 \\
\hline 100 & 8 & 0,3 & 0,1 & 0,66 & 0,00 & 0,00 & 3112,48 & 1556,48 & 142,64 \\
\hline 100 & 8 & 0,3 & 0,5 & 24,04 & 15,34 & 13,86 & 7200,00 & 7200,00 & 7200,00 \\
\hline 100 & 8 & 0,3 & 1,0 & 25,55 & 21,27 & 22,07 & 7200,00 & 7200,00 & 7200,00 \\
\hline 100 & 12 & 0,1 & 0,1 & 47,99 & 0,00 & 0,00 & 7200,00 & 5160,58 & 1562,89 \\
\hline 100 & 12 & 0,1 & 0,5 & 38,72 & 20,67 & 19,85 & 7200,00 & 7200,00 & 7200,00 \\
\hline 100 & 12 & 0,1 & 1,0 & 37,55 & 34,63 & 35,03 & 7200,00 & 7200,00 & 7200,00 \\
\hline 100 & 12 & 0,3 & 0,1 & 33,99 & 0,00 & 0,00 & 7200,00 & 3677,00 & 1347,38 \\
\hline 100 & 12 & 0,3 & 0,5 & 40,82 & 32,40 & 32,15 & 7200,00 & 7200,00 & 7200,00 \\
\hline 100 & 12 & 0,3 & 1,0 & 72,74 & 30,61 & 30,98 & 7200,00 & 7200,00 & 7200,00 \\
\hline 100 & 16 & 0,1 & 0,1 & 60,62 & 18,44 & 11,27 & 7200,00 & 7200,00 & 5878,11 \\
\hline 100 & 16 & 0,1 & 0,5 & 58,47 & 30,74 & 30,08 & 7200,00 & 7200,00 & 7200,00 \\
\hline 100 & 16 & 0,1 & 1,0 & 100,00 & 31,46 & 31,71 & 7200,00 & 7200,00 & 7200,00 \\
\hline 100 & 16 & 0,3 & 0,1 & 71,55 & 12,77 & 7,35 & 7200,00 & 6877,58 & 5716,30 \\
\hline 100 & 16 & 0,3 & 0,5 & 66,41 & 40,07 & 46,52 & 7200,00 & 7200,00 & 7200,00 \\
\hline 100 & 16 & 0,3 & 1,0 & 86,10 & 43,47 & 43,57 & 7200,00 & 7200,00 & 7200,00 \\
\hline
\end{tabular}

Tabela 4.2: Resultados comparativos entre os modelos $C_{e}^{+}, F C C$ e $L C C$ para $\Gamma=0.9$ 
por volta de $31 \%$ de ambos os modelos implementados nesta dissertação, o que mostra que ambos modelos obtêm resultados bem mais próximos do valor ótimo, apesar de não alcançarem tal valor.

Nesses testes é possível notar também que a diferença entre executar 200 ou 2000 rodadas de corte é pequena. De forma geral a diferença entre os gaps médios obtidos é em torno de $0-2 \%$, e geralmente o modelo que usa 2000 rodadas de corte obtém os melhores resultados. Porém nas instâncias com $n=100, k=16, \beta \in\{0.1,0.3\}$ e $\alpha=0.1$, o modelo $L C C$ obtém gaps médios entre $5-7 \%$ menores quando em comparação com o método FCC. Em contrapartida, nas instâncias com $n=100, k=16, \beta=0.3$ e $\alpha=0.5$ o modelo $F C C$ obtém gaps médios por volta de $6 \%$ menores que o $L C C$.

Porém, por executar menos rodadas de corte, o $L C C$ executa em um tempo total bem mais rápido que o $F C C$, podendo chegar em média até 13 vezes menor, nas instâncias com $n=50, k=8, \beta=0.3$ e $\alpha=0.1$, por exemplo. Ambas observações reforçam que melhorias podem ser feitas quanto a calibração do branch-and-cut aqui definido, de forma a encontrar um método mais otimizado, bem como uma melhor forma de selecionar esse parâmetro do número de rodadas de corte que o algoritmo executa.

A Figura 4.5 contém um boxplot comparativo do tempo total de execução dos algoritmos $C_{e}^{+}, F C C$ e $L C C$, agrupados pelo valor de $K$. Neste gráfico podemos observar que para $K=4$ ambos os três algoritmos possuem o menor tempo total de execução, porém para $K>4$ o tempo total de execução cresce consideravelmente, principalmente com $K=16$, na qual boa parte das instâncias alcança o tempo limite de 7200 segundos e para sua execução.

Distribuição do tempo total de execução com $\Gamma=0.9$ para diferentes valores de $K \in\{4,8,12,16\}$

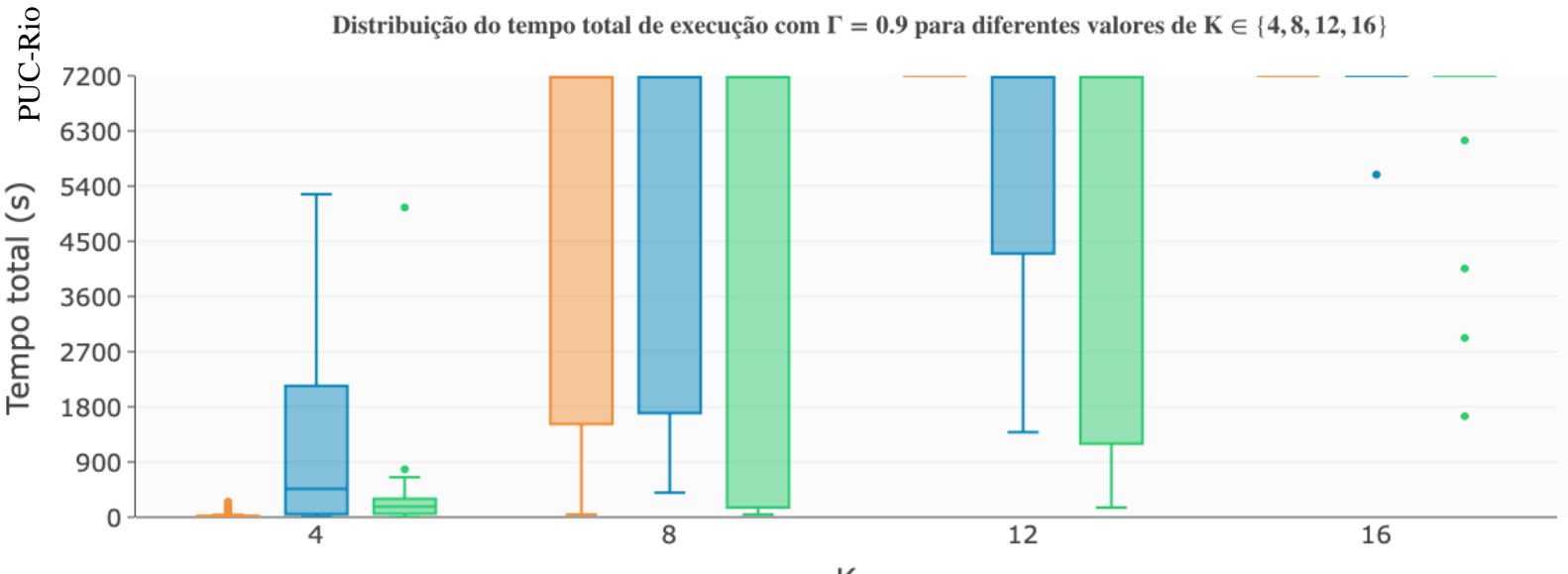

Figura 4.5: Comparação do tempo total de execução entre os modelos $C_{e}^{+}$, $F C C$ e $L C C$ para $K \in\{4,8,12,16\}$ com $\Gamma=0.9$.

O tempo total de execução dos algoritmos é diretamente proporcional com o grau médio de cada nó do grafo $(K)$. Porém quando olhamos também 
para quantidade de nós do grafo $(n)$, este valor tem uma menor influência no tempo total. A Figura 4.6 contém um boxplot comparativo do tempo total de execução dos algoritmos $C_{e}^{+}, F C C$ e $L C C$, agrupados pelo valor de $K$ e também pelo valor de $n$.

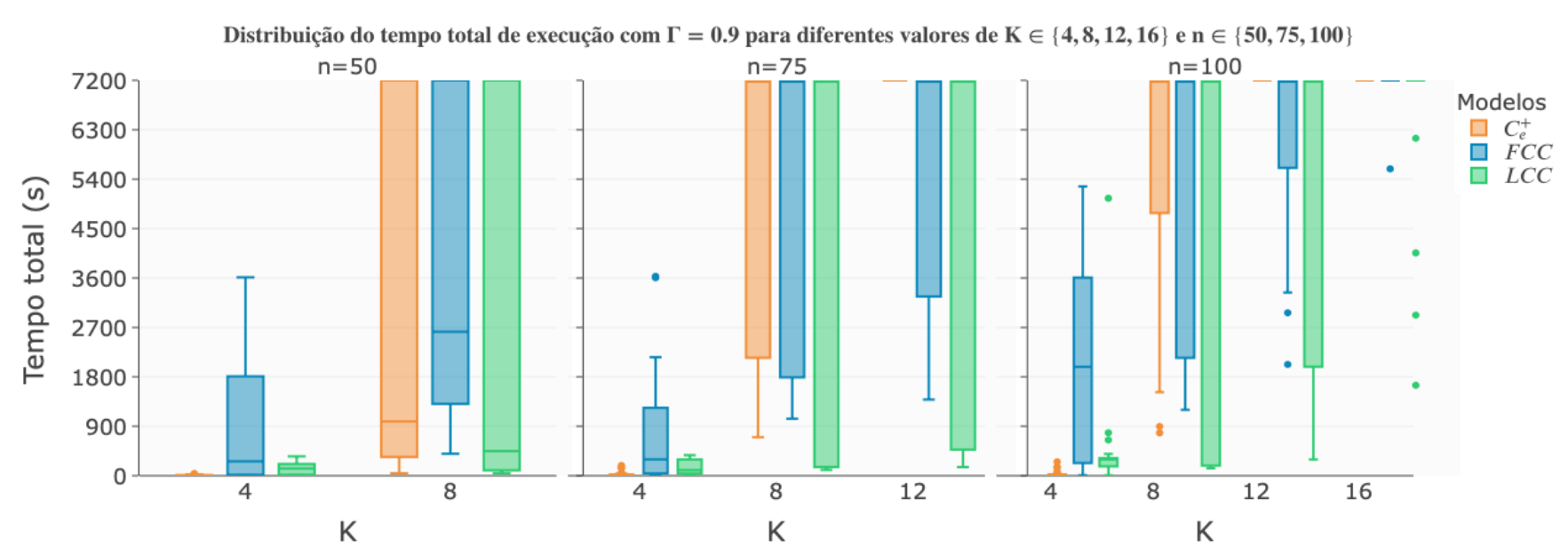

Figura 4.6: Comparação do tempo total de execução entre os modelos $C_{e}^{+}$, $F C C$ e $L C C$ para $K \in\{4,8,12,16\}$ e $n \in\{50,75,100\} \operatorname{com} \Gamma=0.9$.

Os resultados detalhados com $\Gamma=0.9$ para cada instância podem ser encontrados no Apêndice A, nas Tabelas A.1, A.2, e A.3.

Podemos observar que ambos os modelos FCC e $L C C$ resolveram respectivamente $153(57 \%)$ e $156(58 \%)$ das 270 instâncias em otimalidade, contra $129(48 \%)$ do modelo $C_{e}^{+}$proposto em Fischetti et al. (2018), sendo respectivamente 28 e 31 instâncias que estavam em aberto e não se conhecia o valor ótimo. Além disso, o modelo $A$ atinge o tempo limite de 7200 segundos (2 horas) em $141(52,2 \%)$ dos 270 casos, contra $117(43,3 \%)$ para o $F C C$ e $114(42,2 \%)$ para o $L C C$.

\section{Experimentos para $\Gamma=1.0$ :}

Diferentemente do caso anterior, para $\Gamma=1.0$ também comparamos os nossos modelos com o modelo $A$, formulação baseada em arcos definida em Fischetti et al. (2018), como comentada anteriormente. E além disso, assim como o caso com $\Gamma=0.9$, a Figura 4.7 contém também um boxplot comparativo do gap obtido pelos modelos $A, C_{e}^{+}, F C C$ e $L C C$, para $\Gamma=1.0$, agrupados para cada valor de $K$.

De forma geral, podemos observar que o modelo $C_{e}^{+}$, desenvolvido por Fischetti et al. (2018), obtém melhores resultados nas instâncias em que o grau de cada nó do grafo $K=4$. Apesar disso, nosso algoritmo geralmente 


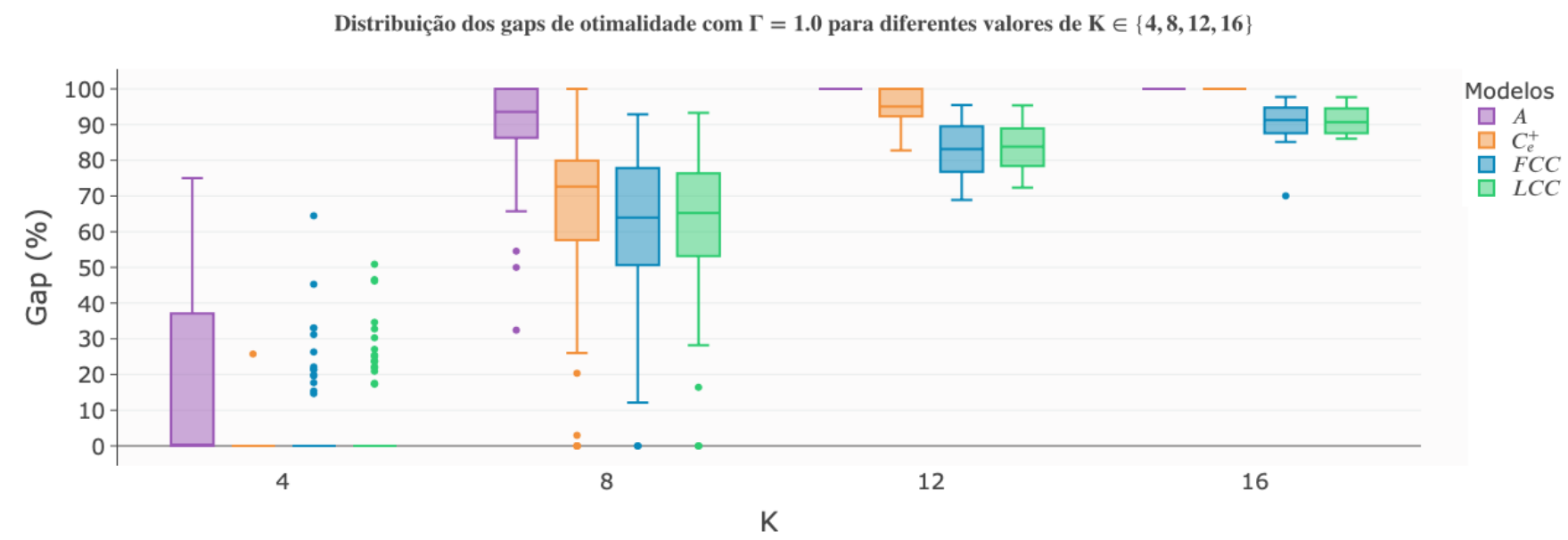

Figura 4.7: Comparação do gap entre os modelos $C_{e}^{+}, F C C$ e $L C C$ para $K \in\{4,8,12,16\} \operatorname{com} \Gamma=1.0$.

obtém soluções com um gap médio maior, mas próximo dos resultados obtidos no método $C_{e}^{+}$. Em contrapartida, para valores de $k>8$, o branch-and-cut proposto nesta dissertação consegue alcançar um gap médio sempre menor. Nesses testes inclusive há resultados dos modelos $A$ e $C_{e}^{+}$em que o gap médio é de $100 \%$.

Assim como nos casos com $\Gamma=0.9$, podemos observar também que o valor de $K$ é determinante quanto à dificuldade do problema. E além disso, o valor de $n$ tem um menor impacto nos resultados, em comparação com o valor de $K$. A Figura 4.8 pode ilustrar mais essa característica, com um boxplot comparativo do valor do gap agrupado pelo valor de $K$ e $n$.

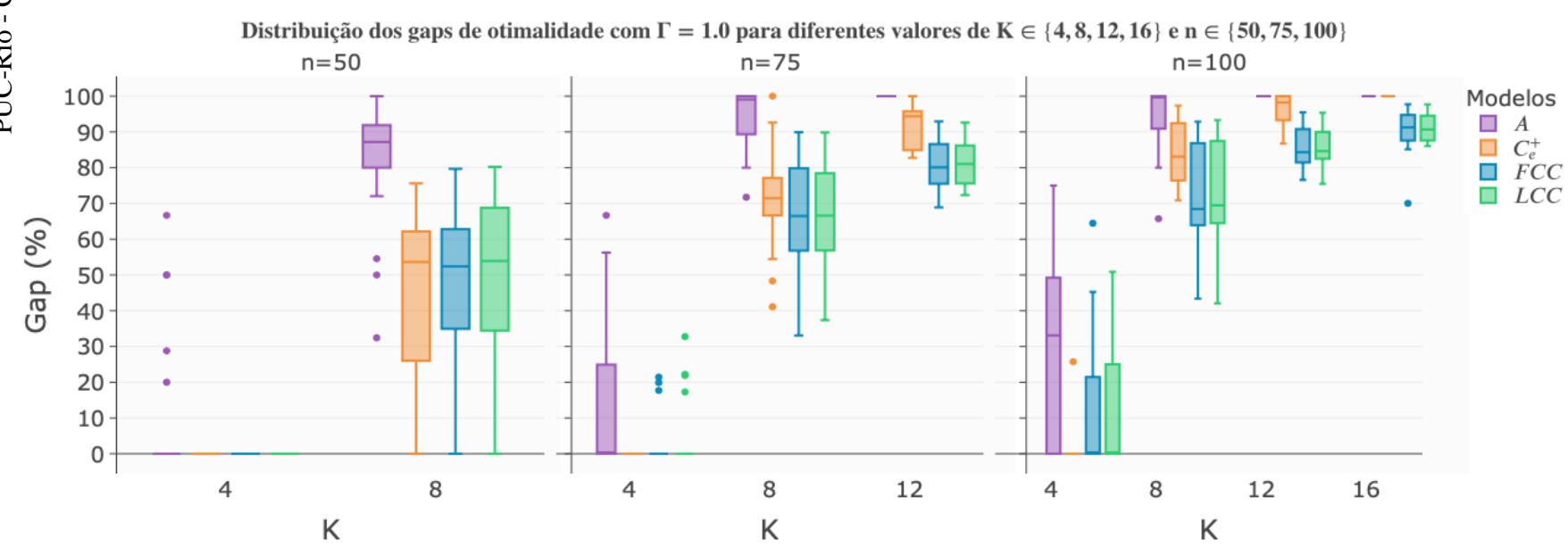

Figura 4.8: Comparação do gap entre os modelos $C_{e}^{+}, F C C$ e $L C C$ para $K \in\{4,8,12,16\} \operatorname{com} \Gamma=1.0$.

A Tabela 4.3 apresenta os resultados do gap médio e o tempo médio das 5 instâncias para cada configuração de parâmetros $n, K, \beta$ e $\alpha$, com $\Gamma=1.0$. 


\begin{tabular}{|c|c|c|c|c|c|c|c|c|c|c|c|}
\hline \multirow[b]{2}{*}{$\mathbf{n}$} & \multirow[b]{2}{*}{$\mathrm{k}$} & \multirow[b]{2}{*}{$\beta$} & \multirow[b]{2}{*}{$\alpha$} & \multicolumn{4}{|c|}{ Avg. gap (\%) } & \multicolumn{4}{|c|}{ Avg. total time (s) } \\
\hline & & & & A & $C_{e}^{+}$ & FCC & LCC & A & $C_{e}^{+}$ & FCC & $\mathrm{LCC}$ \\
\hline 50 & 4 & 0,1 & 0,1 & 10,00 & 0,00 & 0,00 & 0,00 & 1443,82 & 3,05 & 156,80 & 59,81 \\
\hline 50 & 4 & 0,1 & 0,5 & 10,00 & 0,00 & 0,00 & & 831,81 & 4,71 & 2905,66 & 244,89 \\
\hline 50 & 4 & 0,1 & 1,0 & 17,33 & 0,00 & 0,00 & & 973,28 & 1,88 & 1486,82 & 251,52 \\
\hline 50 & 4 & 0,3 & 0,1 & 0,00 & 0,00 & 0,00 & & 0,95 & 0,73 & & 59,58 \\
\hline 50 & 4 & 0,3 & 0,5 & 0,00 & 0,00 & 0,00 & & 887,47 & 273,73 & 1590,47 & 565,75 \\
\hline 50 & 4 & 0,3 & 1,0 & 5,76 & 0,00 & 0,00 & & 585,31 & 29,12 & 1917,82 & 711,79 \\
\hline 50 & 8 & 0,1 & 0,1 & 83,64 & 25,93 & 25,45 & & 00,00 & 4928,09 & 6194,72 & 6482,07 \\
\hline 50 & 8 & 0,1 & 0,5 & 89,59 & 41,80 & 52,24 & & 00,00 & 5871,70 & 7200,00 & 7200,00 \\
\hline 50 & 8 & 0,1 & 1,0 & 90,64 & 25,69 & & & 00,00 & 5893,71 & 200,00 & 200,00 \\
\hline 50 & 8 & 0,3 & 0,1 & 62 , & 39,46 & & & 00,00 & 122,78 & 63 & 1844,06 \\
\hline 50 & 8 & 0,3 & 0,5 & 90 & 66,17 & & & & 200,00 & & 7200,00 \\
\hline 50 & 8 & 0,3 & 1,0 & 85 & & & & & 200,00 & & 7200,00 \\
\hline 75 & 4 & 0,1 & 0,1 & 10 & & & & & 5,95 & & 81,09 \\
\hline 75 & 4 & 0,1 & 0,5 & 20 , & & & & & & 04 & 1649,10 \\
\hline 75 & 4 & 0,1 & 1,0 & 21 & & & & & & & \\
\hline 75 & 4 & 0,3 & 0,1 & & & & & & & & \\
\hline 75 & 4 & 0,3 & 0,5 & & & & & 0 & & & \\
\hline 75 & 4 & 0,3 & 1,0 & 22,2 & & & & & & & \\
\hline 75 & 8 & 0,1 & 0,1 & & 7 & & & & & & \\
\hline 75 & 8 & 0,1 & 0,5 & & & & & & & &, 00 \\
\hline 75 & 8 & 0,1 & 1,0 & & & & & & & & ,00 \\
\hline 75 & 8 & 0,3 & 0,1 & 89 , & 9,45 & 44, & & & & 720 & 7200,00 \\
\hline 75 & 8 & 0,3 & 0,5 & 96 & 85,58 & 84, & 84 & & & 720 & 7200,00 \\
\hline 75 & 8 & 0,3 & 1,0 & 94, & 70,47 & 75,12 & & & & 720 & 7200,00 \\
\hline 75 & 12 & 0,1 & 0,1 & 100 & 84,41 & 75,62 & 76 & & & 720 & 7200,00 \\
\hline 75 & 12 & 0,1 & 0,5 & 100, & 1,18 & 86,16 & 85 & & & 720 & 7200,00 \\
\hline 75 & 12 & 0,1 & 1,0 & 100, & 3,95 & 74,00 & & & & 720 & 7200,00 \\
\hline 75 & 12 & 0,3 & 0,1 & 100, & 7,44 & 74 & & & & 720 & 7200,00 \\
\hline 75 & 12 & 0,3 & 0,5 & 100, & 97,47 & 91,87 & & & & 720 & 7200,00 \\
\hline 75 & 12 & 0,3 & 1,0 & 100, & 98,23 & 83 , & & & 7200,00 & 720 & 7200,00 \\
\hline 100 & 4 & 0,1 & 0,1 & & & & & & 9 & 102 & 117,93 \\
\hline 100 & 4 & 0,1 & 0,5 & 44, & 0 , & 11,03 & 14, & 00,00 & 265,59 & 490 & 3724,01 \\
\hline 100 & 4 & 0,1 & 1,0 & 57,54 & 0,00 & 12,89 & & 200,00 & 13, & 326 & 2046,54 \\
\hline 100 & 4 & 0,3 & 0,1 & & 0,00 & 0,00 & & 12,51 & 208,32 & 1494 & 123,88 \\
\hline 100 & 4 & 0,3 & 0,5 & 26, & 5,15 & 21,90 & 26 & 904,10 & 3459,81 & 645 & 5933,36 \\
\hline 100 & 4 & 0,3 & 1,0 & 50 & 0,00 & 19,48 & 28 & 00,00 & 228,91 & 720 & 7200,00 \\
\hline 100 & 8 & 0,1 & 0,1 & 86 & 74,95 & 55,49 & & 200,00 & 7200,00 & 720 & 7200,00 \\
\hline 100 & 8 & 0,1 & 0,5 & & 80,86 & 76,32 & & 00,00 & 7200 & 720 & 7200,00 \\
\hline 100 & 8 & 0,1 & 1,0 & & 86,76 & 60 & & 00 & 7200,00 & 720 & 7200,00 \\
\hline 100 & 8 & 0,3 & 0,1 & & & 63 , & & 7200,00 & 7200,00 & 7200 & 7200,00 \\
\hline 100 & 8 & 0,3 & 0,5 & & 93, & 91,90 & & 200,00 & 7200,00 & 7200 & 7200,00 \\
\hline 100 & 8 & 0,3 & 1,0 & & 89,54 & 85,86 & & 7200,00 & 7200,00 & 7200 & 7200,00 \\
\hline 100 & 12 & 0,1 & 0,1 & 100, & & 82,92 & & 7200,00 & 7200,00 & 7200 & 7200,00 \\
\hline 100 & 12 & 0,1 & 0,5 & & 94,56 & 86,98 & & 7200,00 & 7200,00 & 7200,00 & 7200,00 \\
\hline 100 & 12 & 0,1 & 1,0 & 100,00 & 94,19 & 78,0 & & 7200,00 & 7200,00 & 7200,00 & 7200,00 \\
\hline 100 & 12 & 0,3 & 0,1 & 100,00 & 100,00 & 81,43 & & 7200,00 & 7200,00 & 7200,00 & 7200,00 \\
\hline 100 & 12 & 0,3 & 0,5 & 100,00 & 100,00 & 95,21 & & 7200,00 & 7200,00 & 7200,00 & 7200,00 \\
\hline 100 & 12 & 0,3 & 1,0 & & 100,00 & 90,79 & & 7200,00 & 7200,00 & 7200,00 & 7200,00 \\
\hline 100 & 16 & 0,1 & 0,1 & & & 92,79 & & 7200,00 & 7200,00 & 7200,00 & 7200,00 \\
\hline 100 & 16 & 0,1 & 0,5 & & & 93,29 & $\mathbf{9 3 , 2}$ & 7200,00 & 7200,00 & 7200,00 & 7200,00 \\
\hline 100 & 16 & 0,1 & 1,0 & & & 86,74 & & 7200,00 & 7200,00 & 7200,00 & 7200,00 \\
\hline 100 & 16 & 0,3 & 0,1 & & & & & 7200,00 & 7200,00 & 7200,00 & 7200,00 \\
\hline 100 & 16 & 0,3 & 0,5 & & & 96,02 & & & & 7200,00 & 7200,00 \\
\hline 100 & 16 & 0,3 & 1,0 & 100,00 & 100,00 & 91,23 & 90,99 & 7200,00 & 7200,00 & 7200,00 & 7200,00 \\
\hline
\end{tabular}

Tabela 4.3: Resultados comparativos entre os modelos $A, C_{e}^{+}, F C C$ e $L C C$ para $\Gamma=1.0$ 
De forma similiar ao caso anterior, os resultados entre usar 200 ou 2000 rodadas de corte são bem próximos, sendo que executar 2000 rodadas de corte obtém gaps menores, porém executar 200 rodadas de corte leva a tempos médios bem menores, chegando a ser mais de 10x mais rápido em certas instâncias.

Apesar do gap médio menor, o branch-and-cut implementado tem os piores tempos de execução médios, inclusive até na versão light, que executa só 200 rodadas de corte. Os métodos desenvolvidos em Fischetti et al. (2018) obtém os menores tempos de execução, inclusive quando o método $C_{e}^{+}$resolve alguma instância, este costuma ser bem rápido. Apesar disso, nas instâncias com $k \geq 8$, basicamente quase sempre ambos os quatro modelos não conseguem chegar no valor ótimo da função objetivo, atingindo o tempo limite de 7200 segundos (2 horas).

A Figura 4.10 ilustra um comparativo dos tempos de execução dos algoritmos $A, C_{e}^{+}, F C C$ e $L C C$, agrupados pelo grau médio de cada nó. O mesmo fenômeno pode ser observado quando esses resultados são agrupados também pelo número de vértices do grafo $(n)$, e a Figura 4.10 ilustra o tempo

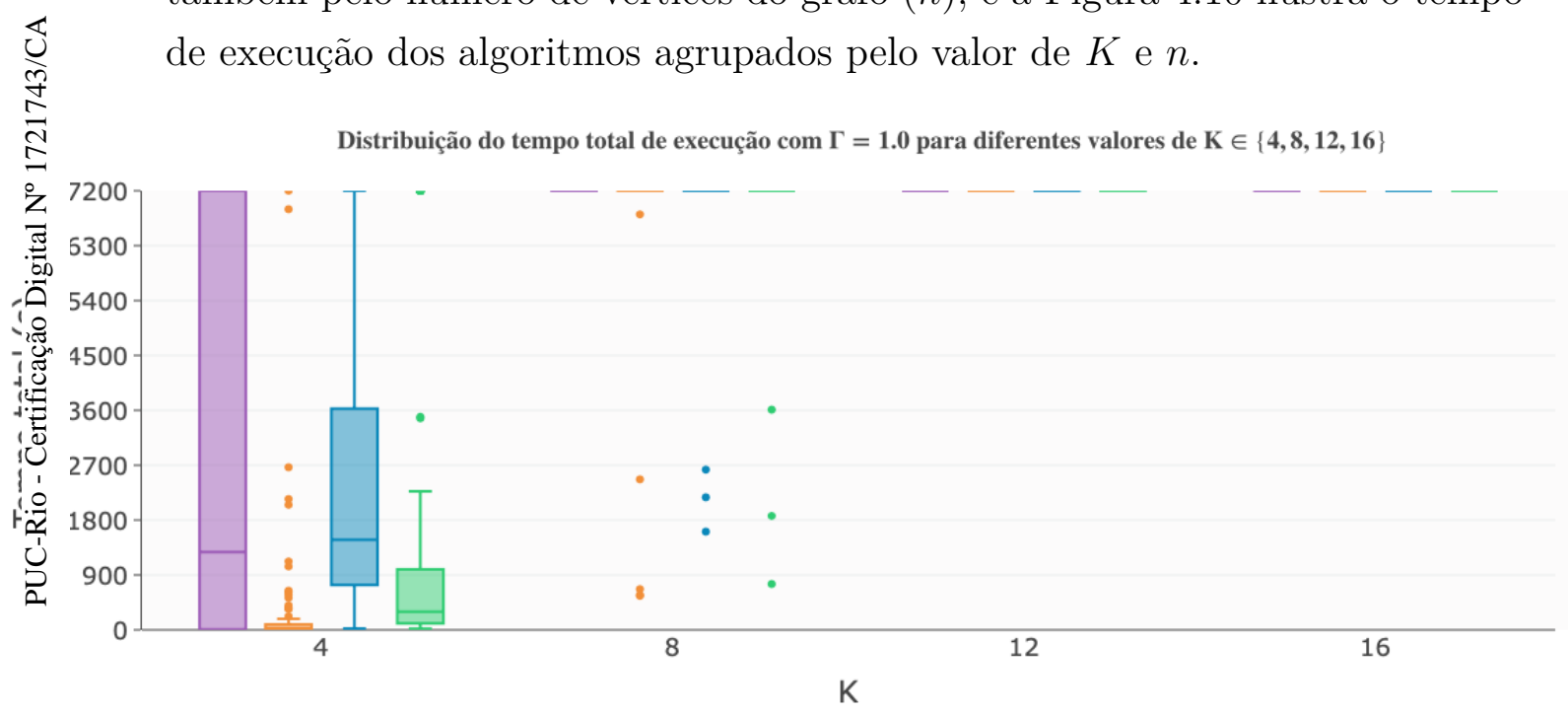

Figura 4.9: Comparação do tempo total de execução entre os modelos $A, C_{e}^{+}$, $F C C$ e $L C C$ para $K \in\{4,8,12,16\} \operatorname{com} \Gamma=1.0$

Os resultados detalhados, com os valores obtidos em cada instância podem ser vistos no Apêndice A, nas Tabelas A.4, A.5, e A.6. Desses resultados, podemos observar que apenas uma instância foi resolvida, que estava em aberto anteriormente. Os modelos $F C C$ e $L C C$ obtiveram o valor ótimo em respectivamente $79(29,3 \%)$ e $77(28,5 \%)$ das 270 instâncias, número maior que o modelo $A R C$, por exemplo, que alcançou o ótimo em 54(20\%) delas, porém o modelo $C_{e}^{+}$garantiu otimalidade em $94(34,8 \%)$ casos. Além disso, podemos destacar também os modelos $A, C_{e}^{+}, F C C$ e $L C C$ atingiram o limite de 


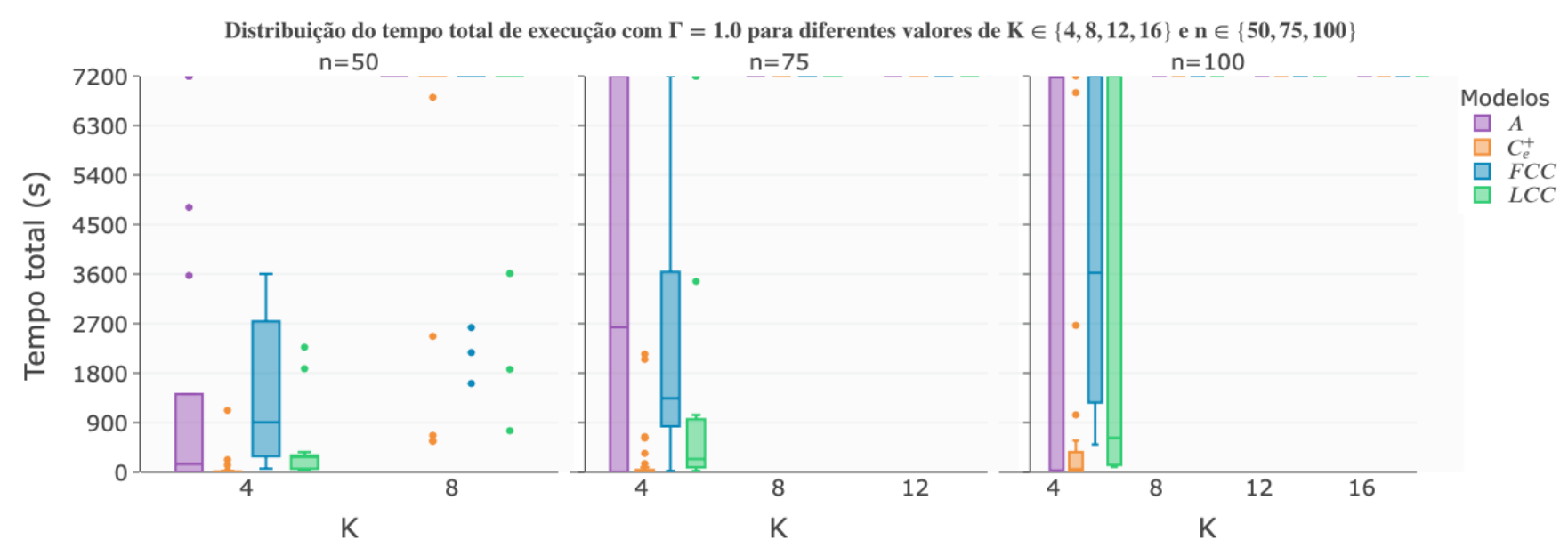

Figura 4.10: Comparação do tempo total de execução entre os modelos $A, C_{e}^{+}$, $F C C$ e $L C C$ para $K \in\{4,8,12,16\}$ e $n \in\{50,75,100\} \operatorname{com} \Gamma=1.0$

tempo de 7200 segundos (2 horas) em respectivamente $216(80 \%), 176(65,2 \%)$, $191(70,7 \%)$ e $193(71,5 \%)$ dos casos.

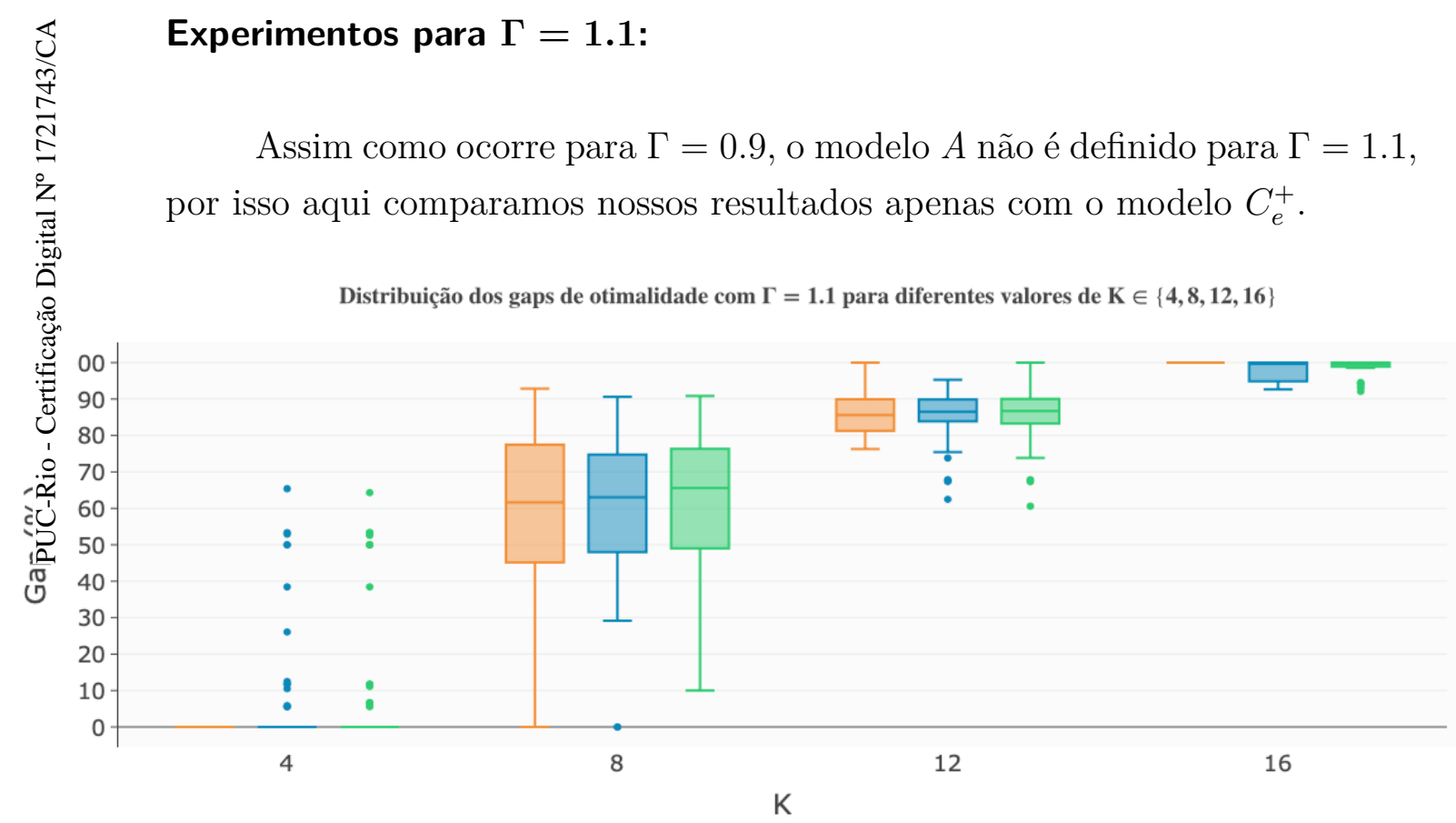

Figura 4.11: Comparação do gap entre os modelos $C_{e}^{+}, F C C$ e $L C C$ para $K \in\{4,8,12,16\} \operatorname{com} \Gamma=1.1$.

A Figura 4.11 exibe um boxplot comparativo do gap obtido pelos modelos $C_{e}^{+}, F C C$ e $L C C$, para $\Gamma=1.0$, agrupados para cada valor de $K$. De forma geral, podemos observar que diferentemente dos casos anteriores, para $\Gamma=1.1$, o modelo $C_{e}^{+}$obtém melhores resultados com gaps médios e tempos médios menores que os modelos $F C C$ e $L C C$. Em todos os casos para $K=4$ o 
método $C_{e}^{+}$obtém um gap médio igual a zero, o que não acontece sempre para os modelos propostos neste trabalho. Para as instâncias com $K>4$, o $C_{e}^{+}$tem gaps médios menores em 18 casos, contra respectivamente 10 e 6 casos para o $F C C$ e $L C C$. E mais uma vez, a quantidade de nós do grafo teve um menor efeito quanto o grau médio de cada nó em relação ao gap obtido pelos algoritmos. A Figura 4.12 ilustra esse fato, com um boxplot comparativo do gap agrupado pelos valores de $K$ e $n$ para $\Gamma=1.1$.

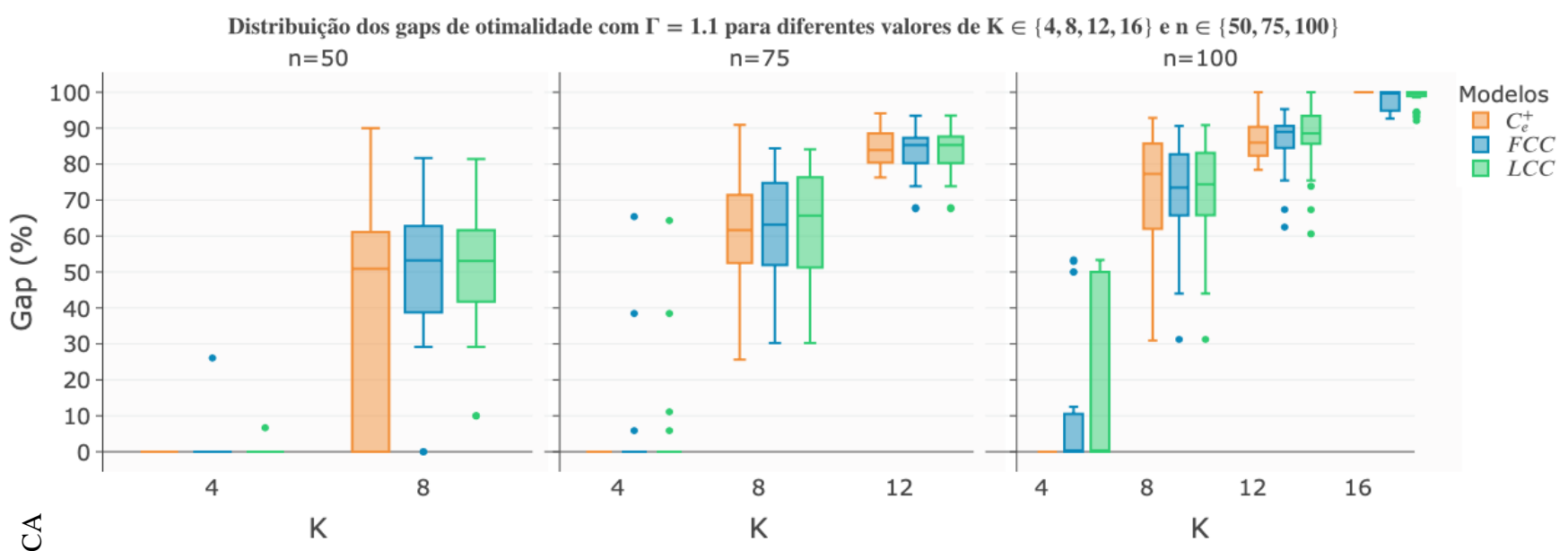

Figura 4.12: Comparação do gap entre os modelos $C_{e}^{+}, F C C$ e $L C C$ para $K \in\{4,8,12,16\} \operatorname{com} \Gamma=1.1$.

Os resultados agregados dessas avaliações podem ser vistos na Tabela 4.4, com o gap médio e tempo médio das 5 instâncias para cada configuração de parâmetros obtido nos modelos $C_{e}^{+}, F C C$ e $L C C$ para $\Gamma=1.1$. Assim como a tabela anterior, também são exibidas as configurações da instância $n, k, \beta$; bem como o valor de $\alpha$, com a fração mínima de nós para serem ativados.

Quanto ao tempo, para $\Gamma=1.1$, na maioria dos casos o $L C C$ obtém tempos médios menores que o $F C C$, mas de forma geral essa diferença é mais tímida que os casos com $\Gamma \in\{0.9,1.0\}$. Mas nos casos com $n=100, k=4$, $\beta=0.3$ e $\alpha \in\{0.5,1.0\}$ por exemplo, o $L C C$ obteve um tempo médio maior que o $F C C$, provavelmente porque nesses casos as 200 rodadas de corte não foram suficientes para uma melhor convergência do algoritmo.

A Figura 4.13 demonstra uma comparação do tempo total de execução dos algoritmos agrupados para cada valor de $K$. Assim como a Figura 4.14 exibe a mesma informação agrupada também pelo número de nós no grafo, e que enfatiza novamente que o valor de $K$ é bem mais determinante quanto ao sucesso do algoritmo.

Os resultados detalhados, com as avaliações para cada instância, podem ser encontrados no Apêndice A, nas Tabelas A.7, A.8, e A.9. Desses resultados 


\begin{tabular}{|c|c|c|c|c|c|c|c|c|c|}
\hline \multirow[b]{2}{*}{$\mathbf{n}$} & \multirow[b]{2}{*}{$\mathbf{k}$} & \multirow[b]{2}{*}{$\beta$} & \multirow[b]{2}{*}{$\alpha$} & \multicolumn{3}{|c|}{ Avg. gap (\%) } & \multicolumn{3}{|c|}{ Avg. total time (s) } \\
\hline & & & & $C_{e}^{+}$ & FCC & $\mathrm{LCC}$ & $C_{e}^{+}$ & FCC & $\mathrm{LCC}$ \\
\hline 50 & 4 & 0,1 & 0,1 & 0,00 & 0,00 & 0,00 & 0,41 & 227,56 & 51,54 \\
\hline 50 & 4 & 0,1 & 0,5 & 0,00 & 0,00 & 0,00 & 1,58 & 1904,95 & 171,53 \\
\hline 50 & 4 & 0,1 & 1,0 & 0,00 & 0,00 & 0,00 & 0,29 & 14,11 & 14,18 \\
\hline 50 & 4 & 0,3 & 0,1 & 0,00 & 0,00 & 0,00 & 0,33 & 567,36 & 75,73 \\
\hline 50 & 4 & 0,3 & 0,5 & 0,00 & 0,00 & 1,33 & 3,51 & 1443,40 & 1604,75 \\
\hline 50 & 4 & 0,3 & 1,0 & 0,00 & 5,21 & 0,00 & 4,91 & 2323,31 & 235,82 \\
\hline 50 & 8 & 0,1 & 0,1 & 20,77 & 53,56 & 54,30 & 4529,79 & 7200,00 & 7200,00 \\
\hline 50 & 8 & 0,1 & 0,5 & 25,82 & 53,60 & 55,41 & 5235,15 & 7200,00 & 7200,00 \\
\hline 50 & 8 & 0,1 & 1,0 & 30,49 & 20,43 & 26,30 & 4649,12 & 4714,00 & 7200,00 \\
\hline 50 & 8 & 0,3 & 0,1 & 33,69 & 50,32 & 51,56 & 5468,89 & 7200,00 & 7200,00 \\
\hline 50 & 8 & 0,3 & 0,5 & 61,57 & 71,87 & 70,30 & 7200,00 & 7200,00 & 7200,00 \\
\hline 50 & 8 & 0,3 & 1,0 & 72,53 & 53,08 & 53,08 & 7200,00 & 7200,00 & 7200,00 \\
\hline 75 & 4 & 0,1 & 0,1 & 0,00 & 0,00 & 0,00 & 0,11 & 1249,34 & 110,66 \\
\hline 75 & 4 & 0,1 & 0,5 & 0,00 & 0,00 & 2,22 & 0,78 & 1225,29 & 1579,96 \\
\hline 75 & 4 & 0,1 & 1,0 & 0,00 & 0,00 & 0,00 & 0,43 & 30,18 & 29,10 \\
\hline 75 & 4 & 0,3 & 0,1 & 0,00 & 0,00 & 0,00 & 34,14 & 1450,51 & 121,69 \\
\hline 75 & 4 & 0,3 & 0,5 & 0,00 & 13,08 & 12,86 & 487,90 & 3116,99 & 2964,17 \\
\hline 75 & 4 & 0,3 & 1,0 & 0,00 & 8,87 & 8,87 & 87,60 & 3006,02 & 2935,24 \\
\hline 75 & 8 & 0,1 & 0,1 & 53,97 & 67,94 & 68,72 & 7200,00 & 7200,00 & 7200,00 \\
\hline 75 & 8 & 0,1 & 0,5 & 48,71 & 66,28 & 68,52 & 7200,00 & 7200,00 & 7200,00 \\
\hline 75 & 8 & 0,1 & 1,0 & 54,59 & 43,45 & 43,45 & 7200,00 & 7200,00 & 7200,00 \\
\hline 75 & 8 & 0,3 & 0,1 & 59,10 & 67,84 & 70,76 & 7200,00 & 7200,00 & 7200,00 \\
\hline 75 & 8 & 0,3 & 0,5 & 77,76 & 75,17 & 75,71 & 7200,00 & 7200,00 & 7200,00 \\
\hline 75 & 8 & 0,3 & 1,0 & 76,13 & 51,55 & 51,55 & 7200,00 & 7200,00 & 7200,00 \\
\hline 75 & 12 & 0,1 & 0,1 & 79,29 & 84,54 & 85,29 & 7200,00 & 7200,00 & 7200,00 \\
\hline 75 & 12 & 0,1 & 0,5 & 85,22 & 87,17 & 87,57 & 7200,00 & 7200,00 & 7200,00 \\
\hline 75 & 12 & 0,1 & 1,0 & 82,22 & 73,11 & 73,11 & 7200,00 & 7200,00 & 7200,00 \\
\hline 75 & 12 & 0,3 & 0,1 & 81,11 & 85,89 & 86,17 & 7200,00 & 7200,00 & 7200,00 \\
\hline 75 & 12 & 0,3 & 0,5 & 87,82 & 89,99 & 90,29 & 7200,00 & 7200,00 & 7200,00 \\
\hline 75 & 12 & 0,3 & 1,0 & 89,59 & 80,92 & 80,70 & 7200,00 & 7200,00 & 7200,00 \\
\hline 100 & 4 & 0,1 & 0,1 & 0,00 & 2,50 & 0,00 & 0,70 & 2250,33 & 132,33 \\
\hline 100 & 4 & 0,1 & 0,5 & 0,00 & 10,67 & 20,67 & 7,40 & 3719,67 & 3030,47 \\
\hline 100 & 4 & 0,1 & 1,0 & 0,00 & 0,00 & 0,00 & 5,57 & 130,26 & 136,07 \\
\hline 100 & 4 & 0,3 & 0,1 & 0,00 & 1,11 & 10,00 & 224,34 & 2241,59 & 2646,24 \\
\hline 100 & 4 & 0,3 & 0,5 & 0,00 & 31,70 & 52,37 & 175,89 & 6339,22 & 7200,00 \\
\hline 100 & 4 & 0,3 & 1,0 & 0,00 & 6,81 & 7,15 & 109,82 & 4437,58 & 5785,19 \\
\hline 100 & 8 & 0,1 & 0,1 & 66,15 & 73,13 & 75,48 & 7200,00 & 7200,00 & 7200,00 \\
\hline 100 & 8 & 0,1 & 0,5 & 47,84 & 70,63 & 73,78 & 7200,00 & 7200,00 & 7200,00 \\
\hline 100 & 8 & 0,1 & 1,0 & 64,56 & 45,97 & 45,97 & 7200,00 & 7200,00 & 7200,00 \\
\hline 100 & 8 & 0,3 & 0,1 & 79,84 & 76,83 & 79,02 & 7200,00 & 7200,00 & 7200,00 \\
\hline 100 & 8 & 0,3 & 0,5 & 83,51 & 87,78 & 87,83 & 7200,00 & 7200,00 & 7200,00 \\
\hline 100 & 8 & 0,3 & 1,0 & 85,78 & 70,10 & 73,83 & 7200,00 & 7200,00 & 7200,00 \\
\hline 100 & 12 & 0,1 & 0,1 & 82,32 & 88,21 & 89,05 & 7200,00 & 7200,00 & 7200,00 \\
\hline 100 & 12 & 0,1 & 0,5 & 83,47 & 87,26 & 88,90 & 7200,00 & 7200,00 & 7200,00 \\
\hline 100 & 12 & 0,1 & 1,0 & 85,19 & 72,71 & 72,05 & 7200,00 & 7200,00 & 7200,00 \\
\hline 100 & 12 & 0,3 & 0,1 & 87,33 & 90,08 & 96,01 & 7200,00 & 7200,00 & 7200,00 \\
\hline 100 & 12 & 0,3 & 0,5 & 93,26 & 93,71 & 94,04 & 7200,00 & 7200,00 & 7200,00 \\
\hline 100 & 12 & 0,3 & 1,0 & 92,22 & 86,44 & 85,26 & 7200,00 & 7200,00 & 7200,00 \\
\hline 100 & 16 & 0,1 & 0,1 & 100,00 & 94,48 & 93,91 & 7200,00 & 7200,00 & 7200,00 \\
\hline 100 & 16 & 0,1 & 0,5 & 100,00 & 99,31 & 99,61 & 7200,00 & 7200,00 & 7200,00 \\
\hline 100 & 16 & 0,1 & 1,0 & 100,00 & 99,77 & 99,78 & 7200,00 & 7200,00 & 7200,00 \\
\hline 100 & 16 & 0,3 & 0,1 & 100,00 & 94,96 & 98,39 & 7200,00 & 7200,00 & 7200,00 \\
\hline 100 & 16 & 0,3 & 0,5 & 100,00 & 100,00 & 100,00 & 7200,00 & 7200,00 & 7200,00 \\
\hline 100 & 16 & 0,3 & 1,0 & 100,00 & 100,00 & 100,00 & 7200,00 & 7200,00 & 7200,00 \\
\hline
\end{tabular}

Tabela 4.4: Resultados comparativos entre os modelos $C_{e}^{+}, F C C$ e $L C C$ para $\Gamma=1.1$ 


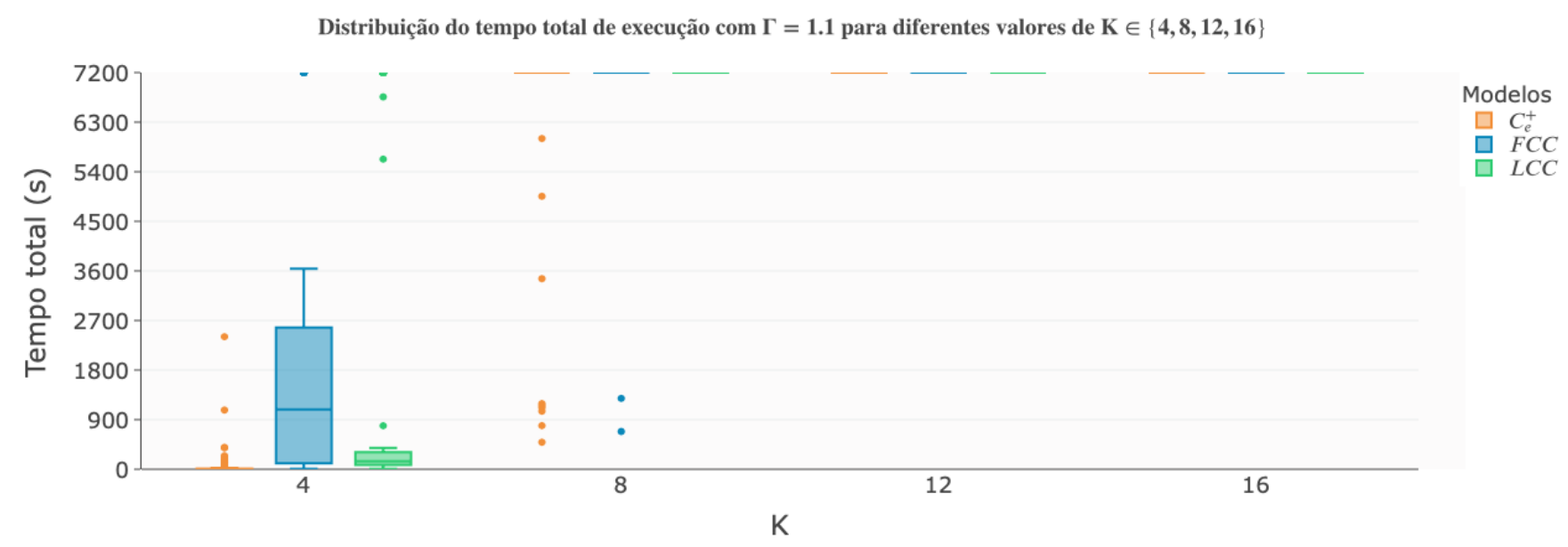

Figura 4.13: Comparação do tempo total de execução entre os modelos $C_{e}^{+}$, $F C C$ e $L C C$ para $K \in\{4,8,12,16\}$ com $\Gamma=1.1$

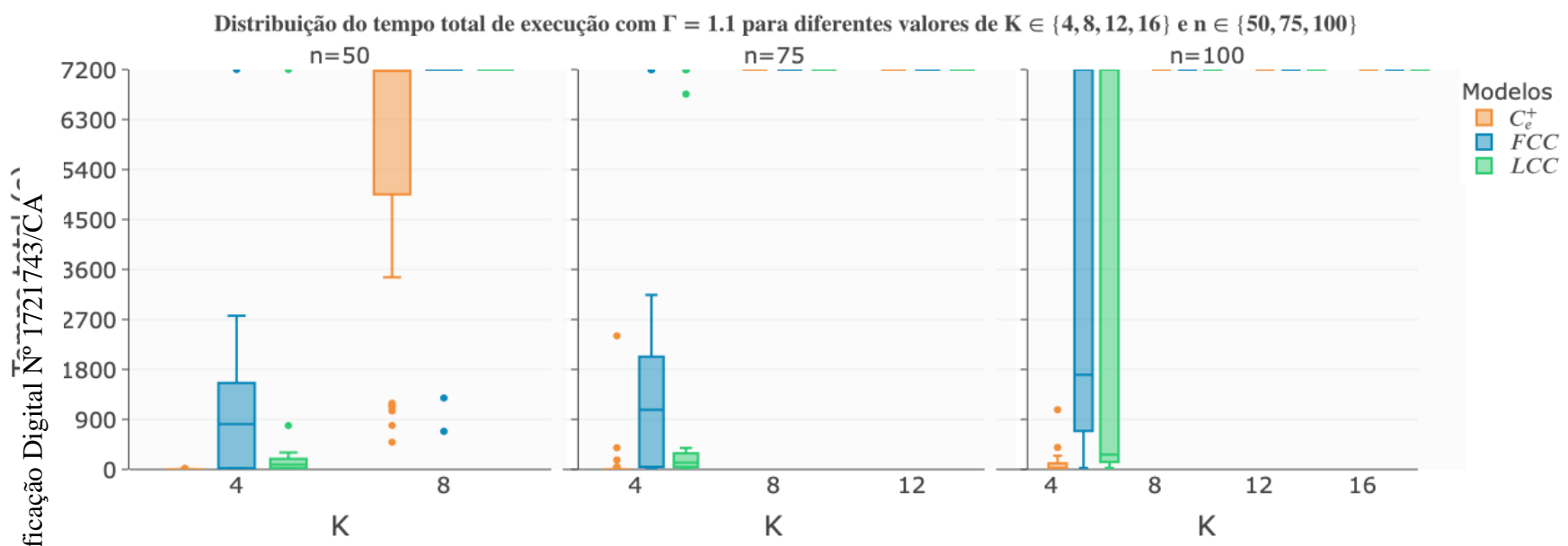

Figura 4.14: Comparação do tempo total de execução entre os modelos $C_{e}^{+}$, $F C C$ e $L C C$ para $K \in\{4,8,12,16\}$ e $n \in\{50,75,100\} \operatorname{com} \Gamma=1.1$

os modelos alcançaram o valor ótimo em 99(36.7\%), 78(28.9\%) e 73(27\%) dos casos, respectivamente para os modelos $C_{e}^{+}, F C C$ e $L C C$. Dos casos que estavam em aberto, nenhum deles foi garantido otimalidade, então quando os métodos $F C C$ e $L C C$ alcançaram o valor ótimo, eram soluções que já tinha sido garantido antes pelo modelo $C_{e}^{+}$, por exemplo.

Nessas tabelas é possível observar outro detalhe importante, que diz respeito ao tempo de execução de ambos os três algoritmos. Para $\Gamma=1.1$, os modelos $C_{e}^{+}, F C C$ e $L C C$ executam até o tempo limite de 7200 segundos (2 horas) respectivamente em 171(63\%), 192(71\%) e 197(73\%) dos 270 casos. 


\section{Conclusões}

\section{1}

\section{Discussões e contribuições}

Neste trabalho desenvolvemos um novo algoritmo de branch-and-cut para o GLCIP. Nosso modelo é baseado no modelo (ARC) proposto por Fischetti et al. (2018), com uma extensão para lidar com valores de $\Gamma \neq 1.0$ e com a adição de uma nova família de cortes ao modelo. Para isso desenvolvemos também um modelo exato de separação dessas restrições que são adicionadas ao modelo caso estejam violadas.

A principal contribuição deste trabalho é essa nova família de cortes que foi proposta, denominada de Cover Propagation Elimination Cut. Demonstramos empiricamente que introduzir tais cortes ao modelo traz bons resultados em relação ao valor do gap médio, já que o modelo obtém maiores valores do limite inferior, principalmente nos casos com $\Gamma=0.9$.

Em contrapartida, o método desenvolvido ainda possui um tempo de execução alto e demora em comparação com o modelo $C_{e}^{+}$apresentado em Fischetti et al. (2018), que ao resolver uma instância, costuma ser bem rápido. A partir desse modelo aqui implementado, outras formulações e cortes podem ser deduzidos.

Além disso, outra limitação do método diz respeito ao número de rodadas de cortes que o algoritmo executa. Esse valor é bem sensível, com um impacto muito grande não só no tempo total de execução, como também na qualidade da solução e pode chegar a uma diferença de quase $40 \%$ menor, como ocorre com a instância com $\Gamma=0.9, n=100, k=16, \beta=0.3, \alpha=0.5$ e $i=5$.

O branch-and-cut proposto tem os melhores resultados para $\Gamma=0.9$, ou seja, quando na função de ativação $f_{i}(U, p)=\left(\sum_{j i n U} d_{j, i}\right)^{\Gamma}+p \geq h_{i}$. Esse fato ainda necessita de maiores investigações e será foco de pesquisas futuras.

\section{2}

\section{Trabalhos Futuros}

Um caminho a seguir a partir deste trabalho é tratar diferentes modelos de propagação de influência, não só o modelo linear, para tratar casos mais 
realistas. Além disso, se mostra interessante tratar o problema como uma abordagem baseada em teoria dos jogos, onde há dois jogadores: um influenciando positivamente e outro negativamente, com o objetivo de propagar a influência na rede.

Além disso, o modelo é limitado em relação ao número de rodadas de corte, e definir esse valor tem um grande impacto nos resultados, já que dependendo da instância um número muito grande de rodadas de corte pode fazer o algoritmo passar muito tempo adicionando cortes, sobrando pouco tempo para o branch-and-cut; em contrapartida se poucas rodadas de corte forem utilizadas, estas podem não ser suficientes para uma melhor convergência do modelo. Isso sugere que devemos buscar um algoritmo de separação mais rápido, bem como calibrar esse parâmetro afim de reduzir o número de rodadas de corte na raiz nos casos em que a separação é mais demorada, possivelmente até usar algum método de machine learning para prever esse valor.

Cada MIP de separação gera apenas um corte e isso é computacionalmente muito caro. Por isso, tentar extrair mais cortes violados a partir desse corte gerado utilizando alguma busca local, com um critério de diversidade pode gerar melhores resultados. Outra opção é introduzir novas formulações e novos tipos de corte para o GLCIP, visando fortalecer ainda mais o modelo ou tornar o algoritmo de separação mais leve. 


\section{Referências bibliográficas}

Ackerman, E., Ben-Zwi, O., and Wolfovitz, G. (2010). Combinatorial model and bounds for target set selection. Theoretical Computer Science, 411(4446):4017-4022.

Bakshy, E., Hofman, J. M., Mason, W. A., and Watts, D. J. (2011). Everyone's an influencer: quantifying influence on twitter. In Proceedings of the fourth ACM international conference on Web search and data mining, pages 65-74. ACM.

Banerjee, S., Jenamani, M., and Pratihar, D. K. (2018). A survey on influence maximization in a social network. arXiv preprint arXiv:1808.05502.

Brown, J. J. and Reingen, P. H. (1987). Social ties and word-of-mouth referral behavior. Journal of Consumer research, 14(3):350-362.

Buja, A., Hastie, T., and Tibshirani, R. (1989). Linear smoothers and additive models. Ann. Statist., 17(2):453-510.

Centola, D. and Macy, M. (2007). Complex contagions and the weakness of long ties. American journal of Sociology, 113(3):702-734.

Chen, N. (2009). On the approximability of influence in social networks. SIAM Journal on Discrete Mathematics, 23(3):1400-1415.

Chen, W., Lakshmanan, L. V., and Castillo, C. (2013). Information and influence propagation in social networks. Synthesis Lectures on Data Management, 5(4):1-177.

Chen, W., Wang, C., and Wang, Y. (2010). Scalable influence maximization for prevalent viral marketing in large-scale social networks. In Proceedings of the 16th ACM SIGKDD international conference on Knowledge discovery and data mining, pages 1029-1038. ACM.

Cheng, R.-G., Chen, N.-S., Chou, Y.-F., and Becvar, Z. (2015). Offloading multiple mobile data contents through opportunistic device-to-device communications. Wireless Personal Communications, 84(3):1963-1979. 
Cordasco, G., Gargano, L., Rescigno, A. A., and Vaccaro, U. (2015). Optimizing spread of influence in social networks via partial incentives. In International Colloquium on Structural Information and Communication Complexity, pages 119-134. Springer.

Crowder, H., Johnson, E. L., and Padberg, M. (1983). Solving large-scale zeroone linear programming problems. Operations Research, 31(5):803-834.

Demaine, E. D., Hajiaghayi, M., Mahini, H., Malec, D. L., Raghavan, S., Sawant, A., and Zadimoghadam, M. (2014). How to influence people with partial incentives. In Proceedings of the 23rd international conference on World wide web, pages 937-948.

Domingos, P. and Richardson, M. (2001). Mining the network value of customers. In Proceedings of the seventh ACM SIGKDD international conference on Knowledge discovery and data mining, pages 57-66. ACM.

Dreyer Jr, P. A. and Roberts, F. S. (2009). Irreversible k-threshold processes: Graph-theoretical threshold models of the spread of disease and of opinion. Discrete Applied Mathematics, 157(7):1615-1627.

Dunning, I., Huchette, J., and Lubin, M. (2017). Jump: A modeling language for mathematical optimization. SIAM Review, 59(2):295-320.

Fischetti, M., Kahr, M., Leitner, M., Monaci, M., and Ruthmair, M. (2018). Least cost influence propagation in (social) networks. Mathematical Programming, 170(1):293-325.

Floyd, R. W. (1962). Algorithm 97: shortest path. Communications of the ACM, 5(6):345.

Goldenberg, J., Libai, B., and Muller, E. (2001). Talk of the network: A complex systems look at the underlying process of word-of-mouth. Marketing letters, 12(3):211-223.

Granovetter, M. (1978). Threshold models of collective behavior. American journal of sociology, 83(6):1420-1443.

Grötschel, M., Jünger, M., and Reinelt, G. (1985). On the acyclic subgraph polytope. Mathematical Programming, 33(1):28-42.

Gunnec, D. (2012). Integrating social network effects in product design and diffusion. PhD thesis. 
Gunnec, D. and Raghavan, S. (2017). Integrating social network effects in the share-of-choice problem. Decision Sciences, 48(6):1098-1131.

Günneç, D., Raghavan, S., and Zhang, R. (2017). Tailored incentives and least cost influence maximization on social networks. Technical report, Technical report, University of Maryland.

Han, B., Hui, P., Kumar, V. A., Marathe, M. V., Pei, G., and Srinivasan, A. (2010). Cellular traffic offloading through opportunistic communications: a case study. In Proceedings of the 5th ACM workshop on Challenged networks, pages $31-38$.

Houle, M. E., Oria, V., Satoh, S., and Sun, J. (2011). Knowledge propagation in large image databases using neighborhood information. In Proceedings of the 19th ACM international conference on Multimedia, pages 1033-1036.

Houle, M. E., Oria, V., Satoh, S., and Sun, J. (2013). Annotation propagation in image databases using similarity graphs. ACM Transactions on Multimedia Computing, Communications, and Applications (TOMM), 10(1):1-21.

Ienco, D., Bonchi, F., and Castillo, C. (2010). The meme ranking problem: Maximizing microblogging virality. In 2010 IEEE International Conference on Data Mining Workshops, pages 328-335. IEEE.

Kempe, D., Kleinberg, J., and Tardos, É. (2003). Maximizing the spread of influence through a social network. In Proceedings of the ninth ACM SIGKDD international conference on Knowledge discovery and data mining, pages 137-146. ACM.

Kimura, M., Saito, K., and Motoda, H. (2009). Blocking links to minimize contamination spread in a social network. ACM Transactions on Knowledge Discovery from Data (TKDD), 3(2):1-23.

Kleinberg, J. (2007). Cascading behavior in networks: Algorithmic and economic issues. Algorithmic game theory, 24:613-632.

Leskovec, J., Krause, A., Guestrin, C., Faloutsos, C., VanBriesen, J., and Glance, N. (2007). Cost-effective outbreak detection in networks. In Proceedings of the 13th ACM SIGKDD international conference on Knowledge discovery and data mining, pages 420-429. ACM.

Ostfeld, A., Uber, J. G., Salomons, E., Berry, J. W., Hart, W. E., Phillips, C. A., Watson, J.-P., Dorini, G., Jonkergouw, P., Kapelan, Z., di Pierro, F., Khu, S.-T., Savic, D., Eliades, D., Polycarpou, M., Ghimire, S. R., Barkdoll, 
B. D., Gueli, R., Huang, J. J., McBean, E. A., James, W., Krause, A., Leskovec, J., Isovitsch, S., Xu, J., Guestrin, C., VanBriesen, J., Small, M., Fischbeck, P., Preis, A., Propato, M., Piller, O., Trachtman, G. B., Wu, Z. Y., and Walski, T. (2008). The battle of the water sensor networks (bwsn): A design challenge for engineers and algorithms. Journal of Water Resources Planning and Management, 134(6):556-568.

Richardson, M. and Domingos, P. (2002). Mining knowledge-sharing sites for viral marketing. In Proceedings of the eighth ACM SIGKDD international conference on Knowledge discovery and data mining, pages 61-70.

Schelling, T. C. (2006). Micromotives and macrobehavior. WW Norton \& Company.

Singer, Y. (2012). How to win friends and influence people, truthfully: influence maximization mechanisms for social networks. In Proceedings of the fifth ACM international conference on Web search and data mining, pages 733742. ACM.

Vallet, J., Kirchner, H., Pinaud, B., and Melançon, G. (2015). A visual analytics approach to compare propagation models in social networks. arXiv preprint arXiv:1504.02612.

Warshall, S. (1962). A theorem on boolean matrices. Journal of the ACM (JACM), 9(1):11-12.

Watts, D. J. and Strogatz, S. H. (1998). Collective dynamics of 'smallworld'networks. nature, 393(6684):440-442.

Weng, J., Lim, E.-P., Jiang, J., and He, Q. (2010). Twitterrank: finding topicsensitive influential twitterers. In Proceedings of the third ACM international conference on Web search and data mining, pages 261-270. ACM.

Zhang, H., Alim, M. A., Li, X., Thai, M. T., and Nguyen, H. T. (2016). Misinformation in online social networks: Detect them all with a limited budget. ACM Transactions on Information Systems (TOIS), 34(3):1-24.

Zhang, P., Bao, Z., Niu, Y., Zhang, Y., Mo, S., Geng, F., and Peng, Z. (2019). Proactive rumor control in online networks. World Wide Web, 22(4):1799 1818.

Zhang, R. (2016). Mathematical Programming Models for Influence Maximization on Social Networks. PhD thesis. 
A

\section{Resultados computacionais detalhados}

Neste apêndice estão todos resultados comparativos para todos os modelos, com a execução para todas as instâncias e valores de $\Gamma$ e $\alpha$. Nas Tabelas A.1, A.2 e A.3 estão os resultados para $\Gamma=0.9$. Já nas Tabelas A.4, A.5 e A.6 estão os resultados para $\Gamma=1.0$. Em contrapartida, nas Tabelas A.7, A.8 e A.9 estão os resultados para $\Gamma=1.1$.

Em cada uma das tabelas a seguir estão os detalhes da instância, o valor de $\alpha$ e de $\Gamma$, além do limite inferior, limite superior, gap da razão entre o limite inferior e limite superior e o tempo total de execução para os modelos A (apenas para o caso de $\Gamma=1.0)$ e $C_{e}^{+}$, definidos em Fischetti et al. (2018), bem como os modelos $F C C$ e $L C C$ propostos nesta dissertação. Além disso, os valores marcados com um (*) são os casos em que o algoritmo resolveu a solução em otimalidade, para os casos em que a solução ótima não era conhecida. 


\begin{tabular}{|c|c|c|c|c|c|c|}
\hline & & & & & & ver bou \\
\hline $\mathrm{n}$ & $\mathrm{k}$ & $\beta$ & $\alpha$ & inr & $C_{e}^{+}$ & FCC \\
\hline 50 & 4 & 0,1 & 0,1 & 1 & 7,00 & 7,00 \\
\hline 50 & 4 & 0,1 & 0,1 & 2 & 19,00 & 19,00 \\
\hline 50 & 4 & 0,1 & 0,1 & 3 & 16,00 & 16,00 \\
\hline 50 & 4 & 0,1 & 0,1 & 4 & 23,00 & 23,00 \\
\hline 50 & 4 & 0,1 & 0,1 & 5 & 21,00 & 21,00 \\
\hline 50 & 4 & 0,1 & 0,5 & 1 & 63,00 & 63,00 \\
\hline 50 & 4 & 0,1 & 0,5 & 2 & 73,00 & 73,00 \\
\hline 50 & 4 & 0,1 & 0,5 & 3 & 64,00 & 64,00 \\
\hline 50 & 4 & 0,1 & 0,5 & 4 & 87,00 & 87,00 \\
\hline 50 & 4 & 0,1 & 0,5 & 5 & 63,00 & 63,00 \\
\hline 50 & 4 & 0,1 & 1,0 & 1 & 147,00 & 147,00 \\
\hline 50 & 4 & 0,1 & 1,0 & 2 & 161,00 & 161,00 \\
\hline 50 & 4 & 0,1 & 1,0 & 3 & 160,00 & 160,00 \\
\hline 50 & 4 & 0,1 & 1,0 & 4 & 206,00 & 206,00 \\
\hline 50 & 4 & 0,1 & 1,0 & 5 & 154,00 & 154,00 \\
\hline 50 & 4 & 0,3 & 0,1 & 1 & 7,00 & 7,00 \\
\hline 50 & 4 & 0,3 & 0,1 & 2 & 18,00 & 18,00 \\
\hline 50 & 4 & 0,3 & 0,1 & 3 & 13,00 & 13,00 \\
\hline 50 & 4 & 0,3 & 0,1 & 4 & 16,00 & 16,00 \\
\hline 50 & 4 & 0,3 & 0,1 & 5 & 27,00 & 27,00 \\
\hline 50 & 4 & 0,3 & 0,5 & 1 & 54,00 & 54,00 \\
\hline 50 & 4 & 0,3 & 0,5 & 2 & 95,00 & 95,00 \\
\hline 50 & 4 & 0,3 & 0,5 & 3 & 69,00 & 69,00 \\
\hline 50 & 4 & 0,3 & 0,5 & 4 & 80,00 & 80,00 \\
\hline 50 & 4 & 0,3 & 0,5 & 5 & 88,00 & 88,00 \\
\hline 50 & 4 & 0,3 & 1,0 & 1 & 162,00 & 162,00 \\
\hline 50 & 4 & 0,3 & 1,0 & 2 & 210,00 & 210,00 \\
\hline 50 & 4 & 0,3 & 1,0 & 3 & 153,00 & 153,00 \\
\hline 50 & 4 & 0,3 & 1,0 & 4 & 223,00 & 223,00 \\
\hline 50 & 4 & 0,3 & 1,0 & 5 & 195,00 & 195,00 \\
\hline 75 & 4 & 0,1 & 0,1 & 1 & 21,00 & 21,00 \\
\hline 75 & 4 & 0,1 & 0,1 & 2 & 24,00 & 24,00 \\
\hline 75 & 4 & 0,1 & 0,1 & 3 & 25,00 & 25,00 \\
\hline 75 & 4 & 0,1 & 0,1 & 4 & 23,00 & 23,00 \\
\hline 75 & 4 & 0,1 & 0,1 & 5 & 21,00 & 21,00 \\
\hline 75 & 4 & 0,1 & 0,5 & 1 & 77,00 & 77,00 \\
\hline 75 & 4 & 0,1 & 0,5 & 2 & 96,00 & 96,00 \\
\hline 75 & 4 & 0,1 & 0,5 & 3 & 102,00 & 102,00 \\
\hline 75 & 4 & 0,1 & 0,5 & 4 & 95,00 & 95,00 \\
\hline 75 & 4 & 0,1 & 0,5 & 5 & 98,00 & 98,00 \\
\hline 75 & 4 & 0,1 & 1,0 & 1 & 231,00 & 231,00 \\
\hline 75 & 4 & 0,1 & 1,0 & 2 & 192,00 & 192,00 \\
\hline 75 & 4 & 0,1 & 1,0 & 3 & 265,00 & 265,00 \\
\hline 75 & 4 & 0,1 & 1,0 & 4 & 262,00 & 262,00 \\
\hline 75 & 4 & 0,1 & 1,0 & 5 & 252,00 & 252,00 \\
\hline 75 & 4 & 0,3 & 0,1 & 1 & 14,00 & 14,00 \\
\hline 75 & 4 & 0,3 & 0,1 & 2 & 34,00 & 34,00 \\
\hline 75 & 4 & 0,3 & 0,1 & 3 & 27,00 & 27,00 \\
\hline 75 & 4 & 0,3 & 0,1 & 4 & 14,00 & 14,00 \\
\hline 75 & 4 & 0,3 & 0,1 & 5 & 28,00 & 28,00 \\
\hline 75 & 4 & 0,3 & 0,5 & 1 & 98,00 & 98,00 \\
\hline 75 & 4 & 0,3 & 0,5 & 2 & 133,00 & 133,00 \\
\hline 75 & 4 & 0,3 & 0,5 & 3 & 142,00 & 142,00 \\
\hline 75 & 4 & 0,3 & 0,5 & 4 & 105,00 & 105,00 \\
\hline 75 & 4 & 0,3 & 0,5 & 5 & 126,00 & 126,00 \\
\hline 75 & 4 & 0,3 & 1,0 & 1 & 244,00 & 244,00 \\
\hline 75 & 4 & 0,3 & 1,0 & 2 & 286,00 & 286,00 \\
\hline 75 & 4 & 0,3 & 1,0 & 3 & 320,00 & 320,00 \\
\hline 75 & 4 & 0,3 & 1,0 & 4 & 252,00 & 252,00 \\
\hline 75 & 4 & 0,3 & 1,0 & 5 & 266,00 & 266,00 \\
\hline 100 & 4 & 0,1 & 0,1 & 1 & 21,00 & 21,00 \\
\hline 100 & 4 & 0,1 & 0,1 & 2 & 28,00 & 28,00 \\
\hline 100 & 4 & 0,1 & 0,1 & 3 & 21,00 & 21,00 \\
\hline 100 & 4 & 0,1 & 0,1 & 4 & 26,00 & 26,00 \\
\hline 100 & 4 & 0,1 & 0,1 & 5 & 31,00 & 31,00 \\
\hline 100 & 4 & 0,1 & 0,5 & 1 & 119,00 & 119,00 \\
\hline 100 & 4 & 0,1 & 0,5 & 2 & 145,00 & 145,00 \\
\hline 100 & 4 & 0,1 & 0,5 & 3 & 140,00 & 140,00 \\
\hline 100 & 4 & 0,1 & 0,5 & 4 & 110,00 & 110,00 \\
\hline 100 & 4 & 0,1 & 0,5 & 5 & 129,00 & 129,00 \\
\hline 100 & 4 & 0,1 & 1,0 & 1 & 308,00 & 308,00 \\
\hline 100 & 4 & 0,1 & 1,0 & 2 & 312,00 & 312,00 \\
\hline 100 & 4 & 0,1 & 1,0 & 3 & 364,00 & 364,00 \\
\hline 100 & 4 & 0,1 & 1,0 & 4 & 320,00 & 320,00 \\
\hline 100 & 4 & 0,1 & 1,0 & 5 & 313,00 & 313,00 \\
\hline 100 & 4 & 0,3 & 0,1 & 1 & 24,00 & 24,00 \\
\hline 100 & 4 & 0,3 & 0,1 & 2 & 24,00 & 24,00 \\
\hline 100 & 4 & 0,3 & 0,1 & 3 & 36,00 & 36,00 \\
\hline 100 & 4 & 0,3 & 0,1 & 4 & 24,00 & 24,00 \\
\hline 100 & 4 & 0,3 & 0,1 & 5 & 28,00 & 28,00 \\
\hline 100 & 4 & 0,3 & 0,5 & 1 & 143,00 & 143,00 \\
\hline 100 & 4 & 0,3 & 0,5 & 2 & 142,00 & 142,00 \\
\hline 100 & 4 & 0,3 & 0,5 & 3 & 205,00 & 205,00 \\
\hline 100 & 4 & 0,3 & 0,5 & 4 & 119,00 & 119,00 \\
\hline 100 & 4 & 0,3 & 0,5 & 5 & 125,00 & 125,00 \\
\hline 100 & 4 & 0,3 & 1,0 & 1 & 344,00 & 344,00 \\
\hline 100 & 4 & 0,3 & 1,0 & 2 & 372,00 & 372,00 \\
\hline 100 & 4 & 0,3 & 1,0 & 3 & 494,00 & 494,00 \\
\hline 100 & 4 & 0,3 & 1,0 & 4 & 356,00 & 356,00 \\
\hline 100 & 4 & 0,3 & 1,0 & 5 & 329,00 & 329,00 \\
\hline
\end{tabular}

Tabela A.1: Resultados detalhados dos modelos para $\Gamma=0.9$, em todas as instâncias com $k=4$. 


\begin{tabular}{|c|c|c|c|c|c|c|}
\hline & & & & & & ver bou \\
\hline $\mathbf{n}$ & $\mathrm{k}$ & $\beta$ & $\alpha$ & inr & $C_{e}^{+}$ & FCC \\
\hline 50 & 8 & 0,1 & 0,1 & 1 & 64,00 & 64,00 \\
\hline 50 & 8 & 0,1 & 0,1 & 2 & 49,00 & 49,00 \\
\hline 50 & 8 & 0,1 & 0,1 & 3 & 58,00 & 58,00 \\
\hline 50 & 8 & 0,1 & 0,1 & 4 & 66,00 & 66,00 \\
\hline 50 & 8 & 0,1 & 0,1 & 5 & 71,00 & 71,00 \\
\hline 50 & 8 & 0,1 & 0,5 & 1 & 168,00 & 168,00 \\
\hline 50 & 8 & 0,1 & 0,5 & 2 & 168,00 & 168,00 \\
\hline 50 & 8 & 0,1 & 0,5 & 3 & 186,00 & 186,00 \\
\hline 50 & 8 & 0,1 & 0,5 & 4 & 193,00 & 193,00 \\
\hline 50 & 8 & 0,1 & 0,5 & 5 & 215,00 & 215,00 \\
\hline 50 & 8 & 0,1 & 1,0 & 1 & 303,00 & 271,97 \\
\hline 50 & 8 & 0,1 & 1,0 & 2 & 315,00 & 294,00 \\
\hline 50 & 8 & 0,1 & 1,0 & 3 & 315,00 & 298,40 \\
\hline 50 & 8 & 0,1 & 1,0 & 4 & 355,89 & 333,88 \\
\hline 50 & 8 & 0,1 & 1,0 & 5 & 369,00 & 356,00 \\
\hline 50 & 8 & 0,3 & 0,1 & 1 & 54,00 & 54,00 \\
\hline 50 & 8 & 0,3 & 0,1 & 2 & 53,00 & 53,00 \\
\hline 50 & 8 & 0,3 & 0,1 & 3 & 58,00 & 58,00 \\
\hline 50 & 8 & 0,3 & 0,1 & 4 & 64,00 & 64,00 \\
\hline 50 & 8 & 0,3 & 0,1 & 5 & 73,00 & 73,00 \\
\hline 50 & 8 & 0,3 & 0,5 & 1 & 177,33 & 216,00 \\
\hline 50 & 8 & 0,3 & 0,5 & 2 & 200,46 & 214,00 \\
\hline 50 & 8 & 0,3 & 0,5 & 3 & 177,98 & 210,30 \\
\hline 50 & 8 & 0,3 & 0,5 & 4 & 224,61 & 247,00 \\
\hline 50 & 8 & 0,3 & 0,5 & 5 & 242,03 & 268,00 \\
\hline 50 & 8 & 0,3 & 1,0 & 1 & 324,54 & 283,00 \\
\hline 50 & 8 & 0,3 & 1,0 & 2 & 371,97 & 356,37 \\
\hline 50 & 8 & 0,3 & 1,0 & 3 & 329,57 & 303,70 \\
\hline 50 & 8 & 0,3 & 1,0 & 4 & 417,84 & 401,00 \\
\hline 50 & 8 & 0,3 & 1,0 & 5 & 423,61 & 414,00 \\
\hline 75 & 8 & 0,1 & 0,1 & 1 & 86,00 & 86,00 \\
\hline 75 & 8 & 0,1 & 0,1 & 2 & 75,00 & 75,00 \\
\hline 75 & 8 & 0,1 & 0,1 & 3 & 86,00 & 86,00 \\
\hline 75 & 8 & 0,1 & 0,1 & 4 & 83,00 & 83,00 \\
\hline 75 & 8 & 0,1 & 0,1 & 5 & 88,00 & 88,00 \\
\hline 75 & 8 & 0,1 & 0,5 & 1 & 248,25 & 261,11 \\
\hline 75 & 8 & 0,1 & 0,5 & 2 & 258,00 & 258,00 \\
\hline 75 & 8 & 0,1 & 0,5 & 3 & 273,00 & 273,00 \\
\hline 75 & 8 & 0,1 & 0,5 & 4 & 259,01 & 267,11 \\
\hline 75 & 8 & 0,1 & 0,5 & 5 & 269,99 & 296,00 \\
\hline 75 & 8 & 0,1 & 1,0 & 1 & 466,88 & 455,00 \\
\hline 75 & 8 & 0,1 & 1,0 & 2 & 478,82 & 461,00 \\
\hline 75 & 8 & 0,1 & 1,0 & 3 & 519,63 & 515,00 \\
\hline 75 & 8 & 0,1 & 1,0 & 4 & 503,00 & 514,00 \\
\hline 75 & 8 & 0,1 & 1,0 & 5 & 498,90 & 477,59 \\
\hline 75 & 8 & 0,3 & 0,1 & 1 & 80,00 & 80,00 \\
\hline 75 & 8 & 0,3 & 0,1 & 2 & 79,00 & 79,00 \\
\hline 75 & 8 & 0,3 & 0,1 & 3 & 80,00 & 80,00 \\
\hline 75 & 8 & 0,3 & 0,1 & 4 & 75,00 & 75,00 \\
\hline 75 & 8 & 0,3 & 0,1 & 5 & 93,00 & 93,00 \\
\hline 75 & 8 & 0,3 & 0,5 & 1 & 231,27 & 247,14 \\
\hline 75 & 8 & 0,3 & 0,5 & 2 & 246,15 & 263,01 \\
\hline 75 & 8 & 0,3 & 0,5 & 3 & 301,91 & 326,39 \\
\hline 75 & 8 & 0,3 & 0,5 & 4 & 259,01 & 281,28 \\
\hline 75 & 8 & 0,3 & 0,5 & 5 & 285,25 & 304,78 \\
\hline 75 & 8 & 0,3 & 1,0 & 1 & 455,01 & 412,64 \\
\hline 75 & 8 & 0,3 & 1,0 & 2 & 475,51 & 439,26 \\
\hline 75 & 8 & 0,3 & 1,0 & 3 & 590,00 & 594,00 \\
\hline 75 & 8 & 0,3 & 1,0 & 4 & 493,52 & 476,00 \\
\hline 75 & 8 & 0,3 & 1,0 & 5 & 552,01 & 519,00 \\
\hline 100 & 8 & 0,1 & 0,1 & 1 & 86,22 & 95,00 \\
\hline 100 & 8 & 0,1 & 0,1 & 2 & 79,00 & 79,00 \\
\hline 100 & 8 & 0,1 & 0,1 & 3 & 100,00 & 100,00 \\
\hline 100 & 8 & 0,1 & 0,1 & 4 & 93,00 & 93,00 \\
\hline 100 & 8 & 0,1 & 0,1 & 5 & 96,00 & 96,00 \\
\hline 100 & 8 & 0,1 & 0,5 & 1 & 317,63 & 313,83 \\
\hline 100 & 8 & 0,1 & 0,5 & 2 & 292,60 & 293,44 \\
\hline 100 & 8 & 0,1 & 0,5 & 3 & 399,34 & 411,46 \\
\hline 100 & 8 & 0,1 & 0,5 & 4 & 323,85 & 324,97 \\
\hline 100 & 8 & 0,1 & 0,5 & 5 & 346,33 & 362,16 \\
\hline 100 & 8 & 0,1 & 1,0 & 1 & 616,00 & 631,70 \\
\hline 100 & 8 & 0,1 & 1,0 & 2 & 565,66 & 549,66 \\
\hline 100 & 8 & 0,1 & 1,0 & 3 & 828,72 & 837,25 \\
\hline 100 & 8 & 0,1 & 1,0 & 4 & 630,95 & 622,77 \\
\hline 100 & 8 & 0,1 & 1,0 & 5 & 686,66 & 687,03 \\
\hline 100 & 8 & 0,3 & 0,1 & 1 & 82,00 & 82,00 \\
\hline 100 & 8 & 0,3 & 0,1 & 2 & 91,86 & 95,00 \\
\hline 100 & 8 & 0,3 & 0,1 & 3 & 109,00 & 109,00 \\
\hline 100 & 8 & 0,3 & 1 & 4 & 91,00 & 91,00 \\
\hline 100 & 8 & 0,3 & 0,1 & 5 & 96,00 & 96,00 \\
\hline 100 & 8 & 0,3 & 0,5 & 1 & 325,07 & 335,98 \\
\hline 100 & 8 & 0,3 & 0,5 & 2 & 326,22 & 357,40 \\
\hline 100 & 8 & 0,3 & 0,5 & 3 & 413,32 & 443,15 \\
\hline 100 & 8 & 0,3 & 0,5 & 4 & 357,75 & 359,53 \\
\hline 100 & 8 & 0,3 & 0,5 & 5 & 355,73 & 356,49 \\
\hline 100 & 8 & 0,3 & 1,0 & 1 & 682,33 & 664,00 \\
\hline 100 & 8 & 0,3 & 1,0 & 2 & 681,62 & 676,45 \\
\hline 100 & 8 & 0,3 & 1,0 & 3 & 862,00 & 865,00 \\
\hline 100 & 8 & 0,3 & 1,0 & 4 & 764,14 & 759,75 \\
\hline 100 & 8 & 0,3 & 1,0 & 5 & 735,75 & 729,00 \\
\hline
\end{tabular}

Tabela A.2: Resultados detalhados dos modelos para $\Gamma=0.9$, em todas as instâncias com $k=8$. 


\begin{tabular}{|c|c|c|c|c|c|c|}
\hline & & & & & & wer bou \\
\hline $\mathbf{n}$ & $\mathrm{k}$ & $\beta$ & $\alpha$ & inr & $C_{e}^{+}$ & FCC \\
\hline 75 & 12 & 0,1 & 0,1 & 1 & 90,71 & 152,00 \\
\hline 75 & 12 & 0,1 & 0,1 & 2 & 106,60 & 162,00 \\
\hline 75 & 12 & 0,1 & 0,1 & 3 & 103,77 & 159,00 \\
\hline 75 & 12 & 0,1 & 0,1 & 4 & 104,74 & 145,00 \\
\hline 75 & 12 & 0,1 & 0,1 & 5 & 108,01 & 159,00 \\
\hline 75 & 12 & 0,1 & 0,5 & 1 & 369,27 & 403,47 \\
\hline 75 & 12 & 0,1 & 0,5 & 2 & 405,68 & 434,95 \\
\hline 75 & 12 & 0,1 & 0,5 & 3 & 399,91 & 418,39 \\
\hline 75 & 12 & 0,1 & 0,5 & 4 & 423,85 & 444,26 \\
\hline 75 & 12 & 0,1 & 0,5 & 5 & 438,88 & 463,49 \\
\hline 75 & 12 & 0,1 & 1,0 & 1 & 650,68 & 625,99 \\
\hline 75 & 12 & 0,1 & 1,0 & 2 & 734,46 & 734,78 \\
\hline 75 & 12 & 0,1 & 1,0 & 3 & 737,98 & 739,02 \\
\hline 75 & 12 & 0,1 & 1,0 & 4 & 794,12 & 780,05 \\
\hline 75 & 12 & 0,1 & 1,0 & 5 & 798,25 & 793,44 \\
\hline 75 & 12 & 0,3 & 0,1 & 1 & 93,55 & 151,00 \\
\hline 75 & 12 & 0,3 & 0,1 & 2 & 116,56 & 146,00 \\
\hline 75 & 12 & 0,3 & 0,1 & 3 & 104,13 & 134,00 \\
\hline 75 & 12 & 0,3 & 0,1 & 4 & 113,61 & 144,00 \\
\hline 75 & 12 & 0,3 & 0,1 & 5 & 104,07 & 145,00 \\
\hline 75 & 12 & 0,3 & 0,5 & 1 & 398,04 & 418,30 \\
\hline 75 & 12 & 0,3 & 0,5 & 2 & 428,32 & 435,67 \\
\hline 75 & 12 & 0,3 & 0,5 & 3 & 429,44 & 442,26 \\
\hline 75 & 12 & 0,3 & 0,5 & 4 & 475,71 & 527,51 \\
\hline 75 & 12 & 0,3 & 0,5 & 5 & 428,54 & 462,09 \\
\hline 75 & 12 & 0,3 & 1,0 & 1 & 743,48 & 693,00 \\
\hline 75 & 12 & 0,3 & 1,0 & 2 & 835,15 & 801,46 \\
\hline 75 & 12 & 0,3 & 1,0 & 3 & 822,56 & 788,99 \\
\hline 75 & 12 & 0,3 & 1,0 & 4 & & 944,00 \\
\hline 75 & 12 & 0,3 & 1,0 & 5 & 825,16 & 764,63 \\
\hline 100 & 12 & 0,1 & 0,1 & 1 & 111,32 & 173,00 \\
\hline 100 & 12 & 0,1 & 0,1 & 2 & 115,03 & 183,00 \\
\hline 100 & 12 & 0,1 & 0,1 & 3 & 121,87 & 179,00 \\
\hline 100 & 12 & 0,1 & 0,1 & 4 & 123,26 & 190,00 \\
\hline 100 & 12 & 0,1 & 0,1 & 5 & 117,67 & 191,00 \\
\hline 100 & 12 & 0,1 & 0,5 & 1 & 491,67 & 515,99 \\
\hline 100 & 12 & 0,1 & 0,5 & 2 & 484,32 & 516,23 \\
\hline 100 & 12 & 0,1 & 0,5 & 3 & 547,49 & 552,79 \\
\hline 100 & 12 & 0,1 & 0,5 & 4 & 518,68 & 543,58 \\
\hline 100 & 12 & 0,1 & 0,5 & 5 & 504,30 & 518,18 \\
\hline 100 & 12 & 0,1 & 1,0 & 1 & 943,25 & 934,74 \\
\hline 100 & 12 & 0,1 & 1,0 & 2 & 904,33 & 904,18 \\
\hline 100 & 12 & 0,1 & 1,0 & 3 & 1034,00 & 1044,70 \\
\hline 100 & 12 & 0,1 & 1,0 & 4 & 1000,39 & 1005,94 \\
\hline 100 & 12 & 0,1 & 1,0 & 5 & 968,48 & 958,69 \\
\hline 100 & 12 & 0,3 & 0,1 & 1 & 133,72 & 197,00 \\
\hline 100 & 12 & 0,3 & 0,1 & 2 & 119,20 & 178,00 \\
\hline 100 & 12 & 0,3 & 0,1 & 3 & 133,41 & 176,00 \\
\hline 100 & 12 & 0,3 & 0,1 & 4 & 125,76 & 174,00 \\
\hline 100 & 12 & 0,3 & 0,1 & 5 & 134,88 & 199,00 \\
\hline 100 & 12 & 0,3 & 0,5 & 1 & 592,86 & 677,18 \\
\hline 100 & 12 & 0,3 & 0,5 & 2 & 517,18 & 524,11 \\
\hline 100 & 12 & 0,3 & 0,5 & 3 & 567,26 & 570,87 \\
\hline 100 & 12 & 0,3 & 0,5 & 4 & 524,79 & 591,42 \\
\hline 100 & 12 & 0,3 & 0,5 & 5 & 587,46 & 602,26 \\
\hline 100 & 12 & 0,3 & 1,0 & 1 & - & 1229,55 \\
\hline 100 & 12 & 0,3 & 1,0 & 2 & - & 1012,67 \\
\hline 100 & 12 & 0,3 & 1,0 & 3 & 1117,38 & 1080,71 \\
\hline 100 & 12 & 0,3 & 1,0 & 4 & 1099,50 & 1110,00 \\
\hline 100 & 12 & 0,3 & 1,0 & 5 & - & 1141,11 \\
\hline 100 & 16 & 0,1 & 0,1 & 1 & - & 227,38 \\
\hline 100 & 16 & 0,1 & 0,1 & 2 & 175,28 & 212,59 \\
\hline 100 & 16 & 0,1 & 0,1 & 3 & 143,16 & 235,21 \\
\hline 100 & 16 & 0,1 & 0,1 & 4 & 164,69 & 216,62 \\
\hline 100 & 16 & 0,1 & 0,1 & 5 & 136,61 & 217,23 \\
\hline 100 & 16 & 0,1 & 0,5 & 1 & - & 733,29 \\
\hline 100 & 16 & 0,1 & 0,5 & 2 & 709,70 & 795,04 \\
\hline 100 & 16 & 0,1 & 0,5 & 3 & 710,19 & 789,45 \\
\hline 100 & 16 & 0,1 & 0,5 & 4 & 661,42 & 728,09 \\
\hline 100 & 16 & 0,1 & 0,5 & 5 & 685,12 & 756,82 \\
\hline 100 & 16 & 0,1 & 1,0 & 1 & - & 1433,00 \\
\hline 100 & 16 & 0,1 & 1,0 & 2 & - & 1480,65 \\
\hline 100 & 16 & 0,1 & 1,0 & 3 & - & 1507,00 \\
\hline 100 & 16 & 0,1 & 1,0 & 4 & - & 1408,59 \\
\hline 100 & 16 & 0,1 & 1,0 & 5 & - & 1436,04 \\
\hline 100 & 16 & 0,3 & 0,1 & 1 & - & 221,67 \\
\hline 100 & 16 & 0,3 & 0,1 & 2 & 139,24 & 231,00 \\
\hline 100 & 16 & 0,3 & 0,1 & 3 & 148,52 & 220,65 \\
\hline 100 & 16 & 0,3 & 0,1 & 4 & 158,69 & 229,30 \\
\hline 100 & 16 & 0,3 & 0,1 & 5 & - & 229,00 \\
\hline 100 & 16 & 0,3 & 0,5 & 1 & & 821,25 \\
\hline 100 & 16 & 0,3 & 0,5 & 2 & 680,35 & 761,91 \\
\hline 100 & 16 & 0,3 & 0,5 & 3 & 742,20 & 824,23 \\
\hline 100 & 16 & 0,3 & 0,5 & 4 & 784,84 & 863,53 \\
\hline 100 & 16 & 0,3 & 0,5 & 5 & - & 856,04 \\
\hline 100 & 16 & 0,3 & 1,0 & 1 & - & 1575,88 \\
\hline 100 & 16 & 0,3 & 1,0 & 2 & - & 1450,00 \\
\hline 100 & 16 & 0,3 & 1,0 & 3 & 1512,00 & 1558,88 \\
\hline 100 & 16 & 0,3 & 1,0 & 4 & - & 1653,24 \\
\hline 100 & 16 & 0,3 & 1,0 & 5 & & 1793,87 \\
\hline
\end{tabular}

Tabela A.3: Resultados detalhados dos modelos para $\Gamma=0.9$, em todas as instâncias com $k \in\{12,16\}$. 


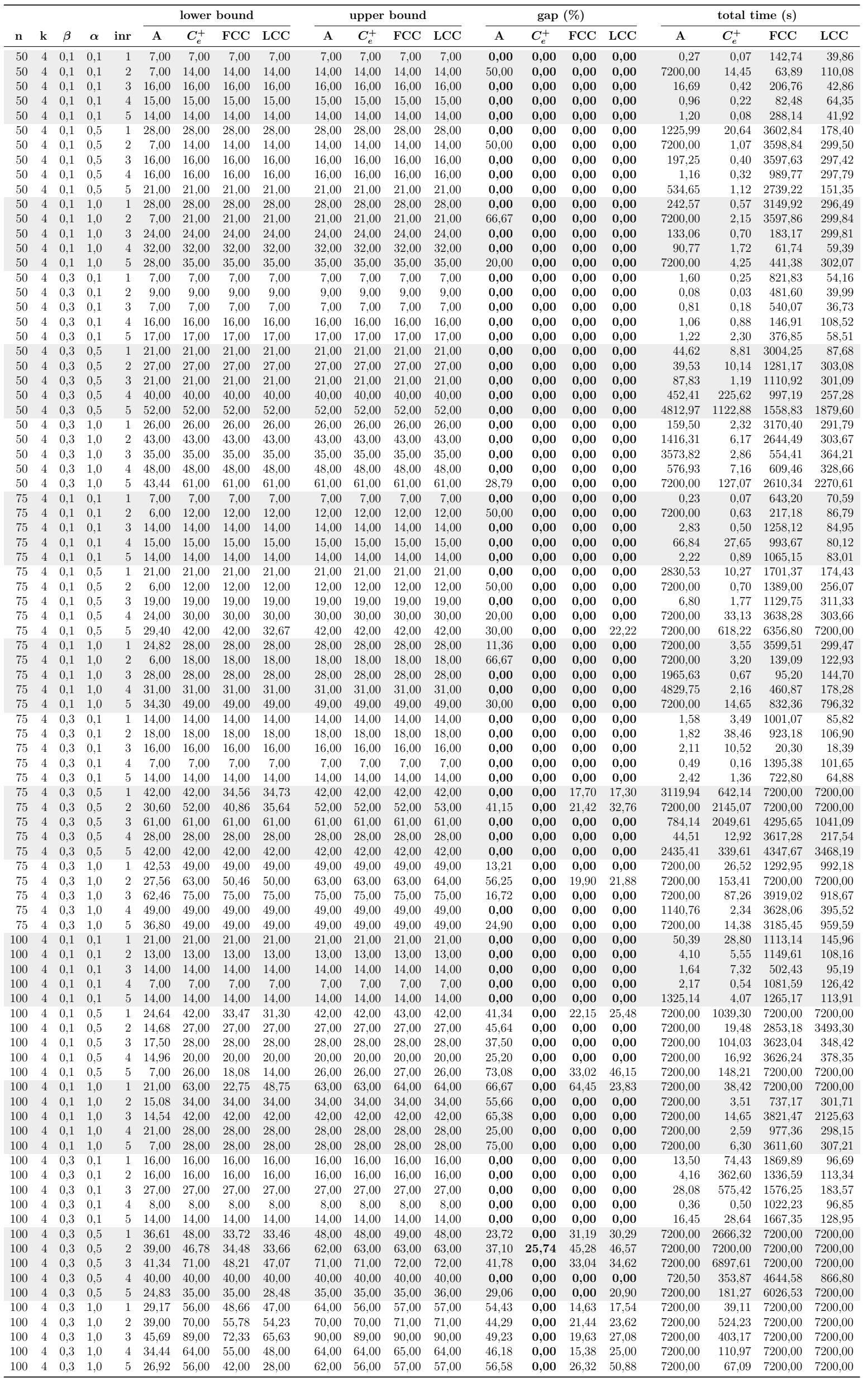

Tabela A.4: Resultados detalhados dos modelos para $\Gamma=1.0$, em todas as instâncias com $k=4$. 


\begin{tabular}{|c|c|c|c|c|c|c|}
\hline & & & & & & lower 1 \\
\hline $\mathrm{n}$ & k & $\beta$ & $\alpha$ & inr & A & $C_{e}^{+}$ \\
\hline 50 & 8 & 0,1 & 0,1 & 1 & 10,00 & 37,00 \\
\hline 50 & 8 & 0,1 & 0,1 & 2 & 10,00 & 40,00 \\
\hline 50 & 8 & 0,1 & 0,1 & 3 & 10,00 & 46,00 \\
\hline 50 & 8 & 0,1 & 0,1 & 4 & 10,00 & 29,69 \\
\hline 50 & 8 & 0,1 & 0,1 & 5 & 0,00 & 35,92 \\
\hline 50 & 8 & 0,1 & 0,5 & 1 & 10,00 & 59,77 \\
\hline 50 & 8 & 0,1 & 0,5 & 2 & 10,00 & 50,00 \\
\hline 50 & 8 & 0,1 & 0,5 & 3 & 10,00 & 60,52 \\
\hline 50 & 8 & 0,1 & 0,5 & 4 & 6,82 & 55,98 \\
\hline 50 & 8 & 0,1 & 0,5 & 5 & 0,00 & 51,11 \\
\hline 50 & 8 & 0,1 & 1,0 & 1 & 10,00 & 69,55 \\
\hline 50 & 8 & 0,1 & 1,0 & 2 & 10,00 & 69,00 \\
\hline 50 & 8 & 0,1 & 1,0 & 3 & 10,00 & 73,75 \\
\hline 50 & 8 & 0,1 & 1,0 & 4 & 10,00 & 75,28 \\
\hline 50 & 8 & 0,1 & 1,0 & 5 & 0,00 & 68,43 \\
\hline 50 & 8 & 0,3 & 0,1 & 1 & 29,74 & 29,56 \\
\hline 50 & 8 & 0,3 & 0,1 & 2 & 20,00 & 44,00 \\
\hline 50 & 8 & 0,3 & 0,1 & 3 & 0,95 & 30,88 \\
\hline 50 & 8 & 0,3 & 0,1 & 4 & 13,00 & 28,49 \\
\hline 50 & 8 & 0,3 & 0,1 & 5 & 30,00 & 30,92 \\
\hline 50 & 8 & 0,3 & 0,5 & 1 & 25,56 & 62,12 \\
\hline 50 & 8 & 0,3 & 0,5 & 2 & 11,00 & 57,83 \\
\hline 50 & 8 & 0,3 & 0,5 & 3 & 0,00 & 53,32 \\
\hline 50 & 8 & 0,3 & 0,5 & 4 & 13,18 & 62,25 \\
\hline 50 & 8 & 0,3 & 0,5 & 5 & 17,38 & 62,21 \\
\hline 50 & 8 & 0,3 & 1,0 & 1 & 33,56 & 82,94 \\
\hline 50 & 8 & 0,3 & 1,0 & 2 & 22,89 & 89,26 \\
\hline 50 & 8 & 0,3 & 1,0 & 3 & 0,79 & 74,94 \\
\hline 50 & 8 & 0,3 & 1,0 & 4 & 17,40 & 84,98 \\
\hline 50 & 8 & 0,3 & 1,0 & 5 & 31,67 & 90,97 \\
\hline 75 & 8 & 0,1 & 0,1 & 1 & 0,00 & 23,64 \\
\hline 75 & 8 & 0,1 & 0,1 & 2 & 0,00 & 23,62 \\
\hline 75 & 8 & 0,1 & 0,1 & 3 & 0,00 & 23,85 \\
\hline 75 & 8 & 0,1 & 0,1 & 4 & 12,00 & 26,00 \\
\hline 75 & 8 & 0,1 & 0,1 & 5 & 11,00 & 26,15 \\
\hline 75 & 8 & 0,1 & 0,5 & 1 & 0,00 & 55,28 \\
\hline 75 & 8 & 0,1 & 0,5 & 2 & 0,00 & 41,84 \\
\hline 75 & 8 & 0,1 & 0,5 & 3 & 0,00 & 54,03 \\
\hline 75 & 8 & 0,1 & 0,5 & 4 & 12,00 & 49,73 \\
\hline 75 & 8 & 0,1 & 0,5 & 5 & 11,00 & 68,23 \\
\hline 75 & 8 & 0,1 & 1,0 & 1 & 0,00 & 60,84 \\
\hline 75 & 8 & 0,1 & 1,0 & 2 & 0,00 & 22,00 \\
\hline 75 & 8 & 0,1 & 1,0 & 3 & 0,00 & 68,20 \\
\hline 75 & 8 & 0,1 & 1,0 & 4 & 12,00 & 65,05 \\
\hline 75 & 8 & 0,1 & 1,0 & 5 & 11,00 & 84,24 \\
\hline 75 & 8 & 0,3 & 0,1 & 1 & 16,96 & 23,35 \\
\hline 75 & 8 & 0,3 & 0,1 & 2 & 10,00 & 25,30 \\
\hline 75 & 8 & 0,3 & 0,1 & 3 & 0,00 & 25,35 \\
\hline 75 & 8 & 0,3 & 0,1 & 4 & 0,07 & 23,99 \\
\hline 75 & 8 & 0,3 & 0,1 & 5 & 2,17 & 24,00 \\
\hline 75 & 8 & 0,3 & 0,5 & 1 & 14,89 & 53,98 \\
\hline 75 & 8 & 0,3 & 0,5 & 2 & 12,46 & 52,72 \\
\hline 75 & 8 & 0,3 & 0,5 & 3 & 0,00 & 22,00 \\
\hline 75 & 8 & 0,3 & 0,5 & 4 & 1,16 & 0,00 \\
\hline 75 & 8 & 0,3 & 0,5 & 5 & 0,91 & 60,45 \\
\hline 75 & 8 & 0,3 & 1,0 & 1 & 20,22 & 92,10 \\
\hline 75 & 8 & 0,3 & 1,0 & 2 & 20,00 & 89,77 \\
\hline 75 & 8 & 0,3 & 1,0 & 3 & 0,03 & 82,49 \\
\hline 75 & 8 & 0,3 & 1,0 & 4 & 2,26 & 82,71 \\
\hline 75 & 8 & 0,3 & 1,0 & 5 & 12,00 & 90,59 \\
\hline 100 & 8 & 0,1 & 0,1 & 1 & 8,25 & 24,67 \\
\hline 100 & 8 & 0,1 & 0,1 & 2 & 0,00 & 23,55 \\
\hline 100 & 8 & 0,1 & 0,1 & 3 & 13,00 & 25,88 \\
\hline 100 & 8 & 0,1 & 0,1 & & 0,00 & 24,07 \\
\hline 100 & 8 & 0,1 & 0,1 & 5 & 24,00 & 27,06 \\
\hline 100 & 8 & 0,1 & 0,5 & 1 & 11,00 & 49,25 \\
\hline 100 & 8 & 0,1 & 0,5 & 2 & 0,00 & 38,00 \\
\hline 100 & 8 & 0,1 & 0,5 & 3 & 13,00 & 28,51 \\
\hline 100 & 8 & 0,1 & & & & \\
\hline 100 & 8 & 0,1 & 0,5 & 5 & 16,90 & 62,92 \\
\hline 100 & 8 & 0,1 & 1,0 & 1 & 13,77 & 31,00 \\
\hline 100 & 8 & 0,1 & 1,0 & & & \\
\hline 100 & 8 & 0,1 & 1,0 & & 13,00 & \\
\hline 100 & 8 & 0,1 & 1,0 & 4 & 0,00 & 20,00 \\
\hline 100 & 8 & 0,1 & 1,0 & 5 & 24,00 & 59,00 \\
\hline 100 & 8 & 0,3 & 0,1 & 1 & 0,00 & 22,64 \\
\hline 100 & 8 & 0,3 & 0,1 & 2 & & 23,00 \\
\hline 100 & 8 & 0,3 & 0,1 & 3 & 0,00 & 25,72 \\
\hline 100 & 8 & 0,3 & 0,1 & 4 & 0,00 & 13,00 \\
\hline 100 & 8 & 0,3 & 0,1 & 5 & 12,00 & 12,00 \\
\hline 100 & 8 & 0,3 & & 1 & & \\
\hline 100 & 8 & 0,3 & 0,5 & & & 12,00 \\
\hline 100 & 8 & 0,3 & 0,5 & 3 & 0,00 & 14,00 \\
\hline 100 & 8 & 0,3 & 0,5 & 4 & 0.0 & 24,00 \\
\hline 100 & 8 & 0,3 & 0,5 & 5 & 12,0 & \\
\hline 100 & 8 & 0,3 & 1,0 & 1 & 0,00 & 12,00 \\
\hline 100 & 8 & 0,3 & 1,0 & 2 & 0,00 & 35,02 \\
\hline 100 & 8 & 0,3 & 1,0 & 3 & 14,00 & 95,32 \\
\hline 100 & 8 & 0,3 & 1,0 & 4 & 0,00 & \\
\hline 100 & 8 & 0,3 & 1,0 & 5 & 12,00 & 100,66 \\
\hline
\end{tabular}

Tabela A.5: Resultados detalhados dos modelos para $\Gamma=1.0$, em todas as instâncias com $k=8$. 


\begin{tabular}{|c|c|c|c|c|c|c|}
\hline & & & & & & lower \\
\hline $\mathrm{n}$ & $\mathrm{k}$ & $\beta$ & $\alpha$ & inr & A & $C_{e}^{+}$ \\
\hline 75 & 12 & 0,1 & 0,1 & 1 & 0,00 & 25,00 \\
\hline 75 & 12 & 0,1 & 0,1 & 2 & 0,00 & 27,00 \\
\hline 75 & 12 & 0,1 & 0,1 & 3 & 0,00 & 24,00 \\
\hline 75 & 12 & 0,1 & 0,1 & 4 & 0,00 & 25,00 \\
\hline 75 & 12 & 0,1 & 0,1 & 5 & 0,00 & 28,00 \\
\hline 75 & 12 & 0,1 & 0,5 & 1 & 0,00 & 25,00 \\
\hline 75 & 12 & 0,1 & 0,5 & 2 & 0,00 & 27,00 \\
\hline 75 & 12 & 0,1 & 0,5 & 3 & 0,00 & 24,00 \\
\hline 75 & 12 & 0,1 & 0,5 & 4 & 0,00 & 25,00 \\
\hline 75 & 12 & 0,1 & 0,5 & 5 & 0,00 & 28,00 \\
\hline 75 & 12 & 0,1 & 1,0 & 1 & 0,00 & 25,00 \\
\hline 75 & 12 & 0,1 & 1,0 & 2 & 0,00 & 27,00 \\
\hline 75 & 12 & 0,1 & 1,0 & 3 & 0,00 & 24,00 \\
\hline 75 & 12 & 0,1 & 1,0 & 4 & 0,00 & 25,00 \\
\hline 75 & 12 & 0,1 & 1,0 & 5 & 0,00 & 28,00 \\
\hline 75 & 12 & 0,3 & 0,1 & 1 & 0,00 & 27,00 \\
\hline 75 & 12 & 0,3 & 0,1 & 2 & 0,00 & 28,00 \\
\hline 75 & 12 & 0,3 & 0,1 & 3 & 0,00 & 25,00 \\
\hline 75 & 12 & 0,3 & 0,1 & 4 & 0,00 & 0,00 \\
\hline 75 & 12 & 0,3 & 0,1 & 5 & 0,00 & 28,00 \\
\hline 75 & 12 & 0,3 & 0,5 & 1 & 0,00 & 27,00 \\
\hline 75 & 12 & 0,3 & 0,5 & 2 & 0,00 & 0,00 \\
\hline 75 & 12 & 0,3 & 0,5 & 3 & 0,00 & 14,00 \\
\hline 75 & 12 & 0,3 & 0,5 & 4 & 0,00 & 0,00 \\
\hline 75 & 12 & 0,3 & 0,5 & 5 & 0,00 & 28,00 \\
\hline 75 & 12 & 0,3 & 1,0 & 1 & 0,00 & 0,00 \\
\hline 75 & 12 & 0,3 & 1,0 & 2 & 0,00 & 0,00 \\
\hline 75 & 12 & 0,3 & 1,0 & 3 & 0,00 & 25,00 \\
\hline 75 & 12 & 0,3 & 1,0 & 4 & 0,00 & 0,00 \\
\hline 75 & 12 & 0,3 & 1,0 & 5 & 0,00 & 28,00 \\
\hline 100 & 12 & 0,1 & 0,1 & 1 & 0,00 & 25,00 \\
\hline 100 & 12 & 0,1 & 0,1 & 2 & 0,00 & 24,00 \\
\hline 100 & 12 & 0,1 & 0,1 & 3 & 0,00 & 27,00 \\
\hline 100 & 12 & 0,1 & 0,1 & 4 & 0,00 & 27,00 \\
\hline 100 & 12 & 0,1 & 0,1 & 5 & 0,00 & 27,00 \\
\hline 100 & 12 & 0,1 & 0,5 & 1 & 0,00 & 25,00 \\
\hline 100 & 12 & 0,1 & 0,5 & 2 & 0,00 & 24,00 \\
\hline 100 & 12 & 0,1 & 0,5 & 3 & 0,00 & 27,00 \\
\hline 100 & 12 & 0,1 & 0,5 & 4 & 0,00 & 27,00 \\
\hline 100 & 12 & 0,1 & 0,5 & 5 & 0,00 & 27,00 \\
\hline 100 & 12 & 0,1 & 1,0 & 1 & 0,00 & 25,00 \\
\hline 100 & 12 & 0,1 & 1,0 & 2 & 0,00 & 24,00 \\
\hline 100 & 12 & 0,1 & 1,0 & 3 & 0,00 & 27,00 \\
\hline 100 & 12 & 0,1 & 1,0 & 4 & 0,00 & 27,00 \\
\hline 100 & 12 & 0,1 & 1,0 & 5 & 0,00 & 27,00 \\
\hline 100 & 12 & 0,3 & 0,1 & 1 & 0,00 & - \\
\hline 100 & 12 & 0,3 & 0,1 & 2 & 0,00 & 0,00 \\
\hline 100 & 12 & 0,3 & 0,1 & 3 & 0,00 & 0,00 \\
\hline 100 & 12 & 0,3 & 0,1 & 4 & 0,00 & 0,00 \\
\hline 100 & 12 & 0,3 & 0,1 & 5 & 0,00 & 0,00 \\
\hline 100 & 12 & 0,3 & 0,5 & 1 & 0,00 & \\
\hline 100 & 12 & 0,3 & 0,5 & 2 & 0,00 & 0,00 \\
\hline 100 & 12 & 0,3 & 0,5 & 3 & 0,00 & 0,00 \\
\hline 100 & 12 & 0,3 & 0,5 & 4 & 0,00 & 0,00 \\
\hline 100 & 12 & 0,3 & 0,5 & 5 & 0,00 & 0,00 \\
\hline 100 & 12 & 0,3 & 1,0 & 1 & 0,00 & - \\
\hline 100 & 12 & 0,3 & 1,0 & 2 & 0,00 & 0,00 \\
\hline 100 & 12 & 0,3 & 1,0 & 3 & 0,00 & 0,00 \\
\hline 100 & 12 & 0,3 & 1,0 & 4 & 0,00 & 0,00 \\
\hline 100 & 12 & 0,3 & 1,0 & 5 & 0,00 & 0,00 \\
\hline 100 & 16 & 0,1 & 0,1 & 1 & 0,00 & - \\
\hline 100 & 16 & 0,1 & 0,1 & 2 & 0,00 & - \\
\hline 100 & 16 & 0,1 & 0,1 & 3 & 0,00 & - \\
\hline 100 & 16 & 0,1 & 0,1 & 4 & 0,00 & - \\
\hline 100 & 16 & 0,1 & 0,1 & 5 & 0,00 & - \\
\hline 100 & 16 & 0,1 & 0,5 & 1 & 0,00 & - \\
\hline 100 & 16 & 0,1 & 0,5 & 2 & 0,00 & - \\
\hline 100 & 16 & 0,1 & 0,5 & 3 & 0,00 & - \\
\hline 100 & 16 & 0,1 & 0,5 & 4 & 0,00 & - \\
\hline 100 & 16 & 0,1 & 0,5 & 5 & 0,00 & - \\
\hline 100 & 16 & 0,1 & 1,0 & 1 & 0,00 & - \\
\hline 100 & 16 & 0,1 & 1,0 & 2 & 0,00 & _. \\
\hline 100 & 16 & 0,1 & 1,0 & 3 & 0,00 & - \\
\hline 100 & 16 & 0,1 & 1,0 & 4 & 0,00 & - \\
\hline 100 & 16 & 0,1 & 1,0 & 5 & 0,00 & - \\
\hline 100 & 16 & 0,3 & 0,1 & 1 & 0,00 & - \\
\hline 100 & 16 & 0,3 & 0,1 & 2 & 0,00 & - \\
\hline 100 & 16 & 0,3 & 0,1 & 3 & 0,00 & - \\
\hline 100 & 16 & 0,3 & 0,1 & 4 & 0,00 & \\
\hline 100 & 16 & 0,3 & 0,1 & 5 & 0,00 & - \\
\hline 100 & 16 & 0,3 & 0,5 & 1 & 0,00 & - \\
\hline 100 & 16 & 0,3 & 0,5 & 2 & 0,00 & - \\
\hline 100 & 16 & 0,3 & 0,5 & 3 & 0,00 & - \\
\hline 100 & 16 & 0,3 & 0,5 & 4 & 0,00 & - \\
\hline 100 & 16 & 0,3 & 0,5 & 5 & 0,00 & - \\
\hline 100 & 16 & 0,3 & 1,0 & 1 & 0,00 & \\
\hline 100 & 16 & 0,3 & 1,0 & 2 & 0,00 & - \\
\hline 100 & 16 & 0,3 & 1,0 & 3 & 0,00 & - \\
\hline 100 & 16 & 0,3 & 1,0 & 4 & 0,00 & - \\
\hline 100 & 16 & 0,3 & 1,0 & 5 & 0,00 & - \\
\hline
\end{tabular}

Tabela A.6: Resultados detalhados dos modelos para $\Gamma=1.0$, em todas as instâncias com $k \in\{12,16\}$. 


\begin{tabular}{|c|c|c|c|c|c|c|}
\hline & & & & & low & er bou \\
\hline $\mathrm{n}$ & $\mathrm{k}$ & $\beta$ & $\alpha$ & inr & $C_{e}^{+}$ & FCC \\
\hline 50 & 4 & 0,1 & 0,1 & 1 & 7,00 & 7,00 \\
\hline 50 & 4 & 0,1 & 0,1 & 2 & 12,00 & 12,00 \\
\hline 50 & 4 & 0,1 & 0,1 & 3 & 8,00 & 8,00 \\
\hline 50 & 4 & 0,1 & 0,1 & 4 & 8,00 & 8,00 \\
\hline 50 & 4 & 0,1 & 0,1 & 5 & 7,00 & 7,00 \\
\hline 50 & 4 & 0,1 & 0,5 & 1 & 14,00 & 14,00 \\
\hline 50 & 4 & 0,1 & 0,5 & 2 & 12,00 & 12,00 \\
\hline 50 & 4 & 0,1 & 0,5 & 3 & 8,00 & 8,00 \\
\hline 50 & 4 & 0,1 & 0,5 & 4 & 8,00 & 8,00 \\
\hline 50 & 4 & 0,1 & 0,5 & 5 & 7,00 & 7,00 \\
\hline 50 & 4 & 0,1 & 1,0 & 1 & 14,00 & 14,00 \\
\hline 50 & 4 & 0,1 & 1,0 & 2 & 12,00 & 12,00 \\
\hline 50 & 4 & 0,1 & 1,0 & 3 & 8,00 & 8,00 \\
\hline 50 & 4 & 0,1 & 1,0 & 4 & 8,00 & 8,00 \\
\hline 50 & 4 & 0,1 & 1,0 & 5 & 7,00 & 7,00 \\
\hline 50 & 4 & 0,3 & 0,1 & 1 & 7,00 & 7,00 \\
\hline 50 & 4 & 0,3 & 0,1 & 2 & 9,00 & 9,00 \\
\hline 50 & 4 & 0,3 & 0,1 & 3 & 7,00 & 7,00 \\
\hline 50 & 4 & 0,3 & 0,1 & 4 & 8,00 & 8,00 \\
\hline 50 & 4 & 0,3 & 0,1 & 5 & 9,00 & 9,00 \\
\hline 50 & 4 & 0,3 & 0,5 & 1 & 7,00 & 7,00 \\
\hline 50 & 4 & 0,3 & 0,5 & 2 & 9,00 & 9,00 \\
\hline 50 & 4 & 0,3 & 0,5 & 3 & 14,00 & 14,00 \\
\hline 50 & 4 & 0,3 & 0,5 & 4 & 16,00 & 16,00 \\
\hline 50 & 4 & 0,3 & 0,5 & 5 & 17,00 & 17,00 \\
\hline 50 & 4 & 0,3 & 1,0 & 1 & 7,00 & 7,00 \\
\hline 50 & 4 & 0,3 & 1,0 & 2 & 9,00 & 9,00 \\
\hline 50 & 4 & 0,3 & 1,0 & 3 & 20,00 & 14,79 \\
\hline 50 & 4 & 0,3 & 1,0 & 4 & 16,00 & 16,00 \\
\hline 50 & 4 & 0,3 & 1,0 & 5 & 17,00 & 17,00 \\
\hline 75 & 4 & 0,1 & 0,1 & 1 & 7,00 & 7,00 \\
\hline 75 & 4 & 0,1 & 0,1 & 2 & 6,00 & 6,00 \\
\hline 75 & 4 & 0,1 & 0,1 & 3 & 7,00 & 7,00 \\
\hline 75 & 4 & 0,1 & 0,1 & 4 & 8,00 & 8,00 \\
\hline 75 & 4 & 0,1 & 0,1 & 5 & 7,00 & 7,00 \\
\hline 75 & 4 & 0,1 & 0,5 & 1 & 7,00 & 7,00 \\
\hline 75 & 4 & 0,1 & 0,5 & 2 & 6,00 & 6,00 \\
\hline 75 & 4 & 0,1 & 0,5 & 3 & 7,00 & 7,00 \\
\hline 75 & 4 & 0,1 & 0,5 & 4 & 8,00 & 8,00 \\
\hline 75 & 4 & 0,1 & 0,5 & 5 & 7,00 & 7,00 \\
\hline 75 & 4 & 0,1 & 1,0 & 1 & 7,00 & 7,00 \\
\hline 75 & 4 & 0,1 & 1,0 & 2 & 6,00 & 6,00 \\
\hline 75 & 4 & 0,1 & 1,0 & 3 & 7,00 & 7,00 \\
\hline 75 & 4 & 0,1 & 1,0 & 4 & 8,00 & 8,00 \\
\hline 75 & 4 & 0,1 & 1,0 & 5 & 7,00 & 7,00 \\
\hline 75 & 4 & 0,3 & 0,1 & 1 & 7,00 & 7,00 \\
\hline 75 & 4 & 0,3 & 0,1 & 2 & 16,00 & 16,00 \\
\hline 75 & 4 & 0,3 & 0,1 & 3 & 9,00 & 9,00 \\
\hline 75 & 4 & 0,3 & 0,1 & 4 & 7,00 & 7,00 \\
\hline 75 & 4 & 0,3 & 0,1 & 5 & 7,00 & 7,00 \\
\hline 75 & 4 & 0,3 & 0,5 & 1 & 14,00 & 14,00 \\
\hline 75 & 4 & 0,3 & 0,5 & 2 & 25,00 & 9,00 \\
\hline 75 & 4 & 0,3 & 0,5 & 3 & 18,00 & 18,00 \\
\hline 75 & 4 & 0,3 & 0,5 & 4 & 7,00 & 7,00 \\
\hline 75 & 4 & 0,3 & 0,5 & 5 & 7,00 & 7,00 \\
\hline 75 & 4 & 0,3 & 1,0 & 1 & 14,00 & 14,00 \\
\hline 75 & 4 & 0,3 & 1,0 & 2 & 25,00 & 16,00 \\
\hline 75 & 4 & 0,3 & 1,0 & 3 & 34,00 & 32,00 \\
\hline 75 & 4 & 0,3 & 1,0 & 4 & 7,00 & 7,00 \\
\hline 75 & 4 & 0,3 & 1,0 & 5 & 7,00 & 7,00 \\
\hline 100 & 4 & 0,1 & 0,1 & 1 & 7,00 & 7,00 \\
\hline 100 & 4 & 0,1 & 0,1 & 2 & 7,00 & 7,00 \\
\hline 100 & 4 & 0,1 & 0,1 & 3 & 7,00 & 7,00 \\
\hline 100 & 4 & 0,1 & 0,1 & 4 & 7,00 & 7,00 \\
\hline 100 & 4 & 0,1 & 0,1 & 5 & 7,00 & 7,00 \\
\hline 100 & 4 & 0,1 & 0,5 & 1 & 14,00 & 7,00 \\
\hline 100 & 4 & 0,1 & 0,5 & 2 & 7,00 & 7,00 \\
\hline 100 & 4 & 0,1 & 0,5 & 3 & 14,00 & 14,00 \\
\hline 100 & 4 & 0,1 & 0,5 & 4 & 7,00 & 7,00 \\
\hline 100 & 4 & 0,1 & 0,5 & 5 & 7,00 & 7,00 \\
\hline 100 & 4 & 0,1 & 1,0 & 1 & 14,00 & 14,00 \\
\hline 100 & 4 & 0,1 & 1,0 & 2 & 7,00 & 7,00 \\
\hline 100 & 4 & 0,1 & 1,0 & 3 & 14,00 & 14,00 \\
\hline 100 & 4 & 0,1 & 1,0 & 4 & 7,00 & 7,00 \\
\hline 100 & 4 & 0,1 & 1,0 & 5 & 7,00 & 7,00 \\
\hline 100 & 4 & 0,3 & 0,1 & & 8,00 & 8,00 \\
\hline 100 & 4 & 0,3 & 0,1 & 2 & 8,00 & 8,00 \\
\hline 100 & 4 & 0,3 & 0,1 & 3 & 18,00 & 17,00 \\
\hline 100 & 4 & 0,3 & 0,1 & 4 & 8,00 & 8,00 \\
\hline 100 & 4 & 0,3 & 0,1 & 5 & 14,00 & 14,00 \\
\hline 100 & 4 & 0,3 & 0,5 & 1 & 16,00 & 8,00 \\
\hline 100 & 4 & 0,3 & 0,5 & 2 & 16,00 & 8,00 \\
\hline 100 & 4 & 0,3 & 0,5 & 3 & 18,00 & 17,00 \\
\hline 100 & 4 & 0,3 & 0,5 & 4 & 16,00 & 8,00 \\
\hline 100 & 4 & 0,3 & 0,5 & 5 & 14,00 & 14,00 \\
\hline 100 & 4 & 0,3 & 1,0 & 1 & 16,00 & 15,00 \\
\hline 100 & 4 & 0,3 & 1,0 & 2 & 23,00 & 23,00 \\
\hline 100 & 4 & 0,3 & 1,0 & 3 & 18,00 & 17,00 \\
\hline 100 & 4 & 0,3 & 1,0 & 4 & 16,00 & 15,00 \\
\hline 100 & 4 & 0,3 & 1,0 & 5 & 14,00 & 14,00 \\
\hline
\end{tabular}

Tabela A.7: Resultados detalhados dos modelos para $\Gamma=1.1$, em todas as instâncias com $k=4$. 


\begin{tabular}{|c|c|c|c|c|c|c|}
\hline & & & & & & ver bou \\
\hline $\mathbf{n}$ & $\mathrm{k}$ & $\beta$ & $\alpha$ & inr & $C_{e}^{+}$ & FCC \\
\hline 50 & 8 & 0,1 & 0,1 & 1 & 36,00 & 13,96 \\
\hline 50 & 8 & 0,1 & 0,1 & 2 & 29,00 & 15,45 \\
\hline 50 & 8 & 0,1 & 0,1 & 3 & 29,00 & 17,10 \\
\hline 50 & 8 & 0,1 & 0,1 & 4 & 27,00 & 18,00 \\
\hline 50 & 8 & 0,1 & 0,1 & 5 & 23,00 & 19,83 \\
\hline 50 & 8 & 0,1 & 0,5 & 1 & 31,38 & 17,33 \\
\hline 50 & 8 & 0,1 & 0,5 & 2 & 29,00 & 19,00 \\
\hline 50 & 8 & 0,1 & 0,5 & 3 & 29,00 & 19,00 \\
\hline 50 & 8 & 0,1 & 0,5 & 4 & 31,15 & 18,00 \\
\hline 50 & 8 & 0,1 & 0,5 & 5 & 35,27 & 18,43 \\
\hline 50 & 8 & 0,1 & 1,0 & 1 & 29,86 & 34,00 \\
\hline 50 & 8 & 0,1 & 1,0 & 2 & 29,00 & 29,00 \\
\hline 50 & 8 & 0,1 & 1,0 & 3 & 29,00 & 29,00 \\
\hline 50 & 8 & 0,1 & 1,0 & 4 & 18,00 & 34,00 \\
\hline 50 & 8 & 0,1 & 1,0 & 5 & 34,33 & 34,00 \\
\hline 50 & 8 & 0,3 & 0,1 & 1 & 21,00 & 16,00 \\
\hline 50 & 8 & 0,3 & 0,1 & 2 & 31,00 & 20,00 \\
\hline 50 & 8 & 0,3 & 0,1 & 3 & 38,00 & 20,00 \\
\hline 50 & 8 & 0,3 & 0,1 & 4 & 26,88 & 20,80 \\
\hline 50 & 8 & 0,3 & 0,1 & 5 & 29,00 & 18,92 \\
\hline 50 & 8 & 0,3 & 0,5 & 1 & 30,05 & 15,21 \\
\hline 50 & 8 & 0,3 & 0,5 & 2 & 20,00 & 16,78 \\
\hline 50 & 8 & 0,3 & 0,5 & 3 & 32,21 & 18,71 \\
\hline 50 & 8 & 0,3 & 0,5 & 4 & 25,00 & 16,67 \\
\hline 50 & 8 & 0,3 & 0,5 & 5 & 15,00 & 18,06 \\
\hline 50 & 8 & 0,3 & 1,0 & 1 & 11,00 & 30,00 \\
\hline 50 & 8 & 0,3 & 1,0 & 2 & 30,03 & 30,00 \\
\hline 50 & 8 & 0,3 & 1,0 & 3 & 35,75 & 30,00 \\
\hline 50 & 8 & 0,3 & 1,0 & 4 & 13,00 & 36,00 \\
\hline 50 & 8 & 0,3 & 1,0 & 5 & 15,00 & 28,00 \\
\hline 75 & 8 & 0,1 & 0,1 & 1 & 20,00 & 12,48 \\
\hline 75 & 8 & 0,1 & 0,1 & 2 & 23,19 & 11,94 \\
\hline 75 & 8 & 0,1 & 0,1 & 3 & 23,80 & 15,38 \\
\hline 75 & 8 & 0,1 & 0,1 & 4 & 25,84 & 13,69 \\
\hline 75 & 8 & 0,1 & 0,1 & 5 & 25,52 & 11,11 \\
\hline 75 & 8 & 0,1 & 0,5 & 1 & 30,00 & 12,34 \\
\hline 75 & 8 & 0,1 & 0,5 & 2 & 29,00 & 13,06 \\
\hline 75 & 8 & 0,1 & 0,5 & 3 & 21,00 & 15,90 \\
\hline 75 & 8 & 0,1 & 0,5 & 4 & 23,00 & 14,58 \\
\hline 75 & 8 & 0,1 & 0,5 & 5 & 21,00 & 14,95 \\
\hline 75 & 8 & 0,1 & 1,0 & 1 & 30,13 & 30,00 \\
\hline 75 & 8 & 0,1 & 1,0 & 2 & 20,00 & 29,00 \\
\hline 75 & 8 & 0,1 & 1,0 & 3 & 29,71 & 30,00 \\
\hline 75 & 8 & 0,1 & 1,0 & 4 & 23,00 & 24,00 \\
\hline 75 & 8 & 0,1 & 1,0 & 5 & 30,16 & 30,00 \\
\hline 75 & 8 & 0,3 & 0,1 & 1 & 23,04 & 12,39 \\
\hline 75 & 8 & 0,3 & 0,1 & 2 & 19,00 & 11,72 \\
\hline 75 & 8 & 0,3 & 0,1 & 3 & 22,00 & 15,07 \\
\hline 75 & 8 & 0,3 & 0,1 & 4 & 24,60 & 13,26 \\
\hline 75 & 8 & 0,3 & 0,1 & 5 & 24,01 & 15,60 \\
\hline 75 & 8 & 0,3 & 0,5 & 1 & 20,00 & 13,75 \\
\hline 75 & 8 & 0,3 & 0,5 & 2 & 27,02 & 14,72 \\
\hline 75 & 8 & 0,3 & 0,5 & 3 & 22,00 & 14,69 \\
\hline 75 & 8 & 0,3 & 0,5 & 4 & 20,00 & 13,49 \\
\hline 75 & 8 & 0,3 & 0,5 & 5 & 21,00 & 14,22 \\
\hline 75 & 8 & 0,3 & 1,0 & 1 & 10,00 & 28,00 \\
\hline 75 & 8 & 0,3 & 1,0 & 2 & 27,07 & 27,00 \\
\hline 75 & 8 & 0,3 & 1,0 & 3 & 22,00 & 32,00 \\
\hline 75 & 8 & 0,3 & 1,0 & 4 & 29,17 & 29,00 \\
\hline 75 & 8 & 0,3 & 1,0 & 5 & 21,00 & 31,00 \\
\hline 100 & 8 & 0,1 & 0,1 & 1 & 20,00 & 12,34 \\
\hline 100 & 8 & 0,1 & 0,1 & 2 & 19,00 & 10,87 \\
\hline 100 & 8 & 0,1 & 0,1 & 3 & 24,00 & 13,00 \\
\hline 100 & 8 & 0,1 & 0,1 & 4 & 23,79 & 11,00 \\
\hline 100 & 8 & 0,1 & 0,1 & 5 & 25,60 & 12,00 \\
\hline 100 & 8 & 0,1 & 0,5 & 1 & 20,00 & 11,00 \\
\hline 100 & 8 & 0,1 & 0,5 & 2 & 28,00 & 12,31 \\
\hline 100 & 8 & 0,1 & 0,5 & 3 & 24,09 & 13,00 \\
\hline 100 & 8 & 0,1 & 0,5 & 4 & 29,00 & 13,09 \\
\hline 100 & 8 & 0,1 & 0,5 & 5 & 23,00 & 13,26 \\
\hline 100 & 8 & 0,1 & 1,0 & 1 & 11,00 & 29,00 \\
\hline 100 & 8 & 0,1 & 1,0 & 2 & 28,05 & 28,00 \\
\hline 100 & 8 & 0,1 & 1,0 & 3 & 24,00 & 26,00 \\
\hline 100 & 8 & 0,1 & 1,0 & 4 & 20,00 & 22,00 \\
\hline 100 & 8 & 0,1 & 1,0 & 5 & 23,00 & 33,00 \\
\hline 100 & 8 & 0,3 & 0,1 & 1 & 22,33 & 12,00 \\
\hline 100 & 8 & 0,3 & 0,1 & 2 & 23,03 & 12,00 \\
\hline 100 & 8 & 0,3 & 0,1 & 3 & 14,00 & 14,00 \\
\hline 100 & 8 & 0,3 & 0,1 & 4 & 13,00 & 13,00 \\
\hline 100 & 8 & 0,3 & 0,1 & 5 & 12,00 & 12,00 \\
\hline 100 & 8 & 0,3 & 0,5 & 1 & 12,00 & 12,31 \\
\hline 100 & 8 & 0,3 & 0,5 & 2 & 23,00 & 12,00 \\
\hline 100 & 8 & 0,3 & 0,5 & 3 & 25,25 & 14,00 \\
\hline 100 & 8 & 0,3 & 0,5 & 4 & 24,00 & 13,00 \\
\hline 100 & 8 & 0,3 & 0,5 & 5 & 23,00 & 12,00 \\
\hline 100 & 8 & 0,3 & 1,0 & 1 & 22,01 & 24,00 \\
\hline 100 & 8 & 0,3 & 1,0 & 2 & 12,00 & 27,00 \\
\hline 100 & 8 & 0,3 & 1,0 & 3 & 25,77 & 37,00 \\
\hline 100 & 8 & 0,3 & 1,0 & 4 & 13,00 & 26,00 \\
\hline 100 & 8 & 0,3 & 1,0 & 5 & 23,00 & 33,00 \\
\hline
\end{tabular}

Tabela A.8: Resultados detalhados dos modelos para $\Gamma=1.1$, em todas as instâncias com $k=8$. 


\begin{tabular}{|c|c|c|c|c|c|c|}
\hline & & & & & & ver bou \\
\hline n & $\mathrm{k}$ & $\beta$ & $\alpha$ & inr & $C_{e}^{+}$ & FCC \\
\hline 75 & 12 & 0,1 & 0,1 & 1 & 25,00 & 18,65 \\
\hline 75 & 12 & 0,1 & 0,1 & 2 & 27,00 & 18,11 \\
\hline 75 & 12 & 0,1 & 0,1 & 3 & 24,00 & 17,59 \\
\hline 75 & 12 & 0,1 & 0,1 & 4 & 25,00 & 20,35 \\
\hline 75 & 12 & 0,1 & 0,1 & 5 & 28,00 & 20,48 \\
\hline 75 & 12 & 0,1 & 0,5 & 1 & 25,00 & 21,60 \\
\hline 75 & 12 & 0,1 & 0,5 & 2 & 27,00 & 21,21 \\
\hline 75 & 12 & 0,1 & 0,5 & 3 & 24,00 & 22,21 \\
\hline 75 & 12 & 0,1 & 0,5 & 4 & 25,00 & 21,51 \\
\hline 75 & 12 & 0,1 & 0,5 & 5 & 28,00 & 22,01 \\
\hline 75 & 12 & 0,1 & 1,0 & 1 & 25,00 & 46,00 \\
\hline 75 & 12 & 0,1 & 1,0 & 2 & 27,00 & 41,00 \\
\hline 75 & 12 & 0,1 & 1,0 & 3 & 35,00 & 45,00 \\
\hline 75 & 12 & 0,1 & 1,0 & 4 & 37,03 & 39,00 \\
\hline 75 & 12 & 0,1 & 1,0 & 5 & 28,00 & 43,00 \\
\hline 75 & 12 & 0,3 & 0,1 & 1 & 27,00 & 18,40 \\
\hline 75 & 12 & 0,3 & 0,1 & 2 & 28,00 & 17,67 \\
\hline 75 & 12 & 0,3 & 0,1 & 3 & 25,00 & 18,13 \\
\hline 75 & 12 & 0,3 & 0,1 & 4 & 18,00 & 19,98 \\
\hline 75 & 12 & 0,3 & 0,1 & 5 & 28,00 & 19,20 \\
\hline 75 & 12 & 0,3 & 0,5 & 1 & 27,00 & 21,14 \\
\hline 75 & 12 & 0,3 & 0,5 & 2 & 28,00 & 19,60 \\
\hline 75 & 12 & 0,3 & 0,5 & 3 & 25,00 & 20,25 \\
\hline 75 & 12 & 0,3 & 0,5 & 4 & 18,00 & 20,11 \\
\hline 75 & 12 & 0,3 & 0,5 & 5 & 28,00 & 20,72 \\
\hline 75 & 12 & 0,3 & 1,0 & 1 & 27,00 & 38,00 \\
\hline 75 & 12 & 0,3 & 1,0 & 2 & 28,00 & 41,00 \\
\hline 75 & 12 & 0,3 & 1,0 & 3 & 25,00 & 48,00 \\
\hline 75 & 12 & 0,3 & 1,0 & 4 & 18,00 & 47,00 \\
\hline 75 & 12 & 0,3 & 1,0 & 5 & 28,00 & 52,00 \\
\hline 100 & 12 & 0,1 & 0,1 & 1 & 25,00 & 14,00 \\
\hline 100 & 12 & 0,1 & 0,1 & 2 & 24,00 & 18,37 \\
\hline 100 & 12 & 0,1 & 0,1 & 3 & 27,00 & 16,47 \\
\hline 100 & 12 & 0,1 & 0,1 & 4 & 27,00 & 16,32 \\
\hline 100 & 12 & 0,1 & 0,1 & 5 & 27,00 & 16,58 \\
\hline 100 & 12 & 0,1 & 0,5 & 1 & 25,00 & 19,24 \\
\hline 100 & 12 & 0,1 & 0,5 & 2 & 24,00 & 20,20 \\
\hline 100 & 12 & 0,1 & 0,5 & 3 & 27,00 & 19,54 \\
\hline 100 & 12 & 0,1 & 0,5 & 4 & 27,00 & 19,93 \\
\hline 100 & 12 & 0,1 & 0,5 & 5 & 27,00 & 20,04 \\
\hline 100 & 12 & 0,1 & 1,0 & 1 & 25,00 & 39,00 \\
\hline 100 & 12 & 0,1 & 1,0 & 2 & 24,00 & 41,46 \\
\hline 100 & 12 & 0,1 & 1,0 & 3 & 27,00 & 41,00 \\
\hline 100 & 12 & 0,1 & 1,0 & 4 & 27,00 & 42,02 \\
\hline 100 & 12 & 0,1 & 1,0 & 5 & 27,00 & 41,00 \\
\hline 100 & 12 & 0,3 & 0,1 & 1 & 0,00 & 20,00 \\
\hline 100 & 12 & 0,3 & 0,1 & 2 & 27,00 & 15,04 \\
\hline 100 & 12 & 0,3 & 0,1 & 3 & 28,00 & 15,57 \\
\hline 100 & 12 & 0,3 & 0,1 & 4 & 16,00 & 16,00 \\
\hline 100 & 12 & 0,3 & 0,1 & 5 & 29,00 & 16,45 \\
\hline 100 & 12 & 0,3 & 0,5 & 1 & 0,00 & 20,07 \\
\hline 100 & 12 & 0,3 & 0,5 & 2 & 27,00 & 19,69 \\
\hline 100 & 12 & 0,3 & 0,5 & 3 & 28,00 & 19,51 \\
\hline 100 & 12 & 0,3 & 0,5 & 4 & 16,00 & 19,83 \\
\hline 100 & 12 & 0,3 & 0,5 & 5 & 29,00 & 19,79 \\
\hline 100 & 12 & 0,3 & 1,0 & 1 & 0,00 & 40,00 \\
\hline 100 & 12 & 0,3 & 1,0 & 2 & 27,00 & 41,00 \\
\hline 100 & 12 & 0,3 & 1,0 & 3 & 28,00 & 43,00 \\
\hline 100 & 12 & 0,3 & 1,0 & 4 & 30,00 & 43,00 \\
\hline 100 & 12 & 0,3 & 1,0 & 5 & 29,00 & 45,00 \\
\hline 100 & 16 & 0,1 & 0,1 & 1 & 0,00 & 20,00 \\
\hline 100 & 16 & 0,1 & 0,1 & 2 & - & 20,42 \\
\hline 100 & 16 & 0,1 & 0,1 & 3 & - & 19,09 \\
\hline 100 & 16 & 0,1 & 0,1 & 4 & - & 19,92 \\
\hline 100 & 16 & 0,1 & 0,1 & 5 & - & 19,25 \\
\hline 100 & 16 & 0,1 & 0,5 & 1 & 0,00 & 25,52 \\
\hline 100 & 16 & 0,1 & 0,5 & 2 & - & 27,96 \\
\hline 100 & 16 & 0,1 & 0,5 & 3 & - & 27,37 \\
\hline 100 & 16 & 0,1 & 0,5 & 4 & - & 26,99 \\
\hline 100 & 16 & 0,1 & 0,5 & 5 & - & 26,17 \\
\hline 100 & 16 & 0,1 & 1,0 & 1 & 0,00 & 53,56 \\
\hline 100 & 16 & 0,1 & 1,0 & 2 & - & 53,54 \\
\hline 100 & 16 & 0,1 & 1,0 & 3 & - & 52,36 \\
\hline 100 & 16 & 0,1 & 1,0 & 4 & - & 55,00 \\
\hline 100 & 16 & 0,1 & 1,0 & 5 & - & 54,59 \\
\hline 100 & 16 & 0,3 & 0,1 & 1 & - & 20,00 \\
\hline 100 & 16 & 0,3 & 0,1 & 2 & - & 19,98 \\
\hline 100 & 16 & 0,3 & 0,1 & 3 & - & 20,00 \\
\hline 100 & 16 & 0,3 & 0,1 & 4 & & 20,31 \\
\hline 100 & 16 & 0,3 & 0,1 & 5 & - & 6,37 \\
\hline 100 & 16 & 0,3 & 0,5 & 1 & - & 25,80 \\
\hline 100 & 16 & 0,3 & 0,5 & 2 & - & 27,45 \\
\hline 100 & 16 & 0,3 & 0,5 & 3 & - & 25,74 \\
\hline 100 & 16 & 0,3 & 0,5 & 4 & - & 26,80 \\
\hline 100 & 16 & 0,3 & 0,5 & 5 & - & 25,69 \\
\hline 100 & 16 & 0,3 & 1,0 & 1 & & 55,05 \\
\hline 100 & 16 & 0,3 & 1,0 & 2 & - & 54,61 \\
\hline 100 & 16 & 0,3 & 1,0 & 3 & - & 58,04 \\
\hline 100 & 16 & 0,3 & 1,0 & 4 & - & 55,00 \\
\hline 100 & 16 & 0,3 & 1,0 & 5 & & 57,00 \\
\hline
\end{tabular}

Tabela A.9: Resultados detalhados dos modelos para $\Gamma=1.1$, em todas as instâncias com $k \in\{12,16\}$. 